\title{
FACTORS INFLUENCING CAREER MATURITY IN THE SOUTH AFRICAN NATIONAL DEFENCE FORCE: A DIAGNOSTIC APPROACH
}

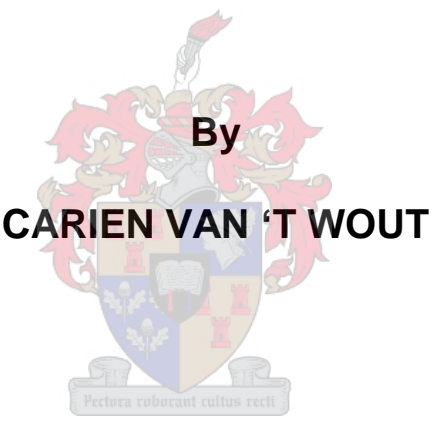

THESIS PRESENTED IN PARTIAL FULFILMENT OF THE REQUIREMENTS FOR THE DEGREE OF MASTER OF COMMERCE (INDUSTRIAL PSYCHOLOGY) AT STELLENBOSCH UNIVERSITY

Supervisor: Prof G.A.J. van Dyk 


\section{Declaration}

I declare that the entirety of the work contained herein is my own, original work, that I am the sole author hereof (save to the extent explicitly otherwise stated), that reproduction and publication hereof by Stellenbosch University will not infringe any third party rights and that I have not previously in its entirety or in part submitted it for obtaining any qualification.

Carien van 't Wout

8 September 2014

Copyright (C) 2014 Stellenbosch University

All rights reserved 


\section{ABSTRACT}

The Military Skills Development System (MSDS) of the South African National Defence Force (SANDF) is the military contribution towards the South African National Skills Development Strategy. The purpose of this study was to determine if the SANDF is succeeding in contributing towards youth development, by investigating the career maturity (CM) of MSDS members. The adolescent years are a critical time for youth to explore and confirm their career choices, and to make major decisions at what can be perceived as a turning point in their lives. The factors that influence CM were investigated in order to determine the most suitable focus for possible career guidance programmes or interventions within the MSDS. A sample of 310 MSDS members was used to gather information on CM and the most prominent factors that have an impact on CM were identified from the literature review. Data was collected by means of administering five questionnaires; The Career Maturity Inventory- Revised short form (CMI-R), The Career Decision Self-Efficacy scale short form (CDSE), The Military Hardiness Scale (MHS), the Seven Habits Profile (SHP) and a Biographical Information Form (BIF).

The CM of the MSDS members was found to be moderate. MSDS members seem to have high levels of confidence in their abilities to make career decisions (self-efficacy) and they perceive themselves as being hardy and having very good life skills. Moderate and weak, positive relationships were discovered between all twenty of the factors (scales and subscales of independent variables) and CM (dependent variable); however, they were not all significant. Multiple regression analysis resulted in a set of predictor variables (factors) which were used as the focus for recommendation on how CM may be improved for MSDS in the SANDF.- These factors include: self-efficacy, seeking occupational information, self-appraisal, commitment, challenge, conscientiousness and continuous improvement. 


\section{ACKNOWLEDGEMENTS}

First and foremost, all glory is given to God, Jesus Christ and the Holy Spirit. With Him, all things are possible (Philippians 4:13). I never would have completed this study without His guidance, support, love and forgiveness.

Trust in the Lord with all your heart, do not depend on your own understanding. Seek His will in all you do and He will show you which path to take (Proverbs 3:5-6)

I would like to extend my gratitude and appreciation to the following people without whom this study would not have been possible:

Prof G.A.J. van Dyk, my supervisor, I appreciate your motivation, leadership and guidance as well as the opportunity and freedom you gave me to learn and explore throughout the process of this research project. I have grown. Thank you for your patience and always being there.

My husband, Anton and children (Carmen and Henk) for your patience, understanding and support. We may finally take the pause-button off our lives.

My loyal and patient family and sincere friends, thank you for all your prayers and ongoing support - asking me how things were coming along and always telling me "you can do this," especially when I frequently had the "hare-in-the-headlights" look on my face. Thanks to my mother, Hetta, for all the extra help and support.

Prof M. Kidd, from Stellenbosch University, for his assistance with the statistical analysis of this study.

Dr H.J van Zyl for your prayers, encouragement and constantly challenging me to push myself, to believe in myself and to never give up.

The Department of Industrial Psychology, Stellenbosch University, for equipping me with the necessary knowledge to produce this study. 
The SANDF, the organisation that allowed me the opportunity and resources to conduct this study. Extreme gratitude to the CMIS Division and specifically the Director Information Warfare, Brig Gen A.J. Coetzee and all my colleagues for allowing me this opportunity for part-time studies and for your continuous support.

The participants in this study for their willingness and time in completing the questionnaires.

A big thank you is extended to Lindiwe Mashigo, who assisted me in the data collection process. 


\section{TABLE OF CONTENTS}

Declaration

Page:

Abstract

iii

Acknowledgements iv

List of tables $\quad$ xi

List of figures $\quad$ xii

List of acronyms and abbreviations xiv

CHAPTER 1 INTRODUCTION 1

$1.1 \quad$ BACKGROUND AND MOTIVATION FOR THE STUDY 1

1.2 PROBLEM STATEMENT 3

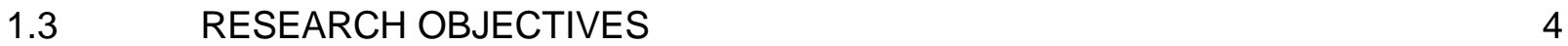

1.3.1 Main objective $\quad 4$

$\begin{array}{lll}\text { 1.3.2 } & \text { Theoretical objective } & 6\end{array}$

1.3.3 Empirical objective $\quad 6$

$1.4 \quad$ RESEARCH PROCESS OVERVIEW 6

1.4.1 Phase 1: Literature review 6

1.4.2 Phase 2: Empirical research 8

1.4.3 Phase 3: Reporting of results 9

1.4.4 Phase 4: Discussion of results 9

1.4.5 Phase 5: Conclusions 9

1.4.6 Phase 6: Limitations 9

1.4.7 Phase 7: Recommendations 10

1.5 CHAPTER OVERVIEW 10

1.5.1 Chapter 1: Introduction 10

1.5.2 Chapter 2: Literature review 11

1.5.3 Chapter 3: Research design 11

1.5.4 Chapter 4: Results 11

1.5.5 Chapter 5: Discussion 11

1.5.6 Chapter 6: Conclusions 12

1.6 CHAPTER SUMMARY 12 
CHAPTER 2 LITERATURE REVIEW

$\begin{array}{lll}2.1 & 13\end{array}$

2.2 CAREER CHALLENGES IN THE CURRENT SOUTH AFRICAN CONTEXT 13

$\begin{array}{lll}2.2 .1 & \text { Choosing a career } & 14\end{array}$

$\begin{array}{ll}\text { 2.2.2 Career life stages } & 15\end{array}$

$\begin{array}{lll}\text { 2.2.3 Nature of careers in current day } & 16\end{array}$

$\begin{array}{llr}2.3 & \text { YOUTH DEVELOPMENT } & 18\end{array}$

2.3.1 The National Skills Development Strategy 22

$\begin{array}{lll}\text { 2.3.2 Adolescence and youth development } 23 & 23\end{array}$

2.4 CAREER SERVICES 24

2.4.1 Diagnostic framework for career services 24

$\begin{array}{lll}2.4 .2 & \text { Theories in career counselling } & 28\end{array}$

$\begin{array}{lll}\text { 2.4.2.1 Trait-and-factor theory } & 28\end{array}$

$\begin{array}{ll}\text { 2.4.2.2 John Holland's theory } & 29\end{array}$

$\begin{array}{lll}2.4 .2 .3 & \text { Social learning theory } & 29\end{array}$

2.4.2.4 Social cognitive theory 30

$\begin{array}{lll}\text { 2.4.2.5 Developmental theories } & 31\end{array}$

2.4.2.5.1 Donald Super 31

2.4.2.5.2 Linda Gottfredson 34

2.4.2.6 Accident theory 36

$\begin{array}{lll}\text { 2.4.3 Approaches to career counselling } & 37\end{array}$

$\begin{array}{lll}\text { 2.4.3.1 Narrative therapy } & 37\end{array}$

2.4.3.2 Logotherapy 38

2.4.3.3 Transpersonal approaches to career therapy 38

$\begin{array}{lll}\text { 2.4.3.4 Egan's counselling approach } & 39\end{array}$

2.4.3.5 Organisational approach 41

2.4.3.6 Application of approaches in the MSDS context 42

2.4.4 Skills and techniques appropriate for career counselling 44

$\begin{array}{lll}2.4 .5 & \text { The career counselling process } & 48\end{array}$

2.4.5.1 Preparation 48

2.4.5.2 Establishment of a working relationship 49

2.4.5.3 Understanding the needs of the client 50

$\begin{array}{lll}\text { 2.4.5.4 Conducting career assessments } & 51\end{array}$ 
2.4.5.5 Working towards a resolution

2.4.5.6 Closure phase 54

2.4.5.7 Evaluating the effectiveness of the guidance process 56

2.5 CAREER MATURITY 56

$\begin{array}{lll}2.5 .1 & \text { Self-efficacy } & 60\end{array}$

2.5.2 Life skills $\quad 62$

2.5.3 Hardiness $\quad 65$

$\begin{array}{lll}2.5 .4 & 6 x+e r n a l \text { factors } & 67\end{array}$

2.5.5 A proposed diagnostic model of career maturity for MSDS 68

$2.6 \quad$ CHAPTER SUMMARY

CHAPTER 3 RESEARCH DESIGN 12

$\begin{array}{lll}3.1 & \text { INTRODUCTION }\end{array}$

$\begin{array}{lll}3.2 & \text { HYPOTHESES } & 73\end{array}$

3.3 RESEARCH DESIGN

$\begin{array}{lll}3.4 & \text { SAMPLING DESIGN } & 77\end{array}$

3.5 MEASURING INSTRUMENTS $\quad 79$

3.5.1 Career maturity inventory revised (CMI-R) 79

3.5.2 Career decision self-efficacy scale (CDSE) 80

3.5.3 Military hardiness scale (MHS) 80

3.5.4 Seven Habits Profile 81

3.5.5 Biographical information form (BIF) 82

3.6 ETHICAL CONSIDERATIONS 82

3.7 STATISTICAL ANALYSIS

3.8 CHAPTER SUMMARY 83

$\begin{array}{ll}\text { CHAPTER } 4 \text { RESULTS } & 84\end{array}$

$4.1 \quad$ INTRODUCTION

4.2 DESCRIPTIVE STATISTICS FOR THE SAMPLE 84

4.2.1 Mean scores on scales and subscales 87

4.3 INTERNAL RELIABILITY ANALYSIS OF SCALES 90 
$\begin{array}{lll}4.4 & \text { INFERENTIAL STATISTICS }\end{array}$

$\begin{array}{lll}\text { 4.4.1 Correlations } & 94\end{array}$

4.4.2 Multiple regression analysis 106

4.4.2.1 Redundancy of independent variables 111

4.4.2.2 Normality 112

4.5 CHAPTER SUMMARY 112

CHAPTER 5 DISCUSSION OF RESULTS 114

$\begin{array}{lll}5.1 & 114\end{array}$

5.2 DISCUSSION OF LEVELS OF CM AND FACTORS 114

5.2.1 CM levels of the sample 115

$\begin{array}{lll}\text { 5.2.2 } & \text { Self-efficacy levels of the sample } & 117\end{array}$

$\begin{array}{lll}\text { 5.2.3 Hardiness levels of the sample } & 120\end{array}$

5.2.4 Life skills levels of the sample 122

$\begin{array}{lll}5.3 & \text { DISCUSSION OF CORRELATION RESULTS } & 124\end{array}$

5.3.1 Self-Efficacy and CM 125

5.3.2 Hardiness and CM 125

$\begin{array}{lll}\text { 5.3.3 Life skills and CM } & 128\end{array}$

5.4 DISCUSSION OF MULTIPLE REGRESSION RESULTS 131

5.5 CHAPTER SUMMARY 132

CHAPTER 6 CONCLUSIONS, LIMITATIONS AND RECOMMENDATIONS 134

$\begin{array}{lll}6.1 & \text { CONCLUSIONS } & 134\end{array}$

$\begin{array}{lll}6.2 & 136\end{array}$

6.3 RECOMMENDATIONS 138

$\begin{array}{lll}\text { 6.3.1 } & \text { Recommendations regarding future research } & 138\end{array}$

6.3.2 Recommendations for career guidance programme for MSDS members 139

6.3.2.1 Career counselling workshops 140

6.3.2.2 Career days 141

6.3.2.3 Intranet career services 142

6.3.2.4 Covey life skills workshops 142

6.3.2.5 Career workbooks 144

6.3.2.6 Career challenge exercises 145 
6.3.2.7 Career research exercises 145

6.3.2.8 Career guidance and educational DVD 145

6.3.2.9 General recommendations for improvement of CM 146

6.4 OVERALL ASSESSMENT OF THE STUDY 146

$\begin{array}{lll}6.4 & 147\end{array}$

$\begin{array}{lr}\text { REFERENCES } & 148\end{array}$ 


\section{LIST OF TABLES}

Page

Table 2.1. Diagnostic Framework for Career Services 25

Table 4.1. Mean Scores on Scales and Subscales 88

Table 4.2. Internal Reliability of Scales and Subscales 93

Table 4.3. Correlation Coefficient Results for Hypothesised Relationships Between Variables 95

Table 4.4. Summary Statistics for the Dependent Variable Scales 107

Table 4.5. Summary Statistics for the Dependent Variable Subscales 108

Table 4.6. Standardised Coefficients for Total Scales ( $N=310) \quad 109$

Table 4.7. Standardised Coefficients for Total Subscales $(\mathrm{N}=310)$

Table 4.8. Redundancy of Independent Variables 111 


\section{LIST OF FIGURES}

Page

Figure 1.1. List of Factors Influencing CM 5

Figure 1.2. Research Process Overview 10

Figure 2.1. Forty Developmental Assets 21

Figure 2.2. Super's Career Life Rainbow 33

Figure 2.3. Diagnostic Model of the Factors Influencing CM 70

Figure 4.1 Age Distribution of Sample $\quad 84$

Figure 4.2 Previous Work Experience of Participants 85

Figure 4.3 Perceived Ability to Compile a CV 86

Figure 4.4 Perceived Ability to Search for Jobs 86

Figure 4.5 Perceived Ability to Successfully Attend Employment Interviews 87

Figure 4.6 The Relationship Between Career Decision Self-efficacy and CM 96

Figure 4.7 The Relationship Between Self-appraisal and CM 96

Figure 4.8 The Relationship Between Seeking Occupational Information and CM 97

Figure 4.9 The Relationship Between Goal Selection and CM 97

Figure 4.10 The Relationship Between Planning and CM 98

Figure 4.11 The Relationship Between Problem Solving and CM 98

Figure 4.12 The Relationship Between Hardiness and CM 99

Figure 4.13 The Relationship Between Control and CM 99

Figure 4.14 The Relationship Between Commitment and CM 100

Figure 4.15 The Relationship Between Challenge and CM 100

Figure 4.16 The Relationship Between Life Skills and CM 101

Figure 4.17 The Relationship Between Conscientiousness and CM 101

Figure 4.18 The Relationship Between Life Balance and CM 102

Figure 4.19 The Relationship Between Pro-active Behaviour and CM 102

Figure 4.20 The Relationship Between Life Goals and CM 103

Figure 4.21 The Relationship Between Self-management and CM 103

Figure 4.22 The Relationship Between Mutual Benefit Thinking and CM 104

Figure 4.23 The Relationship Between Listening and CM 104

Figure 4.24 The Relationship Between Teamwork and CM 105

Figure 4.25 The Relationship Between Continuous Improvement and CM 105

Figure 4.26 Significant Influencing Factors of CM 110 
Figure 4.27 Normal Probability Plot of Residuals

Figure 6.1 Covey's Inside-out Approach

Figure 6.2 Proposed Career Workbook Content 


\section{LIST OF ACRONYMS AND ABBREVIATIONS}

$\begin{array}{ll}\text { CDSE } & \text { Career Decision Self-Efficacy Scale } \\ \text { CM } & \text { Career Maturity } \\ \text { CMI-R } & \text { Career Maturity Inventory Revised } \\ \text { DOD } & \text { Department of Defence } \\ \text { DVD } & \text { Digital Versatile Disk } \\ \text { HR } & \text { Human Resources } \\ \text { MHS } & \text { Military Hardiness Scale } \\ \text { MSDS } & \text { Military Skills Development System } \\ \text { NSDS } & \text { National Skills Development Strategy } \\ \text { RSA } & \text { Republic of South Africa } \\ \text { SAMA } & \text { South African Military Academy } \\ \text { SAAF } & \text { South African Air Force } \\ \text { SA Army } & \text { South African Army } \\ \text { SAMHS } & \text { South African Military Health Service } \\ \text { SAN } & \text { South African Navy } \\ \text { SANDF } & \text { South African National Defence Force } \\ \text { SHP } & \text { Seven Habits Profile Questionnaire }\end{array}$




\section{CHAPTER 1}

\section{INTRODUCTION}

None did so much to turn me into a disciple of Socrates. For it was my master who taught me not only how little I knew, but also that any wisdom to which I might ever aspire, could consist only in realising more fully the infinity of my ignorance.

Karl Popper

\subsection{BACKGROUND AND MOTIVATION FOR THE STUDY}

The Department of Defence's (DOD) Overarching Human Resource Strategy (2009) emphasises the social responsibility of the South African National Defence Force (SANDF) in terms of national skills development. The government of the Republic of South Africa (RSA) is the primary stakeholder in the effective functioning of the DOD. It is thus imperative for the needs of this stakeholder to be met (Noe, Hollenbeck, Gerhart \& Wright, 2008). Theme three of the DOD Overarching Human Resource Strategy (2009, p.42) is "commitments met in pursuance of government human resource policy and strategy". This includes an appropriate defence-related social responsibility that is aligned with government's strategic intent for human resource $(H R)$ development as a strategic goal for the DOD. Its focus is currently on youth development, gender mainstreaming and the affirmation of the physically disabled, while still upholding employment equity.

The Military Skills Development System (MSDS) was implemented in the SANDF to address the abovementioned social responsibility of youth development in the RSA and to provide the required structures for a younger, fitter defence force. A realistic number of young recruits aged between 18 and 25 years are selected and taken into the SANDF annually. During their first year they undergo basic military training and functional training relevant to the mustering (specific field within the military, e.g. signals, intelligence, artillery) for which they were chosen. Some recruits are selected as candidate officers and are afforded the opportunity to receive tertiary education at the South African Military Academy (SAMA). Most MSDS members are employed primarily in deployments or other level four functions. Unit level tasks include practicing drills, maintaining military skills, maintaining military equipment, guard and patrol duties as well as the execution of tactical operations namely actively executing the operational plans within the SANDF during their two years of service. 
After two years, some members enter into new contracts with the SANDF while others are not re-appointed. These decisions are governed by the operational requirements - which include the specific missions that the SANDF are currently involved with at any given time as mandated by the government of the RSA - as well as budgetary and HR structure constraints. Termination of contracts are therefore not indicative of the competence or not of the MSDS members.

It has become clear from conversations with various middle management role players, who are tasked with the responsibility of informing members that their contracts will not be renewed, that this news caused high levels of anxiety, feelings of hopelessness, feelings of betrayal and anger amongst some MSDS members. They feel unprepared to re-enter the labour market and are normally unskilled in compiling good curricula vitae, searching for jobs or conducting job interviews. Such members are also uncertain about which alternative career to pursue outside the SANDF.

National youth development is aimed at increasing in the number of economically contributing people within the RSA. The high number of unemployed young people is a matter of national concern, as is evident from current media (SAPA-AFP, 2012). The SANDF should thus endeavour not merely to train and develop MSDS members for two years, but also to guide and prepare them for re-entering the South African labour market. These members should be taught how to apply the skills and competencies which they have aquired during training, in a globally competitive economy.

MSDS members who obtain further contracts, will benefit from gaining an understanding of the various opportunities and vocations within the SANDF. Effective psycho-education and career guidance can help members to compile a good developmental career plan which will result in all MSDS members making realistic future career decisions.

Themba (2010) conducted a study to investigate the level of career maturity (CM) across the various career stages in the SANDF. His focus was specifically directed at differences in CM amongst the demographic variables (such as age, gender, race, and level of education). The study also looked differences in CM among the military-specific variables (such as arm of service, military rank and mustering category) in the SANDF; as well as developmental progression in CM according to age, level of education and military rank in the SANDF. 
The current study, however, does not focus on the CM of South African military personnel in general. Instead it proposes to answer the question of whether the SANDF is succeeding in discharging its responsibility of contributing towards youth development. The study therefore focusses on the young MSDS members of the SANDF only and measures various factors of CM by means of a comprehensive psychometric battery.

This study will investigate the need for the development of a career counselling and guidance programme for MSDS members in the SANDF and the requirements to be met in such a programme. Industrial and organisational (I/O) psychology can benefit from this study by extending the focus on $\mathrm{CM}$ to the unique military context and more specifically towards military young people. In turn, youth development and career development practices in the military may be enhanced by such a study.

\subsection{PROBLEM STATEMENT}

Career counselling and guidance can make a major contribution to more effective utilisation of SANDF members, as well as to youth development and employability in the RSA. This is a challenge of national importance. The resource constraints experienced by the SANDF as an organisation is, however, an important factor to be considered in the development of a career guidance and counselling programme or plan. A career guidance programme for groups may be regarded as more feasible than individual counselling. It may also be required to incorporate specific interventions or psycho-education into the training programmes, also referred to as force preparation of the training units where MSDS members are placed. In order to effectively address the challenge of MSDS young people that have to exit the SANDF and be able to pursue alternative careers, it is important to firstly investigate the factors that contribute towards effective career decision-making. CM determines the capacity to make such effective career decisions. Vondracek and Reitzle (1998) described CM as an explanatory construct that accounts for the individual differences in the readiness to make career choices, to plan ahead, and to engage in a work role.

The level of CM of MSDS members would thus give an indication of the need for career services in the SANDF for this specific population. The factors that play a role in the levels of $\mathrm{CM}$ of this group can shed light on the specific requirements for the development of a career counselling and guidance programme. 
The research problem of this study is therefore formulated as follows: Which factors influence career maturity and what is the level of career maturity of MSDS members in the SANDF and which of these factors could and/or should be addressed by the organisation towards achieving more effective youth development?

To address this problem, questionnaires will be used to assess the levels of CM and to assess the identified factors that influence CM of MSDS members, in order to investigate which factors play a prominent role in this context. The results of such an investigation will be used to make recommendations on how these factors may be addressed within the SANDF towards better youth development. No study of this nature has been done in the SANDF to date.

Beneficiaries of this research are firstly the MSDS members themselves who would benefit from any measures towards the improvement of their CM. Secondly, the SANDF would benefit by obtaining an understanding of the career development needs of MSDS members, which might have a far-reaching positive impact on the HR management and training practices of the SANDF. Thirdly, the study might create increased awareness of the important and positive role of psychologists in the SANDF and/or provide motivation for the staffing and effective utilisation of more psychologists in the SANDF. Fourthly, the study may serve as an intervention to minimise the negative outcomes of non-renewal of MSDS members' contracts and contribute to youth development on a national level.

\subsection{RESEARCH OBJECTIVES}

The research problem described above led to the formulation of the following objectives:

\subsubsection{Main objective}

The main objective of the study is to investigate the need for career services for MSDS members in the SANDF and to make recommendations as to what would be feasible in this specific context. CM of MSDS members are thus explored in terms of the factors which influence the levels thereof. The factors that influence CM are identified from a literature review. A summary of all the factors indicates that two categories of factors play a role in CM: Firstly, factors concerning the self and secondly, factors concerning the environment (Bandura, 1977; Carr, 2007; Egan, 2014; Matzeder \& Krieshok, 1995; Super, 1957; Schreuder \& Theron, 2004; Super \& Nevill, 1984; Yukl, 2013). 
Three prominent factors (see Figure 1.1) for assessment were extracted from the list based on repitition and similarities in definition (King, 1989; Levinson, Ohler, Caswell, \& Kiewra, 1998; Powell \& Luzzo, 1998; Savickas, 1984; Schreuder \& Theron, 2004). External factors (as a fourth prominent influence) such as a person's context, culture, socio-economic status and quality of education, were also reported to play a significant role in CM (Perron, Vondracek, Skorikov, Tremblay \& Corbiere, 1998; Stead, 1996; Super, 1957).

Assessment of these factors (with their subscales) can thus firstly indicate if a need exists for career services for MSDS members; secondly provide an indication of areas that may require improvement; and thirdly serve as input or guidelines towards the development of a relevant and feasible career development programme and/or measures to be taken by the organisation towards improving CM and thus youth development (Coetzee \& Esterhuizen, 2010; Dodd, 2013). Figure 1.1 illustrates the list of factors in the literature and the prominent factors identified for assessment (Carr, 2007; Egan, 2014; King, 1989; Levinson, et al., 1998; Matzeder \& Krieshok, 1995; Powell \& Luzzo, 1998; Savickas, 1984; Schreuder \& Theron, 2004; Super, 1957; Super \& Nevill, 1984; Yukl, 2013). External factors that describe the characteristics of the sample, were also assessed in a biographical information survey.

LIST OF FACTORS FROM LITERATURE

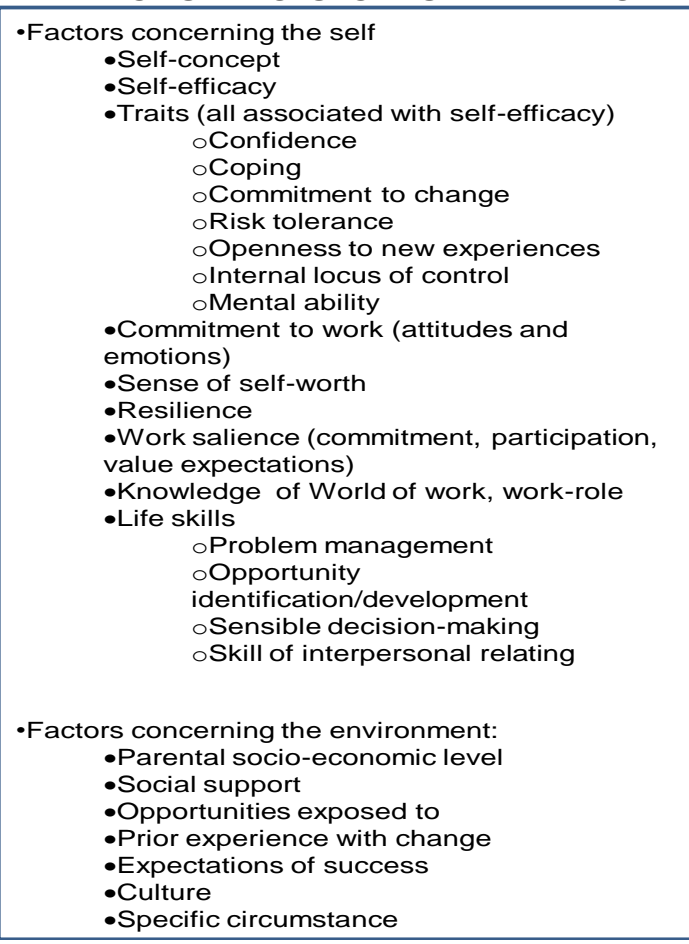

PROMINENT FACTORS ASSESSED

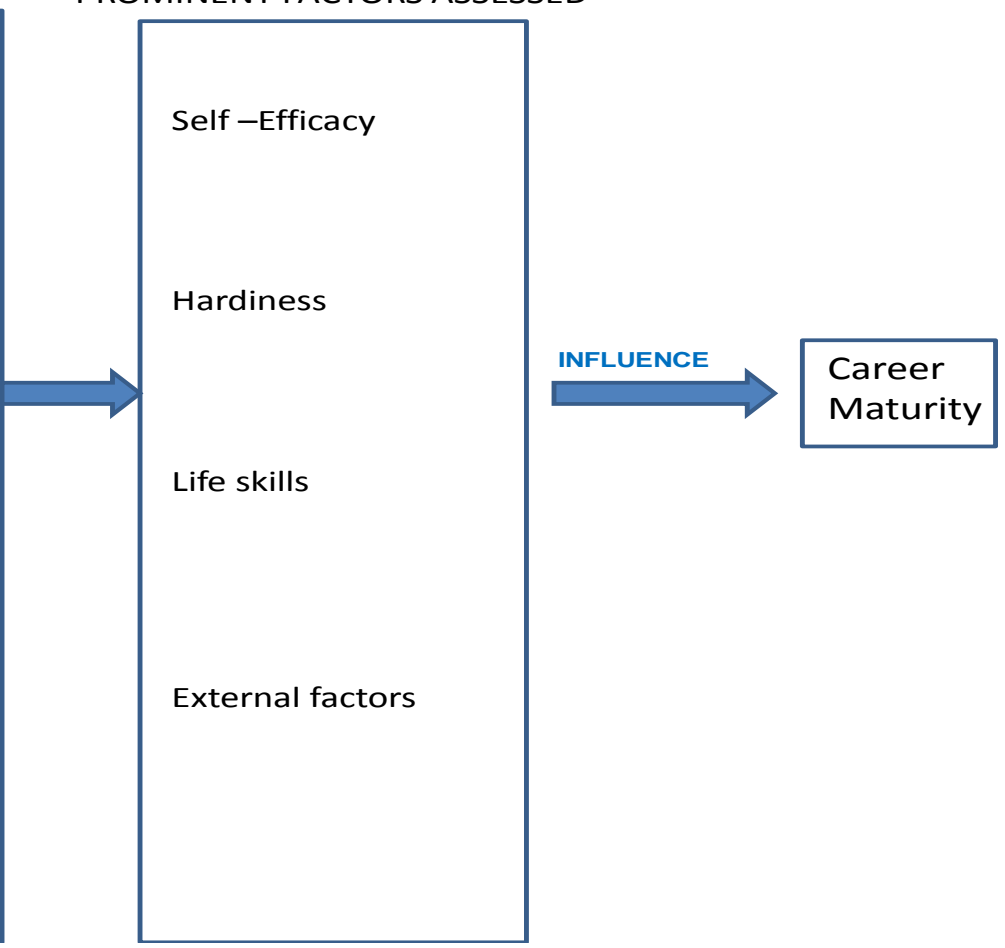

Figure 1.1. List of Factors Influencing CM 


\subsubsection{Theoretical objectives}

The theoretical objectives of the study were to conduct an in-depth literature review to conceptualise career services from a theoretical perspective, in order to shed light on what type of career services may be required by clients, and then an analysis of which of these are feasible and relevant in the MSDS context. This discussion includes a description of youth development as well as career development and counselling theories and approaches. CM is conceptualised from a theoretical perspective in order to identify the factors that influence it, or that could be seen as dimensions of CM. Meta-analysis is used to identify prominent factors that influence CM and which are assessed in the empirical phase of the research (Carr, 2007; Egan, 2014; King, 1989; Levinson et al., 1998; Matzeder \& Krieshok, 1995; Powell \& Luzzo, 1998; Savickas, 1984; Schreuder \& Theron, 2004; Super, 1957; Super \& Nevill, 1984; Yukl, 2013).

\subsubsection{Empirical objectives}

The empirical objectives of the study were to make use of a descriptive correlational survey research methodology (Babbie, 2010; Rogelberg, 2004):

- To determine the level of CM of MSDS members of the SANDF.

- To determine the levels of factors identified as influencing CM within the specific population.

- To determine which of the factors, identified as influencing $\mathrm{CM}$, seem significant in influencing CM within the specific population.

\subsection{RESEARCH PROCESS OVERVIEW}

The research was conducted in seven phases, which include: a literature review, an empirical study, reporting of results, and a discussion of results, conclusions, limitations and recommendations.

\subsubsection{Phase 1: Literature review}

The aim of this study is to investigate the need for career services for MSDS members in the SANDF and what would be feasible in this specific context. In order to achieve this aim, the research methodology included a literature review phase to explore the field of career services, so as to provide a thorough understanding of what career guidance programmes might entail. 
The literature review also provides insight into the $\mathrm{CM}$ construct from the perspective of different theories, which also led to the identification of the most prominent factors involved in the levels of $\mathrm{CM}$ to be explored within the MSDS population.

The construct(s) measured, with their associated definitions, include:

Career maturity: Elements of the definitions by various authors were integrated into a comprehensive definition for this study (Coetzee \& Roythorne-Jocobs, 2007; King, 1989; Levinson et al., 1998; Powell \& Luzzo, 1998; Savickas, 1984). CM is defined as a person's readiness to make realistic, well-informed, age-appropriate career decisions and formulate career goals based on self-knowledge, knowledge of employment opportunities, perceived employability and self-efficacy (see par 2.5).

Self-efficacy: Self-efficacy is defined as people's tendency to "....approach, explore, and try to deal with situations within their self-perceived capabilities..." and to "...avoid transactions with stressful aspects of their environment they perceive as exceeding their ability" (Bandura, 1977, p. 203). For the purposes of career decision-making, self-efficacy in this study will include competency in five career choice processes which include accurate self- appraisal, gathering occupational information, goal selection, making plans for the future and problem-solving (Crites as cited in Betz \& Taylor, 2013).

Hardiness: Hardiness is defined by (Dolan \& Adler, 2006, p.110) as personality style or tendency, fairly stable over time, that is composed of the following interrelated components (1) commitment (vs. alienation), referring to the ability to feel deeply involved in activities of life; (2) control (vs powerlessness), the belief one can control or influence events of one's experience; and (3) challenge (vs. threat), the sense of anticipation of change and an exciting challenge to further development

Life Skills: De Villiers (2001, p. 117) defines life skills as “...a variety of skills that are empowering and extend the abilities of individuals towards greater chances for success in the endeavours undertaken in their lives". Covey (1992) concludes that the skills for achieving success are based on a principle of personal development and growth. He presents an approach to being effective in attaining goals by aligning oneself to what he calls "true north" principles of a character ethic that he presents as universal and timeless. These principles include independence (moving from dependence to independence - self-mastery) and includes the three habits of being proactive, clarifying own life goals, and self-management. 
The next principle is interdependence (working with others) and includes the three habits of seeking mutually beneficial solutions, listening skills and positive teamwork. The principle of continuous improvement in both the personal and interpersonal spheres of influence is described as sharpening the saw (Covey, 1992).

External factors: External factors refer to those factors influencing $\mathrm{CM}$ which are not inherent to the individual and include parental socio-economic status, social support, opportunities exposed to, prior experience with change/vocation(s), expectations of success and socioeconomic circumstances (Stead, 1996; Super, 1957).

The study will explore the levels of these constructs within the MSDS context in order to determine which factors involved in CM need to be addressed by the SANDF towards better youth development. Data will be collected from MSDS members at relevant SANDF training units.

\subsubsection{Phase 2: Empirical research}

The second phase of the methodology is the empirical study. It consists of the measuring of the levels of CM as well as the factors involved in the levels of CM of SANDF MSDS members. Collection of data was done by means of administering the psychometric battery of five paperand-pencil questionnaires. The measuring instruments that were identified were those that proved to be most relevant to the objectives of the study and have in the past been reported to be valid and reliable. It is recognised that due to the multidimentional nature of the $\mathrm{CM}$ construct (Super \& Nevill, 1984), one instrument cannot measure all aspects of CM. Questionnaires were chosen that will provide data on the factors influencing CM that are relevant to this study. The practical implications for administering of the questionnaires to large groups of MSDS members and the maximum time available for the psychometric battery also played a role in the choice of questionnaires.

Four recognised instruments were chosen: the Revised Career Maturity Inventory (CMI-R) short form by Crites and Savickas (1996), the Career Decision Self-Efficacy scale (CDSE) short form by Betz and Taylor (2013), the Military Hardiness Scale (MHS) by Dolan and Adler (2006), the Seven Habits Profile Questionaire (Covey, n.d.) and a Biographical Information Form (BIF) compiled by the author for this study. These instruments are described in more detail in par 3.5. 
The battery of questionnaires was administerd to MSDS members at different SANDF units: 1 Signal Regiment, SAS Saldanha and SA Air Force Command. The sample was drawn from a population of MSDS members in the 2013 and 2014 intake of the SANDF. These members were between the ages of 18 and 27 and hold the ranks of private to corporal, candidate officers and luitenants. Participants were members from different Arms of Service of the SANDF which included the SA Army, SA Navy (SAN) and SA Air Force (SAAF).

Questionnaires were administered by the researcher and assisting post-graduate students. Participants were informed of the purpose of the study and informed consent was obtained for the collection of the data after a verbal explanation was provided and the participants signed a consent form together with the test battery. Completion of the questionnaires took two hours. The answer sheets were scored manually and were numbered for control purposes and for creating the dataset on Microsoft Excel.

\subsubsection{Phase 3: Reporting of results}

The statistical techniques used for the research are discussed in this section. Responses collected from the questionnaires were captured using Microsoft Excel in order to conduct systematic data analyses. The primary data collected by means of the questionnaires were analysed using descriptive and inferential statistics (on STATISTICA 10). This type of statistical analysis included using histograms, tabulations with means and standard deviations, factor analysis, correlations, multiple regression analysis and statistical graphics.

\subsubsection{Phase 4: Discussions of results}

The levels of $\mathrm{CM}$ and the identified factors from a diagnostic model on CM are discussed in terms of the mean scores of the sample. The relationships between each factor and CM are also discussed and the most significant influencing factors identified from multiple regression analysis are discussed.

\subsubsection{Phase 5: Conclusions}

The conclusions of the research are discussed.

\subsubsection{Phase 6: Limitations}

The general limitations to the research as well as the limitations of the measuring instruments are discussed. 


\subsubsection{Phase 7: Recommendations}

The results of the study were used to deduct and explore possible interventions on organisational level (and group level), in order to address the factors involved in CM which may require improvement towards youth development. Recommendations, based on the findings of this research, are made in respect of the need for the development of a career development and guidance programme in the organisation (SANDF) and the required focus of such a programme. Recommendations towards possible future research on this topic are included.

A summary of the research process overview is illustrated in Figure 1.2.

\begin{tabular}{llll|}
\hline DESCRIBE & MEASURE & CONFIRM \\
Career & $\begin{array}{l}\text { Prominent } \\
\text { factors }\end{array}$ & CM of MSDS; & Is the SANDF \\
Services; & influencing & career & succeeding in \\
CM; & $\mathrm{CM}$ & services & its youth \\
Factors & $\mathrm{development}$ & responsibility?
\end{tabular}

Figure 1.2 Research Process Overview

\subsection{CHAPTER OVERVIEW}

The layout of the dissertation includes chapters as listed below. Each separate chapter includes its own introduction and conclusion.

\subsubsection{Chapter 1: Introduction}

This chapter describes the background and creates the setting for the research, and discusses the problem statement and the motivation for the study. Objectives of the study are set out, including the main objective, the theoretical and empirical objectives. Definitions for the constructs to be assessed are also included. The current level of knowledge on the subject and a high-level overview of the research design are provided. Finally, the layout of the rest of the dissertation is included in this chapter. 


\subsubsection{Chapter 2: Literature review}

This chapter meets the objectives of the literature review. It provides definitions of constructs and discusses concepts used in the study. Youth development models and programmes are discussed as the point of departure for the main objective of the study. Career services are conceptualised through integration of present literature, which includes career counselling theories, approaches, models and the career counselling process. CM is then conceptualised and the factors that influence levels of $\mathrm{CM}$ are identified through meta-analysis of the different theoretical perspectives in the literature. A diagnostic model of these identified factors is also presented.

\subsubsection{Chapter 3: Research design}

The chosen research approach and methodology is discussed in this chapter, and its benefits and challenges are identified. The research problem and hypotheses are stated and the sample used for the study is described in detail. The data-gathering process and instruments (questionnaires) are described and the method of analysis of the data is discussed per objective. Lastly, the ethical issues involved in the study are dealt with in this chapter.

\subsubsection{Chapter 4: Results}

The data that was gathered is described in this chapter. The perceived needs of the MSDS members regarding career guidance is assessed by describing the results of descriptive and inferential statistical analyses. The outcome(s) of the objectives of the study are indicated and a summary of the findings is provided.

\subsubsection{Chapter 5: Discussion}

This chapter integrates the key literature findings with the key quantitative analysis findings. The implications and applications of the findings are then discussed. Discussions include the levels of $\mathrm{CM}$ and influencing factors measured in the sample, the relationships between the factors and $\mathrm{CM}$, as well as the identification of a set of most significant factors that influence $\mathrm{CM}$. 


\subsubsection{Chapter 6: Conclusion}

This last chapter includes an overview of the research conducted, including a summary of the problem statement, objectives and research design. The findings and their implications are then summarised. The limitations of the study are also identified, and suggestions for future research included. Recommendations are then made for career educational and guidance programme(s) relevant to the identified needs of SANDF MSDS members deemed feasible in the current SANDF. Lastly, an overall assessment of the study is conducted that includes meeting the problem statement and objectives, as well as adding value to the field of psychology and the SANDF as an organisation.

\section{CHAPTER SUMMARY}

This chapter introduced the study in terms of the background, motivation and the problem statement. The existing knowledge available on the subject of $\mathrm{CM}$ is addressed. It further describes the research objectives, the research design and the methodology. A summary of what is covered in each chapter of the dissertation is also presented.

The SANDF has a social responsibility towards youth development in the RSA. The MSDS programme was implemented as the SANDF's contribution towards the National Skills Development Strategy of South Africa. After completing a two-year contract, some MSDS members enter into new employment contracts with the SANDF while others are informed that their contracts will expire and that they will not be re-appointed in the SANDF. It is expected of such MSDS members to either find employment elsewhere or continue to manage their career in the SANDF. In oter words, they have to become economically contributing citizens. CM was identified as the construct that can provide insight into the readiness of these young MSDS members to make realistic and well-informed career decisions and to take control of their career lives. The factors that influence $\mathrm{CM}$ will be explored to assess the need for a career guidance programme for MSDS members and what the focus of such a programme should be.

The literature review follows in the next chapter, and will shed light on the possible needs of MSDS members in terms of career services, provide a detailed discussion on CM and identify the factors involved in levels of $\mathrm{CM}$. It thus provides the theoretical support towards the main objective of the study. 


\section{CHAPTER 2}

\section{LITERATURE REVIEW}

\section{$2.1 \quad$ INTRODUCTION}

This chapter provides a systematic and thorough literature review in order to provide an overview of youth development within the South African context. It also includes conceptualisation of career services as well as $\mathrm{CM}$ and the factors influencing it. CM has been identified as an indicator to confirm whether the SANDF as an organisation succeeds in its responsibility to contribute to national youth development. Identifying the prominent factors influencing $\mathrm{CM}$ and measuring the levels of these factors in the SANDF's young people provides insight into which of these factors may be feasibly addressed for improvements in CM among MSDS members.

\subsection{CAREER CHALLENGES IN THE CURRENT SOUTH AFRICAN CONTEXT}

The nature of employment has changed and it has become an uncertain issue because of factors such as globalisation, diminishing primary resources, downsizing, advanced technology developments and increased diversity within the work force. Furthermore, changes in employment patterns mean that people cannot rely on maintaining a job with one company, or even follow one career path, throughout their working lives. Employees must now maintain their own employability and take ownership of their careers. This in turn necessitates the need for employees to become aware of market trends and develop skills and knowledge accordingly in order to ensure their employability (Cima, 2002; Coetzee \& Roythorne-Jacobs, 2007; Lee \& Johnston, 2001).

Awareness of this trend in employment is not necessarily addressed during the high school years of most South African young people. In general, young people today seem to lack the ability to take ownership for their own careers, and appear to be unable to maintain their employability. Instead, the prevailing sentiment reflects a sense of entitlement - that my country owes me and will provide for me - this seems to be the general attitude amongst most South African young people. 
Youth unemployment, especially in the 20-24-year age group, is a serious concern in the South African labour market (Coetzee \& Esterhuizen, 2010). The growing uncertainty and lack of job security pose psychological challenges to most employees. The blurring of boundaries whereby one employee is expected to perform multiple functions which were previously undertaken by numerous employees, is another such challenge. The requirement for lifelong learning to maintain one's own employability is an added serious stress factor. Furthermore, people's careers are central to their identity in their specific cultural and socio-economic context. A person's career affects every area of that person's life and career dilemmas can manifest themselves in psycho-emotional and inter-personal problems (Coetzee \& Roythorne-Jacobs, 2007; Mutchinsky, Kriek \& Schreuder, 2002). Career services, such as counselling and guidance, provide ways in which such career dilemmas can be addressed.

\subsubsection{Choosing a career}

The choice of a vocation is one of the most important decisions a person has to make in his or her life. This choice will affect most other aspects of the individual's life. Career guidance (see par 2.4) assists a person in making rational and feasible decisions when choosing a career. Career counsellors also provide other career services (see par 2.4).

A career is defined by Coetzee and Roythorne-Jacobs (2007, p. 7) as significant learnings and experiences that identify a person's professional life (or vocational life), direction, competencies and accomplishments through occupational positions, forms of employment, vocational roles and vocational assignments and contracts. People match their careers with their personal aims, life purpose and competencies.

Cummings and Worley (2008, p. 747) define career as "...the sequence of behaviours and attitudes associated with past, present and anticipated future work-related experiences and role activities. A career is work related and lifelong." A career thus refers to the sequence of workrelated positions occupied by a person during his/her lifetime (Robbins, 1993; Cummings \& Worley, 2008).

A career is therefore a developmental process throughout a person's lifespan that consists of a sequence of jobs and learning experiences in several career-life stages (periods in one's work life identified by changes in activities, concerns and motives) across the career life-cycle, or the totality of work in one's lifetime (Cascio \& Aguinis, 2005; Coetzee \& Roythorne-Jacobs, 2007; Foxcroft \& Roodt, 2009). 


\subsubsection{Career life stages}

Super (1990) proposed five life stages (growth, or childhood; exploration, or adolescence; establishment, or young adulthood; maintenance, or middle adulthood; and decline, or old age) that individuals progress through during their lives. Foxcroft and Roodt, (2009) explain that the career life cycle describes the different periods of early, mid and late career life stages. They state that each life stage offers developmental requirements associated with mastery of career developmental tasks and that investigating CM therefore includes the identification of career developmental tasks that a person has not mastered successfully for a specific life stage. The focus is not on the current and past only, but also on future work-related possibilities. Occupational choice based on culture-specific determinants should be studied as alternatives to the Western assumption of vocational interests being the primary determinants (Gikopoulou, 2008). This is especially relevant in the African context. This study will explore the needs for career education and guidance in the South-African context.

People currently follow multiple career paths, with different career stages in each career-life stage. These career stages are reiterative and have no specific boundaries (Mutchinsky et al., 2002; Schreuder \& Theron, 2004). The early career-life stage (ages 17 to 39 years) is relevant to MSDS members in the SANDF and national youth development in the RSA in general. The key life tasks or challenges of this career-life stage (Coetzee \& Roythorne-Jacobs, 2007) include:

- achieving independence and responsibility;

- developing self-reliance or autonomy;

- establishing one's vocational identity and career anchor (self-perceived talents and abilities, motives, attitudes and values);

- finding one's identity and contributing to society;

- making an impact on one's environment;

- becoming established in an occupation and in family life;

- developing intimacy, becoming committed and involved - developing stable affiliations;

- developing career competency and self-efficacy;

- becoming employable and career resilient (with conscientiousness, dealing with career transitions, career breaks and sustaining one's employability through further education and development); and

- dealing with the quarter-life crisis. 


\subsubsection{Nature of careers in current day}

As described above, the nature of careers since the turn of the millennium is very different from what it was in previous decades - the 1980's and 1990's. Mutchinsky et al. (2002) describe the concept of protean careers of the twenty-first century where technological developments, proliferation of knowledge and diversity in the workforce now require a flexible view. They add that careers are no longer viewed as one type of work in a single organisation. The term 'protean' is derived from an analogy of the Greek god, Proteus, who could change shape of his own volition (Mutchinsky et al., 2002, p. 279). Schreuder and Theron (2004, p. 137) list the characteristics of the protean career as:

- psychological success;

- being managed by the individual;

- a series of identity changes;

- continuous learning;

- chronological age being unimportant;

- employability and work challenges provided by the organisation;

- a high level of self-awareness;

- personal responsibility;

- freedom of growth being valued;

- a high degree of mobility; and

- internal career thinking being emphasised.

Psychological success in this context is defined as "the feeling of pride and accomplishment that comes from achieving life goals" (Noe et al., 2008, p. 402). Ingrid, Majda and Dubravka (2009) add that having goals and striving towards achieving them, positively contributes to the overall well-being of a person. Coetzee and Esterhuizen (2010) propagate that career counselling in the current South African context also needs to shift from predominantly vocational assessment and job search, to assisting young people to engage in proactive, self-directed career planning activities and assessing readiness to participate in life as independent individuals. Career services therefore need to focus on the current nature of careers as listed above. 
People perform well when placed in jobs to which they are best suited (Gikopoulou, 2008). Whilst providing an income, it enables people to participate in other spheres of life and sustain basic needs, such as physical and security needs. People also attach meaning to their work; it provides them with a sense of purpose. It also provides self-fulfilment, challenges and opportunities for growth and development (Coetzee \& Roythorne-Jacobs, 2007; Mutchinsky et al., 2002; Schreuder \& Theron, 2004).

Bretz and Judge (1994) link person-organisation fit and the theory of work adjustment (propagating that individuals and environments impose requirements on one another and that successful adjustment leads to positive work relations) to positive work-related outcomes. These include work motivation and subsequent career success, tenure and satisfaction. It is still necessary however, that the young people be assisted in finding a vocation that best suit their personalities, abilities, and skills and to receive guidance in developing a suitable career.

Career anchors are self-perceived talents, motives and values that guide, stabilise and integrate the individual's career - these anchors tend to remain stable throughout the person's career (Coetzee \& Roythorne-Jacobs, 2007; French \& Bell, 1999; Mutchinsky et al., 2002; Robbins, 1993; Schreuder \& Theron, 2004). These perceptions (career anchors) may be distorted and might be the focus of guidance towards CM. Career choice could furthermore be said to be the product of a dream. A person has a dream of the type of life that he/she wants to live and builds towards that goal by choosing a career that will help reach the goal (Coetzee \& RoythorneJacobs, 2007).

According to Brooks (as cited in Coetzee \& Roythorne-Jacobs, 2007), there are five ways to explain clients' career-related problems:

- problems matching one's interests, skills or needs with the appropriate occupation;

- problems of vocational immaturity or development;

- problems related to the self-concept, personal and vocational identity;

- problems regarding the career decision-making process;

- problems with obstacles or barriers posed by the social environment.

A well-developed career counselling programme for MSDS members in the SANDF may address all the above challenges. 


\subsection{YOUTH DEVELOPMENT}

The research-initiating question for this study was: "Is the SANDF succeeding in their contribution towards youth development in South Africa by the implementation of the Military Skills Development Programme?" Career development is an integral part of youth development and therefore this study focuses on answering the question of whether MSDS members obtain adequate levels of CM for their particular life stage and if not, how the SANDF can address it. In this section youth development in general as well as in the South African context will be discussed.

According to Walker and Dunham (2014, p.1), "youth development is the process of growing up and developing one's capacities in positive ways. This typically takes place in the context of the family, the peer group, the school, and the neighbourhood or community." They further describe youth development organisations to include the following (Walker \& Dunham, 2014):

- organisations exist to promote the positive, healthy development of young people;

- such organisations are different from agencies and systems that exist to provide social control, treatment or training for young people;

- the socialisation of youth is the organisation's primary task;

- providing the challenges, experiences, support and help young people need to develop to their fullest potential;

- organisations are usually community-based and work to meet needs in the environment and enhance the learning experiences of young people;

- no single organisation is able to do it all.

In the SANDF MSDS programme, young people are trained within the context of their own peer groups. They are frequently exposed to challenges in groups, and teamwork is of utmost importance in the military context. Strong bonds usually form in terms of socialisation. Exposure to challenges and new experiences is part of training and members are systematically developed to realise the extent of their potential (both physically and mentally), while always being aware that the group is important and that members will always help one another (interdependence). Opportunities also exist within the MSDS programme for officer candidates to undergo tertiary education, in other words, for them to develop their potential. 
The National Clearinghouse on Families and Youth (NCFY) (2001), asserts that youth development emphasizes the provision of services and opportunities in order to support young people in developing a sense of a competence, value, belonging and empowerment. Individual programs can provide youth development activities. An approach where entire communities, including its young people, are involved in creating a continuum of services and opportunities for youth to grow into happy and healthy adults is, however, more positive (NCFY, 2001). Youth development strategies should also focus on giving young people the chance to form relationships with caring adults, in order to build skills, exercise leadership and help their communities (Center for Youth Development Policy, 2014).

The underlying philosophy of youth development should be holistic, preventative and positive. The focus should be on the development of assets and competencies in young people. Key elements to be included in a positive youth development approach are the following (Teipel, 2002, p.1):

- "Youth are viewed as a valued and respected asset to society;

- Policies and programs focus on the evolving developmental needs and tasks of adolescents, and involve youth as partners rather than clients;

- Families, schools and communities are engaged in developing environments that support youth;

- Adolescents are involved in activities that enhance their competence, connections, character, confidence and contribution to society;

- Adolescents are provided an opportunity to experiment in a safe environment and to develop positive social values and norms; and

- Adolescents are engaged in activities that promote self-understanding, self-worth, and a sense of belonging and resiliency."

The definition of youth development refers to the positive development of capacities. Various theories exist on what exactly these capacities that should be developed are. Hawkins and Weiss (1985) propose the Social Development Model to include a process in which youth are sequentially influenced by families, schools, peers and their community. Three things must happen within each of these spheres in order to facilitate positive development:

- Youth must be given opportunities for meaningful involvement;

- Skills for successful participation and interaction must be developed;

- A consistent system of positive reinforcement for positive behaviour must be executed. 
Key competencies are defined as "generic competencies that are essential for effective participation in the workplace" (http://www.vcaa.vic.edu.au/faqs/acronymsglossary.html). Young and Chapman (2010) state that employers who operate in global labour markets seek employees who possess not only high-level technical or job-specific competencies, but also have high levels of what are known as "generic competencies". They report that this term is used to refer to competencies that can be applied across different job and life contexts and are alternatively labelled core skills, employability skills, life skills or soft skills.

The Australian Education Council's Mayer Committee, in 1992, labelled the Mayer key competencies as a set of seven competencies deemed essential for preparing entry-level employees for the workforce - this set includes (Young \& Chapman, 2010):

- collecting, analysing, and organising information;

- communicating ideas and information;

- planning and organising activities;

- working with others and in a team;

- using mathematical ideas and techniques;

- problem-solving; and

- using technology.

Brewer (2013) argues that employability results from several factors that are critical for enabling workers to attain decent work and manage change - these factors include:

- a foundation of core skills;

- access to education;

- availability of training opportunities;

- motivation;

- ability and support to take advantage of opportunities for continuous learning; and

- recognition of acquired skills.

The Search Institute (2014) identified forty development assets that enable young people to succeed in life - a useful set of measuring blocks that integrate the social development model and the concept of key competencies. Figure 2.1 below shows the forty development assets of the Search Institute. 


\begin{tabular}{|c|c|c|c|c|}
\hline \multirow{21}{*}{ 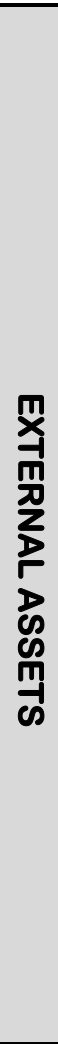 } & \multicolumn{2}{|l|}{$\begin{array}{l}\text { Asset } \\
\text { type }\end{array}$} & \multirow{2}{*}{$\begin{array}{l}\text { Asset name } \\
\text { FAMILY SUPPORT }\end{array}$} & \multirow{2}{*}{$\begin{array}{l}\text { Definition } \\
\text { Family life supplies high levels of support } \\
\end{array}$} \\
\hline & \multirow{6}{*}{ 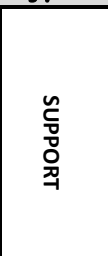 } & 1 & & \\
\hline & & 2 & POSITIVE FAMILY COMMUNICATION & $\begin{array}{l}\text { Young person and his/her parents communicate positively, and young person is willing to } \\
\text { seek advice \&counsel from parents }\end{array}$ \\
\hline & & 3 & OTHER ADULT RELATIONSHIPS & Young person receives support from three or more nonparent adults \\
\hline & & 4 & CARING NEIGHBOURHOOD & Young person experiences caring neighbours \\
\hline & & 5 & CARING SCHOOL CLIMATE & School provides a caring, encouraging environment \\
\hline & & 6 & PARENT INVOLVEMENT IN SCHOOLING & Parent(s) are actively involved in helping young person succeed in school \\
\hline & & 7 & COMMUNITY VALUES YOUTH & Young person perceives that adults in the community value youth \\
\hline & $3 \frac{3}{0}$ & 8 & YOUTH AS RESOURCES & Young people are given useful roles in the community \\
\hline & 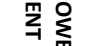 & 9 & SERVICE TO OTHERS & Young person serves in the community one hour or more per week \\
\hline & & 10 & SAFETY & Young person feels safe at home, at school and in the neighbourhood \\
\hline & & & FAMILY BOUNDARIES & Family has clear rules and consequences and monitors the young person's whereabouts \\
\hline & 胥 & 12 & SCHOOL BOUNDARIES & School provides clear rules \& consequences \\
\hline & 魚 z & 13 & NEIGHBOURHOOD BOUNDARIES & Neighbours take responsibility for monitoring young people's behaviour \\
\hline & 正 & & ADULT ROLE MODELS & Parent(s) and other adults model positive, responsible behaviour \\
\hline & $\bar{z} \overline{\tilde{m}}$ & 15 & POSITIVE PEER INFLUENCE & Young person's best friends model responsible behaviour \\
\hline & & 16 & HIGH EXPECTATIONS & Both parent(s) \& teachers encourage the young person to do well \\
\hline & 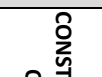 & 17 & CREATIVE ACTIVITIES & $\begin{array}{l}\text { Young person spends 3or more hours/week in lessons or practice in music, theatre or } \\
\text { other arts }\end{array}$ \\
\hline & 유릴 & & YOUTH PROGRAMMES & $\begin{array}{l}\text { Young person spends } 3 \text { or more hours/week in sports, clubs or organizations at school } \\
\text { and/or in the community }\end{array}$ \\
\hline & $\bar{m} \overline{\mathrm{m}}$ & 19 & RELIGIOUS COMMUNITY & Young person spends one or more hours/week in activities in a religious institution \\
\hline & & 20 & TIME AT HOME & Young person is out with friends 'with nothing special to do' two or fewer nights per week \\
\hline \multirow{21}{*}{ 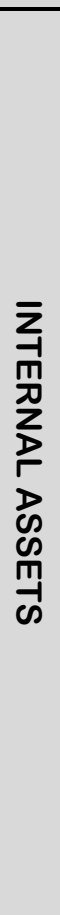 } & \multirow{5}{*}{ 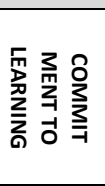 } & 21 & ACHIEVEMENT MOTIVATION & Young person is motivated to do well at school \\
\hline & & 22 & SCHOOL ENGAGEMENT & Young person is actively engaged in learning \\
\hline & & 23 & HOMEWORK & Young person reports doing at least one hour of homework every school day \\
\hline & & 24 & BONDING TO SCHOOL & Young person cares about his/her school \\
\hline & & 25 & READING AND PLEASURE & Young person reads for pleasure three or four hours per week \\
\hline & \multirow{6}{*}{ 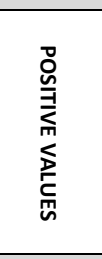 } & 26 & CARING & Young person places high value on helping other people \\
\hline & & 27 & EQUALITY \& SOCIAL JUSTICE & Young person places high value on promoting equality and reducing hunger and poverty \\
\hline & & & INTEGRITY & Young person acts on conviction and stands up for his/her beliefs \\
\hline & & 29 & HONESTY & Young person 'tells the truth even when it is not easy' \\
\hline & & 30 & RESPONSIBILITY & Young person accepts and takes personal responsibility \\
\hline & & & RESTRAINT & $\begin{array}{l}\text { Young person believes it is important not to be sexually active or to use alcohol or other } \\
\text { drugs }\end{array}$ \\
\hline & & & & \\
\hline & \multirow{5}{*}{ 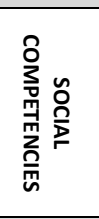 } & & PLANNING AND DECISION MAKING & Young person knows how to plan ahead and make choices \\
\hline & & & INTERPERSONAL COMPETENCE & Young person has empathy, sensitivity and friendship skills \\
\hline & & & CULTURAL COMPETENCE & $\begin{array}{l}\text { Young person has knowledge of and comfort with people of different cultural/racia/ethnic } \\
\text { backgrounds }\end{array}$ \\
\hline & & 35 & RESISTANCE SKILLS & Young person can resist negative peer pressure and dangerous situations \\
\hline & & 36 & PEACEFUL CONFLICT RESOLUTION & Young person seeks to resolve conflict non-violently \\
\hline & \multirow{4}{*}{ 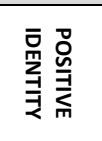 } & 37 & PERSONAL POWER & Young person feels he/she has control over 'things that happen to me' \\
\hline & & 38 & SELF-ESTEEM & Young person reports having a high self esteem \\
\hline & & & SENSE OF PURPOSE & Young person reports that 'my life has a purpose' \\
\hline & & 40 & POSITIVE VIEW OF PERSONAL FUTURE & Young person is optimistic about his/her future \\
\hline
\end{tabular}

Figure 2.1. Forty Developmental Assets

(Search Institute, 2014, p. 2) 
The Development Bank of Southern Africa reports that youth unemployment poses a formidable policy challenge for South Africa. The unemployment rate of $25 \%$ in the fourth quarter of 2010 (Stats SA, 2011) is among the highest in the world. Unemployment seems to be concentrated in the 14 to 35 age range, which accounted for $72 \%$ of the unemployed in 2010.

The country's unemployment crisis is consequently seen as a youth unemployment crisis. South Africa's growth trajectory in the 19 years since attaining democracy has not absorbed labour at the required scale. The lack of access to the labour market and wage income has driven up poverty and inequality, despite a significant rollout of social grants and basic services (Mayer, 2011). In the South African context, it is imperative that the youth become employable and take responsibility for their future.

Due to the legacy of Apartheid in South Africa which resulted in a high rate of unemployment among previously disadvantaged youth, the South African government has established national strategies to deal with these inequalities, such as the National Skills Development Strategy and the National Human Resources Development Strategy (Coetzee \& Esterhuizen, 2010).

\subsubsection{The National Skills Development Strategy}

The National Skills Development Strategy Document version three (NSDS III) is a South African policy on skills development for the 2011 to 2016 period (Department of Higher Education and Training RSA, 2014). The NSDS III is a subcomponent of the Human Resource Development Strategy of South Africa and operates concurrently with the first five-year term of the country's second Human Resource Development Strategy. Since its inception, the three versions have evolved in terms of its specific focus. NSDS I (2001-2005) placed emphasis on equality and the need to cultivate lifelong learning in a workplace environment. Learning was to be demanddriven, based on the needs of employees in both the public and private sectors. The effectiveness of delivery was seen as essential. NSDS II (2005-2010) emphasized equity, quality training and skills development in the workplace. The need for the promotion of employability was identified. It also specified the need for assisting designated groups to gain knowledge and experience in a workplace environment in order to gain critical skills. The quality of the provision of learning was identified as a problem area needing improvement. The current NSDS III changed emphasis in the direction of institutional learning linked to occupationally directed programmes. It promotes the growth of Further Education and Training (FET) Colleges in order to address national skills needs. 
Better use of workplace skills programmes such as worker-initiated training, is encouraged. It also includes a focus on public sector improved service delivery as an imperative. The issue of language and literacy was identified as an area of concern in terms of enabling additional learning (Department of Higher Education and Training RSA, 2014).

The MSDS is the SANDF's contribution towards the NSDS. It is expected that the outcomes of the MSDS programme will address the objectives of the NSDS, which include cultivating lifelong learning and employability (gaining knowledge, skills and experience). It should include awareness of the trends in the labour market - knowledge of the world of work.

\subsubsection{Adolescence and youth development}

MSDS members (when joining) fall between the age group 18 to 23 , although some of the special skills intakes also include members between 23 and 27 years of age. This group can be considered as late adolescents (and young adults). According to the theories of human development, adolescents have to accomplish the following developmental tasks (Havigurst, 1972):

- Achieving mature relations with both sexes

- Achieving a masculine or feminine social role

- Accepting one's physique

- Achieving emotional independence of adults

- Preparing for marriage and family life

- Preparing for an economic career

- Acquiring values and an ethical system to guide behaviour

- Desiring and achieving socially responsible behaviour

- Selecting a mate

- Learning to live with a partner

- Starting a family

- Rearing children

- Managing a home

- Starting an occupation

- Assuming civic responsibility. 
Youth development programmes were described in par 2.3 to promote the healthy and positive development of young people in order to help such young people discover (and reach) their full potential. Teipel (2002) adds that programmes should focus on the developmental tasks of adolescents (as listed above), and thus facilitate the positive achievement of the developmental tasks.

This includes, by implication, being able to make good decisions regarding these tasks. Teipel also maintains that youth development should enhance the competence, connections, confidence, character and contribution to society of adolescents. He stresses the importance of promoting self-understanding. When considering the contribution of the SANDF towards youth development, the achievement of the developmental tasks of adolescents and the description of youth development programmes and approaches in par 2.3 may serve as criteria for evaluation.

\subsection{CAREER SERVICES}

To assist clients in addressing career-related problems, career counsellors must be able to identify the specific need of the client (diagnosis of the client's career-related problem) and have knowledge of counselling theories, approaches, skills and techniques. In order to explore the possibilities for empowerment and development of competencies of South African youth towards becoming assets in the labour market, career services will be discussed in detail in the section below. The theories, approaches, and useful skills and techniques are included towards formulating a career guidance programme or appropriate career services for MSDS members.

\subsubsection{Diagnostic framework for career services}

Coetzee and Roythorne-Jacobs (2007, p. 132) define career services as "...career counselling, career guidance, career placement, career therapy, career education and career coaching". They developed a diagnostic framework for career services to guide the diagnosis of the careerrelated needs or problems of clients in the workplace across their adult life-span. It provides a useful structure for determining the most appropriate strategy, models and theories for the counselling process. The career services in the framework apply different career theories to address each problem related to the client's vocational self, career self and various life roles (see Table 2.1). 
Table 2.1: Diagnostic Framework for Career Services

\begin{tabular}{|c|c|c|c|c|}
\hline \multirow{2}{*}{ Purpose } & \multicolumn{4}{|l|}{ Locus of Career Service } \\
\hline & Career Self & Vocational Self & Environment (Life Roles) & Outcome \\
\hline $\begin{array}{l}\text { Facilitate } \\
\text { Career } \\
\text { Competency }\end{array}$ & $\begin{array}{l}\text { Career Counselling } \\
\text { Client need: } \\
\text { To learn more about subjective views } \\
\text { of life, develop personal and vocational } \\
\text { identity, crystalise occupational } \\
\text { field and ability level preferences, } \\
\text { mature / deepen personality } \\
\text { Purpose: } \\
\text { To crystalise vocational identity and } \\
\text { envision a subjective career by } \\
\text { facilitating self-reflection and cognitive } \\
\text { restructuring, elaboration of self-concep } \\
\text { through introspection and discussion of } \\
\text { subjective career } \\
\text { Model(s) } \\
\text { Person-centered (Rogers) }\end{array}$ & $\begin{array}{l}\text { Career Guidance } \\
\text { Client need: } \\
\text { To articulate behaviour repertoire } \\
\text { (interests, abilities, preferences, motives, } \\
\text { anchors) and translate it into vocational } \\
\text { choices and options (congruent } \\
\text { occupational fields and levels) } \\
\text { Purpose: } \\
\text { To translate self-concepts into } \\
\text { occupational titles for clients who possess } \\
\text { clear and stable vocational identities but } \\
\text { have no vocational destiny in mind } \\
\text { Model(s) } \\
\text { Trait and factor theories (e.g. Holland) } \\
\text { Tests and inventories (e.g. MBTI/Schein's } \\
\text { Career Anchors / Driver's Career Patterns) }\end{array}$ & $\begin{array}{l}\text { Career Placement } \\
\text { Client need: } \\
\text { To implement vocational choice and } \\
\text { secure a position in a chosen occupation. } \\
\text { Purpose: } \\
\text { To reduce employment seeking anxiety, } \\
\text { increase assertiveness, counter mistaken } \\
\text { beliefs, coax exploratory behaviour, } \\
\text { increase social skills, and refine self- } \\
\text { presentation behaviour by assisting clients } \\
\text { who are ready to implement a choice with } \\
\text { information gathering, writing resumes, } \\
\text { networking, searching for forms of } \\
\text { employment, and preparing for interviews } \\
\text { guidance on self-employment / learner } \\
\text { ships } \\
\frac{\text { Model(s) }}{\text { Social learning theory 9e.g. Krumboltz) }} \\
\text { Career Management Model (Greenhaus ee } \\
\text { al, 2000) }\end{array}$ & $\begin{array}{lr}\text { Career } & \text { Self- } \\
\text { efficacy } / \text { Career } \\
\text { Maturity }\end{array}$ \\
\hline $\begin{array}{l}\text { Facilitate Career } \\
\text { Adjustment }\end{array}$ & $\begin{array}{l}\text { Career Therapy } \\
\text { Client needs: } \\
\text { To form personally meaningful } \\
\text { vocational identity } \\
\text { Purpose: } \\
\text { To help clients who experience } \\
\text { motivational problems (e.g. job loss } \\
\text { career transition / midlife / late life } \\
\text { quarter life crises), excessive } \\
\text { indecisiveness, anxiety and conflicts to } \\
\text { develop a clear and stable vocational } \\
\text { identity by examining personal motives } \\
\text { and recurring problems, and modifying } \\
\text { distorted motives } \\
\text { Model(s): } \\
\text { Personal and career counselling models } \\
\text { (e.g. Psychodynamic approach of } \\
\text { Bordin), Postmodern (e.g. Narrative } \\
\text { Approach / Frankl's Logotherapy } \\
\text { Transpersonal approaches) }\end{array}$ & $\begin{array}{l}\text { Career Education } \\
\text { Client needs: } \\
\text { To learn to better manage one's } \\
\text { motivation and implement one's self- } \\
\text { concept, enact one's subjective career } \\
\text { intentions (life / career stage challenges) } \\
\text { Purpose: } \\
\text { To assist the development of self- } \\
\text { management attitudes (foresight } \\
\text { autonomy) and competencies (planning } \\
\text { decision-making) and readiness to cope } \\
\text { with vocational development tasks), } \\
\text { fostering coping attitudes and } \\
\text { competencies } \\
\text { Model(s): } \\
\text { Developmental (e.g. Super) } \\
\text { Decision-making theory } \\
\text { (Miller-Tiedeman, Tiedeman \& O'Hara } \\
\text { Career Invention Model (Coetzee, 2006a) }\end{array}$ & $\begin{array}{l}\text { Career Coaching } \\
\text { Client needs: } \\
\text { To adjust to / cope with challenges of } \\
\text { occupational position (e.g. organisational } \\
\text { culture, job requirements, co-workers, } \\
\text { entering the world of work, accelerated } \\
\text { career development challenges, work- } \\
\text { family imbalances, limited progression } \\
\text { routes) } \\
\text { Purpose: } \\
\text { To teach adaptive mechanisms through } \\
\text { mentoring and coaching (skills training) } \\
\text { Model(s): } \\
\text { Organisational } \\
\text { Organisational Career Management } \\
\text { System (Support practices. } 3 . g . \\
\text { mentoring) } \\
\text { Theory of work } \\
\text { Adjustment (Dawis) } \\
\text { Career Invention Model (Coetzee, 2006a) }\end{array}$ & Career Resilience \\
\hline
\end{tabular}

(Coetzee \& Roythorne-Jacobs, 2007, pp. 133-134) 
Use of the framework requires counsellors to have a sound knowledge of a broad range of theories (see par 2.4.2), concepts and approaches related to career counselling, to enable the counsellor to use a combination of services and models for addressing each problem. Intuitive skills and creativity are characteristics of a counsellor that are conducive to effective choices in the combination of models and theories. Most clients have more than one problem which needs to be addressed and may require a combination of treatments, approaches and experiences. Career interventions thus usually include more than one career service at a time. The career services (Coetzee \& Roythorne-Jacobs, 2007) are briefly described below:

- Career counselling is aimed at developing the career competency, maturity and selfefficacy of the client by facilitating self-reflection and cognitive restructuring. Selfreflection techniques are mostly used for this, such as the person-centred approach or post-modern approaches such as narrative therapy, logotherapy and transpersonal approaches.

- Career guidance aids clients' career decision-making. The trait-and-factor theory of Holland and career assessments (tests and inventories) and occupational information are used to investigate career alternatives and to guide the client towards appropriate career decisions. It also includes assisting the client in forming a vocational identity and subjective career.

- Career placement refers to helping the client secure a position. This includes assistance with gathering information, compiling curricula vitae, searching for employment and preparing for interviews. Social learning theory is applied in this career service to reduce anxiety, correct mistaken beliefs and increase the life skills of the client.

- Career therapy focuses on the psycho-emotional experiences of clients and usually relates to the presence of emotional distress. It includes facilitating career adjustment in clients who are faced with career transitions. Career therapy requires a more supportive style of counselling than the other career services mentioned. 
- Career education focuses on assisting individuals who have difficulty in implementing their subjective career intentions and goals into their objective vocational behaviour. Education is aimed at developing attitudes that foster career self-management, career competencies, conscientiousness and resilience in facing the challenges of the different career life stages. The theories of Super, Miller-Tiedeman, Tiedeman and O'Hara on deliberate psychological education and development may be applied (see par 2.4.2.5).

- Career coaching assists clients to adjust to occupational positions and learn adaptive skills to become more resilient in their careers. Counsellors use mentoring and training based on systems theory, organisational development theory and the theory of work adjustment to help clients balance work and life, cope with organisational culture, interpersonal relationships in the workplace and the specific requirements of their position.

Counselling is defined as "the process of helping people make adjustments in normal developmental processes across the life span ..." (Matsumoto, 2009, p. 137). Any counsellorclient relationship has four basic goals: changes in behaviour and lifestyle, increased knowledge and understanding, relief from suffering and changes in self-perceptions and thoughts (Miars, Burden \& Pedersen, 1997).

Within the current nature of employment, career counselling is therefore no longer merely about finding the best fit between aptitude and job, but includes coaching the client towards career competency, resilience and CM. The career counsellor has become a facilitator, coach and advisor, as well as therapist, and must be competent in dealing with the psycho-emotional issues involved with career experiences. This includes assisting clients to choose a job effectively, to identify and learn the required skills for such a chosen job, to adjust and make effective transitions between jobs as well as to work cross-culturally and cross-nationally (Coetzee \& Roythorne-Jacobs, 2007).

This dynamic employment environment necessitates a carefully considered approach to career counselling. In order to address clients' needs best, career counsellors must make use of approaches that are compatible with the current realities mentioned above (Lee \& Johnston, 2001). 
This study will focus primarily on the counselling goal of increasing knowledge and understanding of careers and career life stages for young people in the SANDF (MSDS members), but may contribute positively to changes in self-perception and thought, as well as changes in behaviour and a decrease in anxiety (relief from suffering) for these young soldiers. With knowledge and understanding of career-possibilities and a positive self-concept, MSDS members that do not obtain extensions of their contracts on completion of their initial two years, may experience less anxiety and may be able to make better informed career decisions.

\subsubsection{Theories in career counselling}

It is of the utmost importance for career counsellors to have a thorough knowledge and understanding of the various career counselling theories. This can promote better understanding of the client's needs and possible approaches and skills available to address such needs. Lee and Johnston (2001) propagate a holistic approach to career counselling, one that integrates attention to career, personal and developmental issues. The main career counselling theories are briefly discussed in the section below.

\subsubsection{Trait-and-factor theory}

Frank Parsons is credited with being the founder of the vocational guidance movement. $\mathrm{He}$ developed the 'talent matching' approach, which was subsequently developed into the trait-andfactor theory of occupational choice within the evolving discipline of differential psychology. This aproach is still viable in contemporary career counselling. Parsons' core concept was that of 'matching' (Gikopoulou, 2008; Hopson, 2009). He suggested a three-step model to help people choose a vocation (Gikopoulou, 2008):

- firstly, developing knowledge and understanding of their individual traits (e.g. personal abilities, aptitudes, interests and resources);

- secondly, developing knowledge about jobs and the labour market (advantages, disadvantages, opportunities, requirements); and

- thirdly, making a suitable judgement about the relationship between these two groups of facts. 
A key assumption is that it is possible to measure both individual talents and the attributes required in particular jobs, which can then be matched to achieve a person - environment fit. This resulted in the development of psychological tests and questionnaires to indicate differences in intelligence, specific abilities, interests and personality traits. Individuals who are in jobs best suited to their abilities perform best and demonstrate high productivity (Foxcroft \& Roodt, 2009; Gikopoulou, 2008; McWhirter, 1997).

\subsubsection{John Holland's theory}

John Holland's theory is classified under both the trait-and-factor theory and the personalitybased theory of career counselling. His theory is called "Personal Career Theory" and uses client-centred conceptualisation as a guiding framework for counselling sessions. The theory of Carl Rodgers has also been influential in this counselling approach.

Both Rodgers and Holland assume that matching is the basis of the career counselling process. Vocational choice is seen as rational and largely devoid of emotions and is also regarded to be a one-off event, based on the assumption that people develop relatively permanent sets of behaviours or personalities (Gikopoulou, 2008; Lee \& Johnston, 2001; McWhirter, 1997; Mutchinsky et al., 2002). The Self Directed Search (SDS) inventory for assessment of interests is based on Holland's theory (Foxcroft \& Roodt, 2009). The SDS suggests that people, work and study environments can be classified according to six basic types: Realistic, Investigative, Artistic, Social, Enterprising, and Conventional (RIASEC).

The SDS assists users in choosing occupations and fields of study that best match their selfreported skills and interests. It is based on the assumption that people tend to consider themselves to be satisfied and successful with their occupational choices when the job and work environments most closely match their personal style and interests (Reardon \& Lenz, 2006).

\subsubsection{Social learning theory}

Krumboltz and Mitchell are the foremost proponents of the social learning approach to career counselling (McWhirter, 1997). They identify four types of factors influencing career decisions, namely:

- genetic endowment and special abilities;

- environmental conditions and events;

- learning experiences; and

- task approach skills. 
The counsellor is primarily interested in the learning experiences that have influenced the client's career development. This is explored in order to identify inaccurate self-observations, beliefs or deficiencies in one of the above factors and to take steps to rectify these (McWhirter, 1997; Schreuder \& Theron, 2004).

\subsubsection{Social cognitive theory}

Social cognitive theory is based on the consequences of individual behaviour, observational learning and behavioural modelling (Evans, Silber-Ashley \& Gard, 2007). Based on Bandura's social cognitive theory, Lent, Brown and Hackett (1994) developed a model for career counselling that emphasises personal participation in the career decision-making process, as well as the way in which external and internal factors influence the person in this process. They suggest that career behaviour is a result of interaction between self-efficacy, outcome expectation and goals. Self-efficacy is defined by Bandura (1986, p. 391) as "'people's judgements of their capabilities to organise and execute courses of action required to attain designated types of performance". The focus is on the strength of the individual's belief that they can successfully accomplish something, and this belief is more powerful than interests, values or abilities. They further advocate that career interests and aspirations also influence career choices and that these are influenced by contextual (such as cultural and family preferences) and social cognitive factors (such as outcome expectations of a specific social or ethnic group). Social cognitive factors also influence self-appraisals and self-efficacy. Self-appraisal refers to the self-evaluation process involved in determining the level of self-efficacy (McWhirter, 1997; Schreuder \& Theron, 2004).

According to Bandura (1997), 'outcome expectations' is a variable that interacts with selfefficacy. Bandura (1997, p. 193) defines outcome expectations as “...a person's estimate that a given behaviour will lead to certain outcomes". For example, a young woman may believe she is able to perform as well as a man for the post of civil engineer, but does not expect that she would easily be selected for the job. Bandura adds that environmental factors may be perceived as controlling or influencing the outcome rather than the level or quality of an individual's behaviour, although sometimes distinguishing outcome expectations from self-efficacy expectations can be difficult. 
'Goals' is another variable influencing whether behaviour will be initiated. Individuals set goals to organise behaviour and guide their actions. An individual may have the necessary selfefficacy and feel confident to succeed in a task. This self-efficacy is a specific area may lead to more interest. It may further increase confidence and perceptions of rewards gained by achieving desired goals. Goals can thus be self-motivating and a source of personal satisfaction (Bandura, 1977).

Behavioural modelling is a training technique based on this theory, and aims to improve interpersonal competencies and thus alleviate interpersonal conflicts in the workplace (French \& Bell, 1999). This method is widely used, with good results, to develop intellectual, social and behavioural competencies (Bandura, 1986). It includes three elements. Firstly, specific skills are modelled to convey the basic competencies. Secondly, individuals receive guided practice under simulated conditions in order to acquire the skills. Thirdly, individuals are assisted in applying their newly acquired skills in work situations (Bandura, 1988).

\subsubsection{Developmental theories}

According to developmental theories, the selection and implementation of careers are viewed as part of a long developmental process starting early in life and ending with death. The contributions of early life experiences, events and opportunities are recognised, as well as the maturation process of developing interests and exploring career opportunities. Proponent theorists who link developmental theory to occupational choice include Ginzberg, Ginsburg, Axelrad, Herma as well as Tiedeman and O'Hara. In the field of developmental theories, Donald Super and Linda Gottfredson's theories made major contributions to career counselling and will be briefly described below (McWhirter, 1997; Schreuder \& Theron, 2004).

\subsection{Donald Super}

Super (1957) in his theory states that individuals choose occupations consistent with their selfconcept. Some of his assumptions further include the following:

- People differ in their abilities, personalities, needs, values, interests, traits and thus selfconcepts.

- A person is qualified for a number of occupations by virtue of his/her characteristics.

- Each occupation requires a characteristic pattern of abilities and personality traits.

- Vocational preference and competencies, the situation in which people live and work, has an influence on the self concept - this will change with time and experience. 
- The career pattern is determined by the individual's parental socio-economic level, mental ability, educational skills, personality characteristics, CM and the opportunities that the person is exposed to.

- The readiness of the individual to cope with the demands of the life stage determines the success in coping at any given life-career stage.

How people implement their self-concept into an occupational choice is a function of their developmental life stage. Vocational behaviours should thus be examined in the context of the specific demands of the individual's developmental life stage. During the normal process of human development, there is constant interaction between the self and the environment, which eventually culminates in a choice of vocation. Super identifies the following vocational developmental stages (Louw, 1994):

- Growth (0-14 years): During this stage the child develops a self concept through contact with adults as role models. The world is explored and experienced driven by curiosity. This stage thus includes the development of interests, aptitudes and needs in conjunction with the self-concept.

- Exploration (15-24 years): This is the stage where the adolescent becomes aware of the need to choose a career (see par 2.3.2). This includes awareness of the fact that society expects one to have a career. He/she starts to gather specific information about careers and start planning towards a career choice. It thus involves a tentative phase of narrowing down options. An individual may enter a particular field as a result of the expectation of parents or others. Such early career choices may later result in a career crises when individuals cannot cope with change because of being accustomed to seeing a career as encompassing an occupation, rather than as different roles or directions.

- Establishment (25-44 years): During this stage the person becomes independent regarding his or her choice of career. It therefore involves choosing and implementing a career, and then stabilisation in that career. It may, however, also include a succession of job changes before a final choice is made. During the period of stabilisation the focus for the individual is on security and advancement. If stabilisation is not successfully achieved, it may lead to frustration, resulting in stagnation or in change. Some individuals thrive on change and do not stabilise in their careers. 
- Maintenance (45-64 years): During this stage the person has had ample experience in the world of work. This stage thus involves continued efforts to improve work position. Some individuals stagnate in the status quo if they have not achieved what they wanted to and they avoid acquiring new skills and knowledge. Others strive for further goals, such as continued education or becoming innovators of change.

- Disengagement (65+ years): This is the stage of a person's life when he/she has to start disengaging from his vocational life. It is the stage of preparation for retirement, as well as the actual retirement (Louw, 1994). This includes the deceleration of work activities by seeking less responsibilities or selectively changing work roles. This stage may either result in a sense of loss for the individual or may be stimulating in that new choices can be made.

All the stages described above are depicted in Super's career life rainbow which is shown in Figure 2.2.

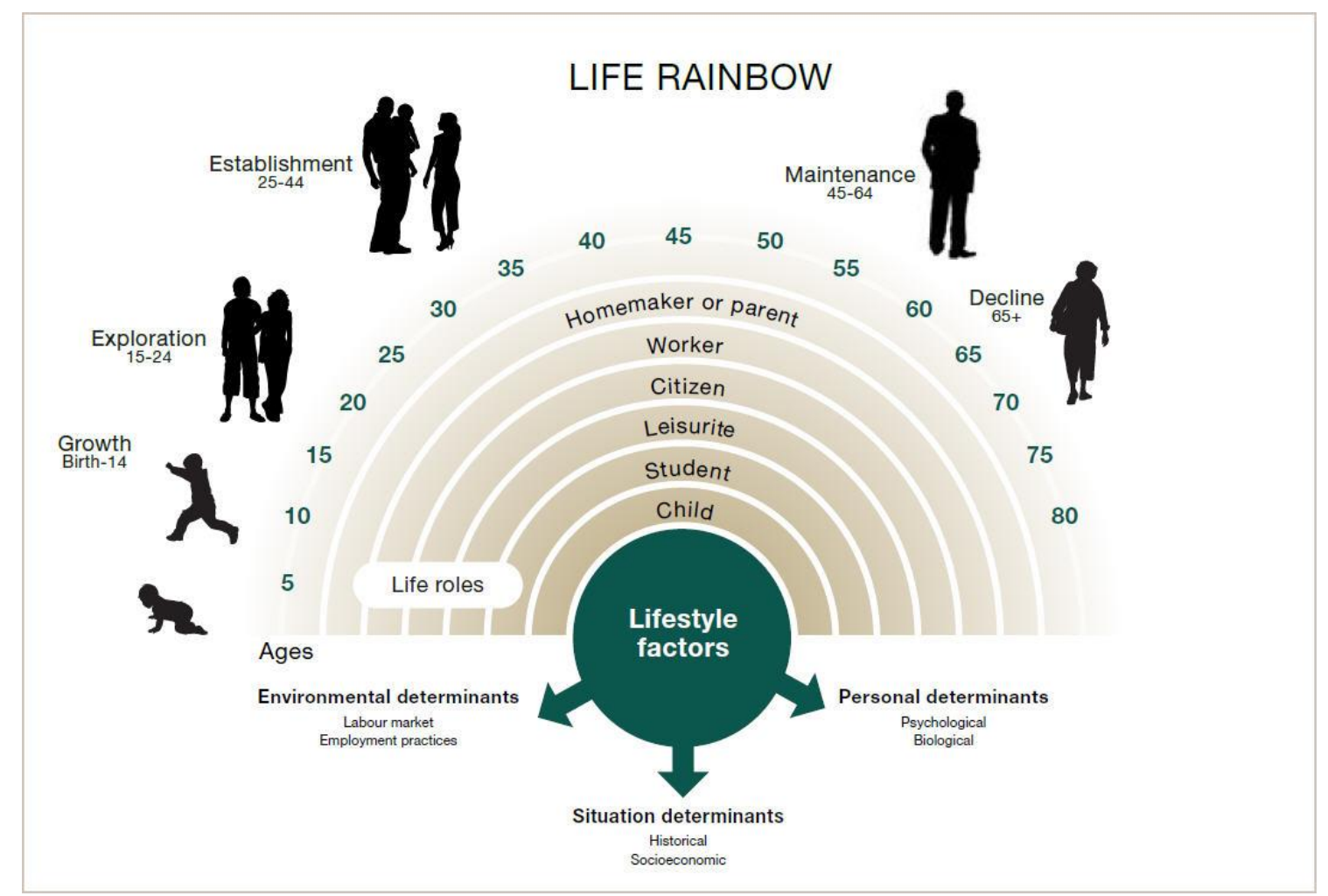

Figure 2.2. Super's Career Life Rainbow

(http://www.careers.govt.nz/educators-practitioners/ career-practice/career-theory-models/supers-theory) 
Super emphasised that although these life stages can be distinguished and normally occur at the approximate ages, individuals do not develop uniformly and thus the stages are not discrete and not invariable. A person may, for example, explore new opportunities during the adult stages or even after retirement when considering a career change, even though exploration is usually associated with adolescence. A career may thus include exploration and new growth in different stages, and even re-establishment in different types of roles or jobs. In career psychology, this is referred to as recycling - the process of recurring life stage characteristics (Schreuder \& Theron, 2004).

Super recognises the overlapping roles that an individual must fulfil in a lifetime, such as child, student, employee, citizen, spouse, leisure participant, homemaker, etc. This is referred to as the career life rainbow (Figure 2.2). The concept of CM was also introduced by Super as a constellation of physical, psychological and social characteristics (McWhirter, 1997; Mutchinsky et al., 2002; Schreuder \& Theron, 2004). CM will be elaborated on in par 2.5.

Super (1957) advocates that development through the life stages can be guided by facilitating a person's maturity of abilities. This includes partly aiding a person in reality testing and the development of the self-concept. The process of career development is thus aimed essentially at the development of the self-concept, and implementing it into the occupational self-concept.

\subsection{Linda Gottfredson}

Gottfredson's theory incorporates the social systems approach into a developmental perspective. The theory describes the influences of gender, social class and intelligence on career choices and aspirations. She postulates that all people have a "zone of acceptable alternatives" consisting of the range of occupations acceptable for the individual's place in society. The "zone of acceptable alternatives" is influenced as the self-concept develops from early childhood in the social context (McWhirter, 1997).

Many developmental theories focus on how an individual's self concept develops with age. Gottfredson (2002) also describes how career choice develops in young people. The theory assumes that people build a cognitive map of occupations by assimilating occupational stereotypes from others. Occupations are placed on this map using only a small number of dimensions: gender, prestige level and field of work. 
As young people build this map, decisions start to form regarding which occupations are acceptable and which are unacceptable - those which fit with their own developing self concept and those which do not (Gottfredson, 2002).

The first process is one of circumscription - ruling out unacceptable options based on their perceived fit with one's self-concept. Circumscription refers to the act of limiting or restricting the choice of career to a set of vocations that will fit the self concept of the individual - thus in Gottfredson's theory referring to the "zone of acceptable alternatives". Compromise also focuses on the development of an individual's view of the occupational choices available. This implies that practical implications, such as availability, also play a role in the choice of career and thus have a limiting impact on the choice of vocation. In the early stages of the individual's development, this filtering process (circumscription) is quite crude and inaccurate, but it is lasting. The proposed stages of circumscription are (Gottfredson, 2002):

- Orientation to size and power (age 3-5). Children become aware that adults have roles in the world. They realise that they will eventually become adults and take on roles for themselves.

- Orientation to sex roles (age 6-8). Children begin to categorise the world around them with simple concrete distinctions. They become aware of the more recognisable job roles and begin to assign them to particular sexes. They may start to see jobs which do not match their gender identity as unacceptable.

- Orientation to social values (age 9-13). At this stage children have encountered a wider range of job roles and are capable of more abstract distinctions. They begin to classify jobs in terms of social status (income, education level, lifestyle, etc.) as well as sex-type, based on the social environment in which they develop. They will begin to designate some jobs as unacceptable because they fall below a minimum status level (tolerable level boundary) and some higher status jobs as unacceptable because they represent too much effort or risk of failure (tolerable effort boundary).

- Orientation to internal, unique self (age 14+). Until this point circumscription has been mainly an unconscious process. As young people approach the entry into the adult world, they engage in a conscious search of the roles still remaining in their social space. In this process they use increasingly complex concepts such as interests, abilities, values, work-life balance and personality to exclude options which do not fit with their self image and identifying those that do fit. 
As circumscription has limited options to those that fit a perceived social and personal space, the next process is one of compromise. In this stage, individuals may be inclined to sacrifice roles they see as more compatible with their self-concept in favour of those that are perceived to be more easily accessible. In this they are often limited by their lack of knowledge about how to access certain roles because of lack of information, lack of know-how and appropriate tactics, and lack of helpful social connections (Gottfredson, 2002).

Gottfredson proposes that when people are forced to compromise their career choices, they are more likely to compromise first on field of work, then on social level and lastly on sex-type as the amount of compromise increases. In the case of South African young people entering the MSDS of the SANDF, the question may be asked: what role does circumscription and compromise play in the choice of a military career and also in an alternative career after their two year military service? One could also consider whether the time served in the SANDF has an impact on either of these processes regarding career choice.

\subsubsection{Accident theory}

Chance events may also influence career choice. Such events are beyond the individual's control and may include inheritance of a family business, war, disease, becoming disabled and economic conditions. Race and ethnic grouping may also play a role in certain countries. Individual capacities and motivation may, however, still have a counteractive effect to assumed inevitable implications for careers (Lee \& Johnston, 2001; Mutchinsky et al., 2002).

The types of theories for career counselling thus include a focus on the fit between the person and the environment (trait-and-factor theory) or on social learning. Career decisions may also be based on the own cognitive choice of the individual, based on own interests and aspirations and influenced by contextual and social factors (social cognitive theory). The developmental theories propagate that careers are part of a life-long process and manifest in typical life stages according to age, with a specific focus and activities associated with each stage. The development of the self-concept during the process of human development is then also seen as a determining factor in career decisions. The accident theory recognises that chance events may influence career choice. 
These differences in career theories indicate that selecting a career and making career decisions may be influenced by various factors. The diagnostic framework for career services in par 2.4.1 identifies the theories or models relevant to different career services. From the theories discussed, one may deduct factors such as personality, competency, social background, interests, aspirations, context/situation, life-stage and self-concept. In this study, individual factors such as personality, interests and aspirations will not be the primary focus, as the intention is not to fit individuals to a specific vocation. The focus of this study is rather on the readiness of MSDS members to make positive career decisions and to successfully enter the South African labour market. The study addresses a specific context and life-stage (adolescents/young adults within the South African military context) - aspects of self-concept and personality viewed as relevant to this context viz self-efficacy, hardiness and life skills will be investigated.

Different approaches to career counselling have developed from the various theories. The most prominent approaches currently used in career counselling practices are described in the section below.

\subsubsection{Approaches to career counselling}

Career counsellors use different approaches in dealing with clients' career related needs and challenges. Combinations of these approaches may also be applied. The most prominent, but not the only, approaches include narrative therapy, logotherapy, the transpersonal approaches, Gerard Egan's approach and the organisational approach. These prominent approaches are described below.

\subsubsection{Narrative therapy}

Narrative therapy is based on the assumption that a client's life is not based on a factual sequence of events, but on how it was interpreted and reinterpreted by the client. It also embraces the post-modern assumption of the ability to reframe experiences. During narrative therapy, clients are guided in constructing a coherent story of their lives. The problem that needs to be dealt with is firstly explored by identifying the gap between the client's present situation and his/her ideal future (Freedman \& Combs, 1996). This is similar to Egan's approach, discussed in par 2.4.3.4. 
The counsellor uses an emotionally warm counselling climate to encourage the client to share his/her life story. The initial stories may be filled with sadness, melancholy, frustration, helplessness and desperation, which usually reflect the client's current life story. This forms the basis of career therapy. The past holds clues to what needs to be changed to reach the desired future state. After the client has completed his/her life story, the counsellor asks questions to clarify and/or broaden the client's account of the story. This process helps the counsellor to explore previous career behaviour, problems that were experienced and the client's method of dealing with these and making decisions. More questions are asked to determine the relative strengths of problems and persons in the client's story and how these influenced his/her life or career. Thereafter, the counsellor guides the client by using reconstructive questions to encourage pondering and the discovery of alternative realities (Freedman \& Combs, 1996). Narrative therapy can also provide information on the CM of the individual by shedding light on the content of the factors that influence CM. This method of assessment is, however, not feasible in a large group context such as the MSDS population.

\subsubsection{Logotherapy}

Logotherapy is based on Frankl's existential theory. It involves helping the individual to recognise the human spirit in finding meaning in life. Counsellors use techniques such as Socratic dialogue, which refers to the use of provocative questioning and challenging statements from the counsellor in order to elicit hidden meaning from the life and efforts of the individual. It is thus a confrontational approach to counselling. The counsellor aims to increase clients' will to find meaning in their life and career. The counsellor may, for instance, suggest a career plan that focuses on the end of a person's career life. This would highlight the client's present work and other life roles, and the meaning of these work and life roles is then explored. This may lead to the client thinking anew of his/her life and career and may enhance his/her will to increase its meaning (Coetzee \& Roythorne-Jacobs, 2007; Frankl, 1986). Attaching meaning to one's career may provide a greater sense of self efficacy and resilience towards problems that may arise in the career life cycle.

\subsubsection{Transpersonal approaches to career therapy}

This approach to career counselling is based on the growing interest in spiritual values. Clients see their work and career as part of their life journey and consider their contribution to making the world a better place. The transpersonal perspective sees all living beings and systems as existing only as part of interdependent systems. 
Careers can only exist as part of nested inseparable or connected systems. The focus on the spiritual helps clients to see the underlying order in the otherwise random-seeming universe. The approach focuses on enhancing the client's own sense of wholeness. This involves understanding the client's current situation while focusing on his/her highest potential and what the client can become. It thus considers not only skills and aptitudes, but also complex human qualities such as spirit, consciousness, life purpose, a heart-felt passion and that a person may be called to follow a specific career (Coetzee \& Roythorne-Jacobs, 2007).

Career therapy primarily focuses on building up self-esteem and self-worth, which may have been affected by involuntary job loss or career transition. The client is then guided into being aware of how his/her beliefs, thoughts and feelings about him/herself affect actions, perceptions and decisions.

Psycho-emotional education is used to lead the client towards understanding his/her own deficiencies in thinking and irrational beliefs or values that may lead to career-related problems, and consequently methods to change these for improved self-efficacy and decision-making. Narrative therapy and logotherapy are also used to uncover and change such limiting beliefs and thinking patterns. The primary focus of transpersonal counselling is thus on creating a heightened, mindful awareness of clients' experiences for creative self-expression as part of their inherent potential. The counsellor's attitudes and values are crucially important and should include cultivated philosophical principles of transpersonal psychology (Coetzee \& RoythorneJacobs, 2007).

In the South African context, there exists a strong influence of spiritual matters in the lives of individuals, especially in the African cultures. Young people are currently also influenced more and more by Western world views due to urbanisation and globalisation.

\subsubsection{Egan's counselling approach}

The counselling theory of Gerard Egan may be effectively applied to career counselling. The counselling process as proposed by Egan (2014) consists of three stages in planning a client's career and a fourth stage to evaluate and review progress on a periodic basis. 
Stage 1 is the analysis of the current state of affairs. It serves to provide the initial information regarding the client's strengths and areas for development, and typically involves the following steps:

- Sharing information - the client is requested to share his/her current state of affairs and his/her interpretation/perception thereof.

- Identifying, assessing and addressing blind spots - the career counsellor seeks clarification on concerns and career-related issues identified by the client, as well as perceptions regarding career progress, appreciations and frustrations.

- Selecting the most appropriate opportunities or solutions - possible career assessments are discussed and arranged, which could include psychometric assessments, competency-based interviews and in-tray techniques. These techniques are then administered and scored to provide further information to the counsellor and client. Possible future scenarios may also be explored.

Stage 2 involves identifying the preferred scenario. This includes discussing various options, based on the outcomes of stage 1. Areas for development are identified and possible interventions are discussed and prioritised. Commitment is then expected from the client and all relevant role-players.

Stage 3 refers to the conceptualising of a plan to achieve the preferred scenario. All possible actions as discussed in the previous stage are logically prioritised into an actionable plan focusing on short-, medium- and long-term solutions. This is then recorded, implemented and managed. Mutual agreement must be reached with all relevant role-players on the best-fit strategy.

Egan's counselling approach could be compared to the planning models used in the SANDF. This approach is similar to that used in other organisations. It entails investigating the current capability and the required capability. A plan is then compiled based on the gap analysis or disparity between what is currently available and future requirements.

In this study, the focus would be on stage one of Egan's theory - determining the current state of $\mathrm{CM}$ of MSDS members in order to provide the initial information regarding the most relevant areas for development. This will include investigating the current perceptions among MSDS members about their careers. This information can then be used to determine if the SANDF can influence the CM of MSDS members. 
The second stage of Egan's theory is aimed at developing goals. In this study, this will include investigating an ideal level of understanding about careers in South Africa among MSDS members, as well as ideal perceptions about their employability - knowing and understanding the possibilities for a better future.

Stage three of Egan's theory includes planning the way forward for individuals to achieve a better future. Based on the findings of the current state of CM amongst MSDS members, recommendations could be made regarding the role of the SANDF in providing guidance to MSDS members towards planning their future careers.

\subsubsection{Organisational approach}

Owing to recent technological advancements and the advent of the information age, there is a vast array of career options to choose from. Global competitiveness has also orientated organisations towards advanced HR management. Organisations are aware of the protean nature of careers, and thus implement career management systems to retain and motivate employees, by identifying and addressing their developmental needs in order to reduce turnover and retain skills. Such organisations implement training programmes and career development plans (Cascio \& Aguinis, 2005; Mutchinsky et al., 2002; Noe et al., 2008).

Employee assistance programmes are also implemented in some organisations to address problems such as substance dependency or psychological problems, encountered by workers (Noe et al., 2008). Some organisations make use of career workbooks for self-assessment to guide employees in career development (Schreuder \& Theron, 2004).

Another method currently used by organisations for career development, is online career assessments on the intranet of the organisation to identify career interests and skills and to encourage employees to consider possible steps to take to achieve the career success they are aiming for (Noe et al., 2008). A non-profit organisation such as the SANDF should consider the protean nature of careers and endeavour to empower its members to achieve employability, psychological success and freedom of growth. 
The trend towards managing careers and developing human capital has become important in giving organisations a competitive edge (Cummings \& Worley, 2008). Organisations are therefore committed to train employees continually and upgrade their skills. Career development is an organisational process of increasing and sustaining employees' productivity and/or preparing them for the outside world, increasing employability (Robbins, 1993). Cascio and Aguinis (2005) add that the empowered worker is no passing fad. The constant pressure on organisations to achieve maximum output with minimum input requires that workers be empowered for multiple functions, flexibility, self-managed teams and continuous learning.

This implies that workers must be able to adjust to changes in the environment and be prepared for multiple careers. This is also necessary in the SANDF. Career planning and development opportunities are crucial in recruiting and retaining skilled personnel, as well as in preparing members, especially the MSDS young people, for the outside world of alternative employment.

Noe et al. (2008) mention four organisational approaches to employee development: formal education, assessment, job experience and interpersonal relationships. These approaches can also be used in combination. This is dependent on the specific organisational context. Formal educational programmes may be presented in-house or off-site and may include short courses offered by consultants or training institutions. Assessment involves the gathering of information about individual employees and providing feedback on their behaviour, communication style and/or skills. This information can be used to identify developmental areas and subsequently a career development plan. Job experiences are also learning experiences that contribute to the development of employee competencies.

Such learning experiences include adding challenges or responsibilities, job rotation, transfers, promotions, downward moves, special assignments, projects and sabbaticals. Interpersonal relationships for employee development include mentoring and coaching in organisations (Noe et al., 2008).

\subsubsection{Application of approaches in the MSDS context}

The approaches to career counselling described above are mostly aimed at individuals and have in common that they are aimed at helping a client to achieve individual effectiveness. This includes aspects such as job satisfaction, performance, absenteeism, personal development and CM (Cummings \& Worley, 2008). 
Not all of these approaches are practical in investigating the level of CM in a large group - a population such as the MSDS members of the SANDF. It is, however, important to consider all the contributions that can be made by the different approaches in understanding the challenges in the levels of CM of MSDS members and also how such challenges may be addressed or further investigated in future. Elements of each of these approaches may also be applied when developing a career guidance programme for MSDS members. This could include the following:

- Narrative therapy (Freedman \& Combs, 1996)

- Members may be encouraged to write down their own stories and to acknowledge that stories are not entirely factual.

- Encourage members to construct new stories; change perspectives.

- Encourage members to be solution-driven rather than problem-driven (this has always been part of the SANDF training approach).

- Logotherapy (Frankl, 1986)

- Encourage members to find meaning in life.

- Challenge members into seeking the meaning of their work and life roles.

- Challenge members into making their lives count.

- Transpersonal approach (Coetzee \& Roythorne-Jacobs, 2007)

- Assist members in seeing their careers as contributing towards making the world a better place.

- Emphasize individuals' highest potential.

- Build up self-esteem and self-worth of members.

- Assist members in developing self-efficacy and decision-making skills.

- Egan's approach (Egan, 2014)

- Encourage members to investigate their current situation in terms of skills, competencies, experiences and challenges.

- Encourage members to decide where they would like to be in five years and in ten years - to set goals.

- Challenge members to find out what needs to be done to achieve these goals.

- Assist members in compiling a plan towards attaining their goals. 
- Organisational approach (Cascio \& Aguinis, 2005; Mutchinsky et al., 2002; Noe et al., 2008; Schreuder \& Theron, 2004)

- SANDF to implement career development programmes.

- Employee assistance exists within the SANDF in the form of multi-professional teams, consisting of medical personnel, psychologists, social workers and chaplains - MSDS members must be made aware of the availability of such assistance.

- Career workbooks could be introduced into the MSDS programme.

- Online career assessments could be made available via the DOD intranet.

- Training of MSDS members should be focussed on increasing specific competencies - MSDS is a training programme.

- Sensitise and expose MSDS members to multiple functions.

- Emphasise continuous learning.

- Provide opportunities for learning:

- Formal education programmes (opportunities are given for officer candidates to attend education at the SAMA).

- Short courses presented by consultants or training institutions.

- Assist members in compiling of career development plans.

It is also clear from the above discussions that employees face many challenges regarding their careers in the current labour market, as well as in the context of the SANDF. The different career services are discussed in par 2.4, in order to provide an understanding of the options for addressing career-related problems. Skills and techniques for use in some of these career services will be discussed in the following section.

\subsubsection{Skills and techniques appropriate for career counselling}

The techniques listed below are useful during the career counselling process. Counsellors should master these techniques and know when to use which technique or combination of techniques to achieve the best results during counselling (Coetzee \& Roythorne-Jacobs, 2007; Gladding, 2000). 
- Attending refers to non-verbal behaviours of the counsellor that communicate to the client that the counsellor is involved in what he/she is sharing. It is aimed at creating trust and encouraging the client to be open and forthcoming during the counselling process. Such non-verbal behaviours include eye contact and a natural, relaxed and open posture that includes facing the client squarely and leaning slightly forward.

- Empathy involves the counsellor's ability to understand the client's world as if it were one's own, to the extent that the client is aware of this shared understanding and support. The counsellor must be able to establish rapport and interest in the client and also to develop insight into the true psycho-emotional concerns of the client.

- Joining refers to a step beyond empathy. It is not just a feeling of the moment, but rather a deep appreciation for the life struggles of the client and convincing the client of this awareness. Counsellors may draw on own experiences and wisdom related to the current events, roles or stages of the client. The counsellor also endeavours to focus on and confirm the client's strengths and so become a source of self-esteem to the client. This is also referred to as advanced empathy and is usually more appropriate in follow-up sessions.

- Metaphoric language includes parables, fairy tales, fables, poems, novels, songs and movies. It is used to help change clients' perceptions of their problems or illustrate possible solutions. It is especially helpful with resistant clients. Clients also often include metaphors when telling their stories. It is important that the counsellor listen carefully to these metaphors and gather the embedded information provided in them. This will facilitate empathy and be valuable in the therapeutic process.

- Confrontation is sometimes required to assist clients to become aware of aspects about themselves, their environment and/or their interaction with the environment in order to provide them with an alternative frame of reference to clear up problematic perceptions of experiences.

- Client self-disclosure is crucial for successful counselling. Self-disclosure by the counsellor is used to facilitate openness and enhance the counselling relationship. It involves revealing one's reactions and emotions to events and people. The counsellor can thus relate similar experiences to those of the client. Self-disclosure must be brief and not take the focus off the client. 
- Cognitive restructuring is a process of guiding the client to change the way he/she thinks about a specific situation. An individual's thought patterns and belief systems influence their attitudes, feelings and behaviours. The counsellor must guide the client into recognising irrational or dysfunctional thought patterns and the negative impact these have on the client. This often includes feelings of low self-worth or powerlessness that need to be dealt with so that the client may realise that he/she is not the helpless victim of external forces. Counsellors offer clients an opportunity to explore thoughts, feelings and desires within an accepting, safe and non-judgemental environment.

The client is thus also helped to achieve improved conscientiousness for better decision-making and to be able to maintain cognitive control over his/her emotional state.

- Life career theme interpretation refers to the interpretation of the specific words that the individual uses to describe his/her attitudes, values, ideas and beliefs about him or herself, others, and their world view. It is important that the counsellor should understand these themes in order to explore the client's unique career behavioural patterns. Counsellors often use interpretation of these life career themes to hypothesise about the client's career behaviour patterns.

- Forming tentative hypotheses is an important skill required of a counsellor, especially for the interpretation of the career life themes. It is also helpful to keep the counselling process focussed and to challenge the client's interpretation of his or her own situation. Forming hypotheses furthermore enhances the counselling relationship, as it is an indication to the client of the counsellor's involvement, active listening and joining.

- Paradoxical intention is a method used to help clients distance themselves from their problems or fears. Humour can be used to gain a different perspective and to detach themselves from their own perspective. Gaining a new perspective can help clients to achieve control over their own reactions.

- Resistance to change is common during the counselling process. The client may exhibit resistance by failure to complete the tasks of the career life stage, holding back information or failing to set goals or complete homework assignments. 
The cause of the resistance may include irrational beliefs, lack of motivation, external influences and distorted thinking patterns. It is important for counsellors to be aware of the resistance that will most probably occur during the counselling process. Dealing with client resistance requires an emotionally warm atmosphere, which includes attention, empathy and joining so that the client can be guided through the resistance.

- Expressiveness training involves guiding clients in exploring the full range of their emotions. The client is also taught where and how the expression of emotions is appropriate, especially in the workplace. Using role play and writing a journal are effective reflective techniques to help clients explore and understand their own emotions.

- Leading refers to the persuasive skills of the counsellor to provide direction to the client. Some techniques of leading include silence, acceptance and paraphrasing, as well as persuasion.

- Relaxation training is useful in the counselling process, as it helps the client deal with outward anxiety in order to prepare him/her so that the underlying anxiety can be more effectively dealt with during counselling. Deep breathing and muscle relaxation techniques are used for this purpose. It relaxes the body and calms emotions and thoughts, so that anxiety may subside and the client may deal with problems in a more emotionally intelligent way. This will enhance self-efficacy, power and self-worth.

The career counselling process is discussed in various sources and mainly focuses on aneon-one setting. The steps of the counselling process are, however, also relevant for individuals in an organisational setting, as well as for groups. When developing a career educational and guidance programme for a presentation to groups, one would need to consider these steps as well. The career counselling process will therefore be described in the following section. 


\subsubsection{The career counselling process}

Salomone (1988) describes seven steps of career counselling. These include a schema of the three basic phases: assessment, interventions and evaluation. The intervention phase incorporates the five stages of gaining knowledge about the client's self-interest, gaining knowledge about the world of work, creating a match, implementing a decision and adjusting to the new setting. Coetzee and Roythorne-Jacobs (2007) also describe the career counselling process in the following seven phases:

- Preparation phase

- Establishment of a working relationship

- Understanding the needs of the client

- Conducting career assessments

- Working towards a resolution

- Closure phase

- Evaluation of the effectiveness of the guidance process.

These steps will be discussed in the section to follow.

\subsubsection{Preparation}

Before conducting a career counselling assessment and starting the counselling process, the counsellor must determine the specific aim of the guidance process. The ultimate goal of the career guidance process, according to Coetzee and Roythorne-Jacobs (2007), is to enhance the $\mathrm{CM}$ and career self-efficacy of clients in order to help them make fulfilling career decisions. The guidance process involves a collaborative process where the client is helped to deal with problems regarding work, career and life roles. This includes assistance in clarifying expectations and opportunities, gaining a better understanding of their position and options, as well as alleviating anxiety by helping the client make informed decisions. Clients often seek career counselling when faced with a transition in their work life.

Campbell and Cellini (1981) identified the problems of American adults in a career transition process as including career preparation, entering a new job, on-the-job adjustment, underemployment, organisational adjustment, mid-career change, productivity and retirement. The MSDS members of the SANDF also face these transitions, such as entering a new working environment, adjusting to the organisational culture and, for the research initiating question of this study, the transition of leaving the SANDF and entering another career. 
It is important to ensure that the counselling environment is conducive to the collaborative process for career guidance. The setting and physical appearance of the counsellor, as well as his/her verbal skills, body language, behaviour and attitude to the client contribute to a positive environment. The career counselling climate refers to the perception that the client has about the counselling environment, which should offer a warm and nurturing atmosphere that is influenced to a large extent by the personal values of the counsellor (Gladding, 2000).

Exhibiting respect, empathy and sincerity is paramount to a positive counselling environment. It is furthermore advisable for the counsellor to engage in positive self-talk to prepare for a successful counselling session and to take steps to relax immediately before the session. This will contribute to a positive attitude and demeanour of the counsellor and consequently to positive perceptions from the client. The setting should be a private, relaxed and quiet environment, which is free from interruptions (Coetzee \& Roythorne-Jacobs, 2007; Gladding, 2000).

Relevant documentation, e.g. previous performance appraisals, job descriptions, career history (career workbooks and plans), company career-related policies and procedures, as well as reports from others, must be obtained and the counsellor must read through such documents, as well as other relevant information that will be helpful in answering possible questions from the client. It is recommended that a list be made of all the required documents that have to be read and that this be taken along to the session, as well as preparing an agenda for the session. The agenda should include the objectives of the session and the stages to be followed. This will also contribute to the counsellor being more relaxed and confident (Coetzee \& RoythorneJacobs, 2007).

\subsubsection{Establishment of a working relationship}

A working alliance should unfold during the counselling process. It should start with the creation of rapport and establishment of the relationship; it should then be strengthened to fulfil it and eventually close it again. Rapport is defined as a "sense of mutual understanding and communicative openness between two or more people ... often considered a necessary first step in psychotherapeutic relationships" (Matsumoto, 2009, p. 422). This type of relationship is a therapeutic commitment to the psychological process underlying the career counselling process (Gladding, 2002). 
During this stage, the client's initial career goals and problems are identified and the internal thoughts and feelings, as well as underlying dynamics involved, are explored. It is important that the counsellor work towards empowering the client to take responsibility for his/her career decisions (Miars et al., 1997). Counsellors must also be aware of the influence of culture and gender on the client's career development (Coetzee \& Roythorne-Jacobs, 2007; Stead, 1996).

\subsubsection{Understanding the needs of the client}

The client's specific needs and current situation must be investigated once the working relationship has been established. This requires gathering information about the client that will form the basis of future discussions. The culture-specific and gender-specific challenges of the client must also be clearly understood, as well as how these affect the career self-concept of the client.

Other factors to be taken into consideration by the counsellor are family responsibilities, the socio-political environment of the client, and his/her perceptions on job availability and possibilities for career movements within his/her current organisation or industry (Coetzee \& Roythorne-Jacobs, 2007).

Apart from gathering information about the career problems and concerns of the client, the counsellor must determine the client's CM, self-efficacy, life roles and the priority of these. Selfefficacy furthermore includes clients' belief that they can successfully learn new skills and knowledge (Noe et al., 2008). This will have an impact on their commitment to and expectations of the counselling process. Coetzee and Roythorne-Jacobs (2007) provide checklists and suggest measures to assist the counsellor in determining these dimensions regarding the client. Most importantly, the counsellor must categorise the client's problems into one of four types: no choice, unwise choice, discrepancy between interests and aptitudes or personal/self-conceptrelated problems. After gathering sufficient information, the counsellor will finally reach a stage where a hypothesis about the client's behaviour and career development can be formed. This includes identifying which of the factors mentioned are influencing the client's career development negatively. The counsellor and client will thus reflect together on the specific needs and challenges of the client. 
This is also the primary focus of this study - developing an understanding of the needs of MSDS members regarding their career development. Consideration should be given towards the culture specific needs of African young people. It will therefore be aimed at developing an understanding of the career problems and concerns of MSDS members and more specifically to determine the CM of MSDS members, including the impact of self-efficacy, life roles and other factors and possibly determining the priority of these facts.

\subsubsection{Conducting career assessments}

Career assessment instruments in a variety of forms are available to enhance the career guidance process. Such formal or informal assessments are generally used in all career counselling relationships. Assessments should focus not only on the career-specific information requirements, but also on the whole person in order to enhance the therapeutic growth of the client in all areas of his/her life (Coetzee \& Roythorne-Jacobs, 2007).

Many instruments serve as predictive indicators of potential job performance, as well as job satisfaction. They can thus be used to guide the career decision-making process by means of eliminating choices that may result in poor performance or dissatisfaction (Coetzee \& Roythorne-Jacobs, 2007). Kelloway and Barling (1991), furthermore, argue that individual mental health is influenced by the degree to which a person's job offers him/her the opportunity to apply his/her abilities and interests. Personal accomplishments at work also relate positively to work satisfaction and ultimately productivity.

Specific assessment instruments are to be used only by registered psychologists who have a thorough understanding of the applicable ethical codes, standards and legislation regarding assessments, as well as the reliability, validity, standard error of measures and the application of norming groups (Cascio \& Aguinis, 2005; Coetzee \& Roythorne-Jacobs, 2007; Foxcroft \& Roodt, 2009; Noe et al., 2008). Before conducting assessments, the counsellor should consider the information gathered during the previous phase of the counselling process, where the needs of the client were identified. This will determine the choice of assessment measures to be used. The available time and cost of assessments will also play a role. This is also referred to as planning an assessment strategy. 
Sometimes a career-planning workbook containing a series of assessment exercises can be given to the client as homework and the results of this is discussed in later sessions. This is mostly done in organisational context and often results in employees solving their own career problems (Schreuder \& Theron, 2004). Assessments for career counselling generally include assessing intelligence, aptitude, interests, personality and sometimes values. These are tests that are only allowed to be used by registered psychologists and psychometrists in the RSA. The tests commonly used in the South African context include the following:

- General Scholastic Ability Test (GSAT) or Senior South African Individual ScaleRevised (SSAIS-R) or the Raven's Progressive Matrixes

- Differential Aptitude Test (various forms, e.g. Form K and Form L for grade 11-12 and adults)

- Self Directed Search (SDS) or 19 Field Interest Inventory or "Meyer Belangstellingsvraelys" (MB-10)

- 16 Personality Factor Questionnaire (16PF) or Myers-Briggs Type Indicator (MBTI) or Jung Personality Questionnaire (JPQ) or Clinical Analysis Questionnaire (CAQ). The CAQ may identify elements of psychopathology which may need to be considered in terms of ruling out specific vocations.

- The Values Scale (Foxcroft \& Roodt, 2009).

Many organisations provide detailed job specifications that list knowledge, skills and abilities that an employee must have to perform the job (Noe et al., 2008). The assessment information of the client may thus indicate the feasibility of applying for specific positions. It would have been ideal to assess all MSDS members on a full battery (at least one of each of the above list of tests) and to provide individual career services to each member. This is, however not practically feasible due to budgetary and capacity constraints. For the purpose of this study, a battery of five questionnaires was administered in groups in order to investigate the level of CM of MSDS members and propose an organisational level intervention. These instruments and the factors measured by each are listed below:

- Revised Career Maturity Inventory (CMI-R) short form (Crites \& Savickas, 1996)

- Concern - being oriented towards involvement in the decision-making process;

- Curiosity - exploring the world of work;

- Confidence - having faith in one's ability;

- Consultation - being oriented towards seeking advice. 
- Career Decision Self-efficacy Scale (CDSE) short form (Betz \& Tayler, 2013)

- Self-appraisal;

- Seeking occupational information;

- Goal selection;

○ Planning;

- Problem solving.

- Military Hardiness Scale (MHS) (Dolan \& Adler, 2006)
- Control;
- Commitment;
- Challenge.

- Seven Habits Profile Questionaire (Covey, n.d.)

- Conscientiousness;

- Life balance;

- Being pro-active;

- Life goals;

○ Self-management;

- Mutual benefit thinking;

- Listening - for positive problem solving;

- Teamwork;

- Continuous improvement.

- Biographical Information Form (BIF)

- Age;

- Gender;

○ Ethnic group;

- Previous work experience;

- Consideration of other career options;

- Supporting of dependents;

- Perceived ability to compile a curriculum vitae;

- Perceived ability to search for jobs;

- Perceived ability to successfully attend employment interviews. 


\subsubsection{Working towards a resolution}

Career counselling is not only a process of providing occupational information, but also an empowering process. This includes guiding the client towards a level of self-identity that enables effective career decisions and the derivation of positive meaning from life experiences. The client must be guided towards developing a career development plan. This implies that the client must take responsibility for gathering and integrating information about him or herself, as well as the occupation he/she is in and the current labour market. The information is then used to consider alternatives, make decisions and develop an action plan (Noe et al., 2008).

The plan must then be implemented and can be changed as new information and personal development occurs. Periodical evaluation of the results of the career development plan must also take place and will provide input to update the career development plan. The ultimate goal of the counsellor should be to guide the development of more effective and adaptive behaviour in the client. In career counselling this more specifically includes developing self-efficacy and CM.

Bandura (1977) describes the four sources of self-efficacy as including performance accomplishments, vicarious learning, managing anxiety and provision of encouragement and support. These can be included in career development interventions to develop greater selfefficacy (Coetzee \& Roythorne-Jacobs, 2007; Miars et al., 1997).

\subsubsection{Closure phase}

The closure phase of career counselling can be the most difficult, but also the most satisfying of the counselling process. It is the stage where the process is summarised and its effectiveness is assessed. The process of career counselling and guidance reaches this closure phase when both client and counsellor feel that the goals set at the beginning of the working alliance have been met. The ideal is then that the client should be comfortable with his/her career choices and/or should have resolved problematic issues.

Premature closure may also occur when the client is clear about the next step in his/her career development, but decides not to take action immediately. The counsellor should then try to identify the reason(s) for the client's inaction and offer the client the choice to work on psychological barriers that may be obstacles in his/her career development and life stage. 
Sometimes a mismatch between counsellor and client or a perceived lack of depth in the counselling process may lead to closure. The client may have initiated the counselling process because of emotional pain or stress caused by relationship problems or job stress, and after a few sessions of counselling, the initial powerful affective reaction has subsided. Clients may then choose to end the career counselling relationship, even when the original problems have not been resolved yet (Coetzee \& Roythorne-Jacobs, 2007; Gladding, 2000).

Effective closure should firstly include reflection on the counselling journey, starting with the initial problems or uncertainties experienced by the client and the way in which the counselling process contributed to resolving problems and gaining self-efficacy. This implies a review of the content of the counselling process. Secondly, the process of counselling may be reviewed, including reflection on the working relationship that developed. This can also add to the client's understanding of human interaction and communication, and be a valuable learning experience. Thirdly, the client's strengths should be emphasised, as well as how these may have contributed positively to the counselling process.

Fourthly, the effectiveness of the whole counselling process must be evaluated in terms of what went well and what went poorly. This may serve as a learning experience to both the client and the counsellor. Fifthly, time must be allowed for "things unsaid" during the counselling process. In the sixth place, the client should be guided towards discussing emotions related to the ending of the counselling process (Coetzee \& Roythorne-Jacobs, 2007). Termination of the counselling process is associated with loss, even when it had positive outcomes (Gladding, 2000). It is important that honesty and openness be reinforced and that a range of feelings be normalised to ensure effective closure for the client.

Lastly, the next step for the client in the career development plan must be confirmed. The exact steps the client will take immediately after the end of the career counselling process must be clearly defined. This might include referral to another type of counselling or learning opportunity and an invitation for the client to return to the counsellor for additional information or guidance (Coetzee \& Roythorne-Jacobs, 2007; Gladding, 2000). 


\subsubsection{Evaluating the effectiveness of the guidance process}

After completion of the career counselling process as described above, the counsellor should evaluate the process for the purpose of improvement of the process, tools and techniques and/or the overall career development strategy. The counsellor should thus review all data and information in order to judge the value of the counselling and guidance process. Evaluation may be a continuous consideration for the counsellor during the process or during closure, or it may take place at some time after the closure phase.

Evaluation can also be done by asking clients to complete an evaluation questionnaire. This may serve to strengthen the working relationship of the counsellor and client and can also reveal areas for improvement in the counsellor's skills and techniques (Coetzee \& RoythorneJacobs, 2007).

The literature review has made it clear that career services can be highly beneficial to individuals as well as organisations. This study will investigate the CM of MSDS members as well as the factors that influence CM. Consideration will then be given to which of these factors play a significant role in the MSDS population.

The information may be used to identify specific needs for and requirements of a career guidance or educational programme or relevant measures for implementation in the SANDF in order to improve youth development in general, as well as contributing to effective human resource management practices in the SANDF.

\subsection{CAREER MATURITY}

$\mathrm{CM}$ is a concept first described by Super in his developmental career counselling theory. CM can be described as a person's readiness to make realistic, well-informed, age-appropriate career choices and decisions (Savickas, 1984). Levinson et al., (1998) explain that CM is the ability to make appropriate career choices as well as having an awareness of the requirements of good decision-making - such decisions should also be realistic and consistent over time. Powell and Luzzo (1998) state that high levels of CM usually result in successful and satisfying careers. They add that $\mathrm{CM}$ includes the displaying of an awareness of the decision-making process, high levels of self-reliance and relating present behaviours to future goals. 
A study by King (1989) also describes CM involving realistic career decision-making and concluded that $\mathrm{CM}$ correlates with factors such as realistic self-appraisal, environmental experiences and family cohesion. Coetzee and Roythorne-Jacobs, (2007, p. 53) define CM as a person's "ability to make career decisions that reflect decisiveness, self-reliance, independence and a willingness to compromise between one's personal needs and the requirements of one's career situation". They also describe career decision-making to include obtaining selfknowledge and knowledge of employment opportunities, and to be able to develop career goals and implementing a strategy to achieve or experiment with such goals (Coetzee \& RoythorneJacobs, 2007).

$\mathrm{CM}$ is related to career adjustment as it describes the behaviours conducive to career adjustment. According to Schreuder and Theron (2004), CM amounts to readiness to make career decisions and also to be able to cope with the developmental tasks of a particular life stage. It thus refers to general types of behaviour expected for every life stage - the adjustment to the developmental tasks of a given stage. In this context, CM is not a unitary trait that increases with age, but age is rather a factor in maturity, in that a person is evaluated in terms of the behaviour of other people of the same age (life stage) (Schreuder \& Theron, 2004). According to Super and Nevill (1984), CM is a global construct that is multi-dimensional and is still in the process of study and refinement.

The elements of all the definitions mentioned above were integrated into a comprehensive definition. In this study, a definition for CM is therefore formulated as a person's readiness to make realistic, well-informed, age-appropriate career decisions and formulate career goals based on self-knowledge, knowledge of employment opportunities, perceived employability and self-efficacy.

According to Lopienski and Savickas (2013), comprehensive models of vocational development during adolescence address the process of career decision-making and the content of occupational choices. Choice content should match an individual's abilities and interests to occupational requirements and rewards. A good match leads to success and satisfaction whilst a poor match leads to failure and frustration. The career choice process deals with how individuals make decisions, not which occupation they choose. Individuals, who are able to make sensible and realistic choices, have developed a more mature decisional process. 
In this study, significant levels of CM should thus ensure that MSDS members are better prepared for their further careers (either within the SANDF or in another occupation) after completion of their two year contract. They should be able to make better career decisions and cope better with the challenges that may arise within their career life.

In investigating the factors that influence CM, a study by Nevill and Super (1988) found that commitment to work may be the primary determinant of $\mathrm{CM}$ and that gender and socioeconomic status, which was previously viewed as determinants, are only important in that they are functions of commitment to work. In another study by Super and Nevill (1984), work salience was also indicated to be an important determinant of $\mathrm{CM}$. They describe role salience in terms of three dimensions: commitment, participation and value expectations. Matzeder and Krieshok (1995) investigated the relationship between career self-efficacy and role salience, and they state that the importance of a role (e.g. work role) is determined by commitment to the role, which includes attitudes and emotions, participation in the role, and knowledge about the role. Commitment is a dimension of the hardiness construct (see par 2.5.3).

They further add that an important issue in career development is how individuals integrate the various life roles. They investigated whether there were gender differences in the relationship between career-related self-efficacy expectations, and both work and home role salience. Their findings suggest that self-efficacy in traditionally male-dominated occupations positively predicted commitment to the work role for women but not for men.

Super and Nevill (1984), in describing the Career Development Inventory, identified six factors in vocational maturity: (1) awareness of the need to plan ahead, (2) decision-making skills, (3) knowledge and use of information resources, (4) general career information (5) general world of work information, and (6) detailed information about occupations of preference.

Self-concept is an underlying factor in Super's model (Super, 1957). Matsumoto (2009, p.465) defines self-concept as

The sum of one's idea about one's self, including one's physical, mental, historical, and relational aspects, as well as capacities to learn and perform. Self-concept is usually considered central to personal identity and change over time. It is usually considered partially conscious and partially unconscious or inferred at a given time. 
The assumptions of Super's theory (see par 2.4.2.5.1), included recognition of the trait theories - people differ in their personalities, abilities, needs, values, interests, traits and self-concepts and by virtue of these characteristics, people qualify for a number of occupations. The concept of Holland's theory of person and environment (job) fit (see par 2.4.2.2) is thus incorporated in the developmental career theory of Super. Coertze and Schepers (2004) summarise Super's $\mathrm{CM}$ construct as the ability to identify, choose, plan and execute career goals.

Yukl (2013) describes commitment to change in his theories of good management and leadership as being instrumental in the confidence to cope with change (an element of the definition of $\mathrm{CM}$ ). This confidence in coping with change is included in the challenge dimension of the hardiness construct (see par 2.5.3). The latter is determined by a person's selfconfidence, prior experience with change, risk tolerance, openness to new experiences and internal locus of control. Confidence to cope with change could be also be equated to selfefficacy in a particular career development phase or challenge in one's career life that requires decision-making. Challenge is the third dimension of the hardiness construct.

He further states that a person's resilience (ability to cope with changes) and self-efficacy determine how an individual will react to more changes. He also mentions that repeated change makes some people more resilient and others less resilient, depending on their personality traits and social support system.

In 1971 John O. Crites created a comprehensive theory of CM. He developed the Career Maturity Inventory (CMI), based on 12 years of career development research (Crites, 1978). Because CM is central to adolescent career development, several inventories have been designed to measure career choice readiness. The Career Maturity Inventory was the first such measure to be published, and it subsequently became one of the most popular readiness inventories for students in Grades 6 through 12 (and older). It is currently one of the most widely used $\mathrm{CM}$ measures. The $\mathrm{CMI}$ tests attitudes in regard to decisiveness, involvement, independence, orientation and compromise. It also contains a competence test that assesses knowledge in terms of self-appraisal, occupational information, goal selection, planning and problem solving (Lopienski \& Savickas, 2013). The CMI is used in this study to measure CM of MSDS members (see par 3.5.1). 
The CMI was designed to measure maturity of a person's attitudes and competencies necessary to make a realistic career choice (Hansen, 1974). The CMI revised (in 1995), short form (CMI-R) consists of 24 items consisting of combined attitude and competency thematic elements It tests the concern for one's own career future, a sense of personal control, curiosity to experiment and confidence to engage in designing one's occupational future. Savickas and Portfeli (2011) describe the four subscales as follows:

- Concern: the extent to which an individual is oriented to and involved in the process of making career decisions; becoming aware of choices and being involved in making them.

- Curiosity: the extent to which an individual is exploring the world of work and seeking to obtain information on occupations and their requirements. The information seeking process includes consulting with counselors, self-assessment, making use of the internet, etc.

- Confidence: the extent to which an individual has faith in his/her own ability to make wise career decisions and realistic occupational choices. It also includes anticipating success in solving problems and challenges involved in career decision making and choices.

- Consultation: the extent to which an individual seeks advice from others in making decisions and occupational choices. It is important to find a balance between choosing occupations by ourselves and with the help of others.

These subscales of the $\mathrm{CMI}$ are very similar to the commitment, control and challenge dimensions of the hardiness construct (see par 2.5.3). It is important for MSDS members to become aware of the necessity to make good career decisions. They need to explore the world of work and obtain information about the requirements for specific career choices. Confidence in their own abilities and in the ability to make wise decisions will decrease the anxiety experienced by MSDS members that have to leave the SANDF after their two years of service.

\subsubsection{Self-efficacy}

Perceived self-efficacy refers to beliefs that a person holds about his/her capability to organise and perform tasks within a specific domain to effectively lead to specific goals. This corresponds with control in the hardiness construct. These beliefs guide most of people's lives as it determines the courses of action that are chosen to pursue what is believed probable to be succeed (Carr, 2007). 
Self-efficacy is defined as people's tendency to "...approach, explore, and try to deal with situations within their self-perceived capabilities..." and to "...avoid transactions with stressful aspects of their environment they perceive as exceeding their ability" (Bandura, 1977, p. 203). Bandura (1977) hypothesised that expectations of personal efficacy determines whether coping behavior will be initiated, how much effort will be expended, and how long it will be sustained in the face of obstacles and aversive experiences. He argues that through experiences of mastery in relatively safe contexts, self-efficacy can be enhanced and defensive behaviours reduced.

He describes self-efficacy as being derived from the following four sources of information: performance accomplishments, vicarious learning, verbal persuasion (provision of encouragement and support), and physiological states (managing anxiety). The more dependable the experiential sources, the greater are the changes in perceived self-efficacy.

Egan's counselling theory is aimed at assisting clients toward better problem situation management and opportunity development. This outcome is also applicable in the career life of an individual and can be equated to a person reaching a satisfactory level of $\mathrm{CM}$ - being able to make good career decisions and handle career challenges, as well as being able to make use of opportunities in one's career life (Egan, 2014). Egan states that to achieve this outcome, a person must be guided in developing a better sense of him or herself (self-concept). The client must be helped to undergo constructive change that will lead to life-enhancing results, outcomes and achievements that in turn will lead to satisfaction, symptom reduction, a better perception of self and overall improved functioning. When going through some change or challenge, Egan also advocates assistance in regaining self-confidence and self-respect. Having a sense of worth will ensure more assertiveness for the client facing a challenge in his/her life or career (Egan, 2014). This can be seen as being related to self-efficacy in one's career context.

High levels of self-efficacy will be beneficial to MSDS members faced with the challenge of having to seek other vocations, as well as challenges that may be faced in a career within the SANDF. MSDS members (during their initial two years or thereafter) may be sent on deployments (e.g. Peace Support Operations in the Democratic Republic of Congo or Sudan). This is also a major challenge, due to the stressful nature of military deployments. Self-efficacy is therefore a requirement for MSDS members in the context of career decision-making, as well as in general military skills. The Career Decision Self-efficacy scale by Betz and Taylor (2013) will be used in this study to measure self-efficacy in the context of CM (see par 3.5.2). 


\subsubsection{Life skills}

De Villiers (2001, p. 117) defines life skills as "a variety of skills that are empowering and extend the abilities of individuals towards greater chances for success in the endeavours undertaken in their lives". Life skills also seem to be a factor that impacts on CM levels of individuals. In helping clients, Egan (2014) stresses that the client must be committed to the process of improvement. The latter may have an indirect bearing on commitment to work as a factor of $\mathrm{CM}$.

De Villiers (2001) describes life skills as a variety of skills that are empowering and extend the abilities of individuals towards greater chances for success in the endeavours undertaken in their lives. Education has always included aspects of improvements in life skills, thus preparing people for a rewarding vocation and general quality of life.

She further mentions the generalised list of life skills to include (De Villiers, 2001, p. 117): skills in communication and computation, critical thinking, preparation for work, learning how to learn, cultural sophistication and cross cultural understanding, empathy, understanding and respect for others, loyalty, intimacy, enjoyment of leisure and a sense of social-historical content. These proficiencies are still the roots of education, aiming at delivering people who are informed, thinking and sensitive human beings.

Egan (2014) states that improved life skills will assist clients toward the outcome of better problem situation management and opportunity development. Life skills are seen as preventative measures that can be learned by clients and be applied when required so that individuals become effective self-helpers. Such life skills include (among others) (Egan, 2014):

- Problem management;

- Opportunity identification;

- Sensible decision-making;

- Skill of interpersonal relating. 
In the current era of rapid technical advancement and protean careers, people must be prepared to not only change jobs, but also their skills a few times in their lives - individuals should not only be prepared for jobs, but also for areas of competence to succeed in their career lives (De Villiers, 2001). Various perspectives on life skills exist. For the purpose of this study and the focus on CM, the perspective of Covey was found to be most relevant. The CMI and CDMSE questionnaires also contain elements of life skills as mentioned in the list (see par 2.5.5). The interpersonal skills under life skills as a factor influencing CM is, however, not addressed in the CMI-R or the CDSE questionnaires. The Seven Habits Profile questionnaire by Covey is used in this study to measure life skills (Covey, n.d.) (see par 3.5.4).

Steven Covey (1992) describes the seven habits of highly effective people in his well-known book with the same topic. These "habits" refer to life skills. Life skills refer to those skills that enable a person to achieve success in most contexts, e.g. when entering a new work environment, having a large amount of knowledge on a subject or field, but being unable to interact well with co-workers, may not lead to optimal outcomes. Covey presents an approach to being effective in attaining goals by aligning oneself to what he calls "true north" principles of a character ethic that he presents as universal and timeless.

These principles or life skills include the following (Covey, 1992):

- Independence: The first three habits surround moving from dependence to independence (i.e., self-mastery).

$\circ$ Habit 1: Be proactive. Take initiative in life by realizing that your decisions (and how they align with life's principles) are the primary determining factor for effectiveness in your life. Take responsibility for your choices and the consequences that follow.

$\circ \quad$ Habit 2: Begin with the end in mind. Self-discover and clarify your deeply important character values and life goals. Envision the ideal characteristics for each of your various roles and relationships in life. 
○ Habit 3: Put first things first. A person must manage himself first (before trying to manage others or other things). And managers should implement activities that aim to reach the second habit (deciding on what it is that you want to achieve in life). Covey says that rule two is the mental creation; rule three is the physical creation - In other words to start implementing for yourself, that which you envisioned.

- Interdependence: The next three habits talk about interdependence (e.g. working with others). After achieving self-mastery (independence), a person must be able to interact with the rest of society in order to reach a higher goal and not just own goals. The interdependence habits include:

○ Habit 4: Think win-win. Genuine feelings for mutually beneficial solutions or agreements in your relationships. Value and respect people by understanding a "win" for all is ultimately a better long-term resolution than if only one person in the situation had got his way.

- Habit 5: Seek first to understand, then to be understood. Use empathic listening to be genuinely influenced by a person, which compels them to reciprocate the listening and take an open mind to being influenced by you. This creates an atmosphere of caring, and positive problem solving.

○ Habit 6: Synergize. Combine the strengths of people through positive teamwork, so as to achieve goals no one person could have done alone.

- Continuous Improvements: The final habit is that of continuous improvement in both the personal and interpersonal spheres of influence. This involves making yourself relevant as the world and society changes - one's skills have to be relevant to the complexities and ambiguities of the working environment.

$\circ$ Habit 7: Sharpen the saw. Balance and renew your resources, energy, and health to create a sustainable, long-term, effective lifestyle. It primarily emphasizes exercise for physical renewal, prayer (meditation, yoga, etc.) and good reading for mental renewal. It also mentions service to society for spiritual renewal. 
The seven habits profile provides scores for 9 categories. Other than the 7 mentioned above, "Emotional Bank Account" refers to conscientiousness and "Life Balance" refers to the ability to distribute one's energy in a realistic manner across one's various life roles (e.g. worker, family member, leisure time, friends, etc).

The seven habits and life skills in general are of the utmost importance for MSDS members not only in the context of their career lives, but also for empowering young people to fulfil contributing roles in society and achieving success in life.

\subsubsection{Hardiness}

Dolan and Adler (2006, p.110) define hardiness as "personality style or tendency, fairly stable over time, that is composed of the following interrelated components: (1) commitment (vs. alienation), referring to the ability to feel deeply involved in activities of life; (2) control (vs powerlessness), the belief one can control or influence events of one's experience; and (3) challenge (vs. threat), the sense of anticipation of change and an exciting challenge to further development". Maddi and Kobasa (as cited in Funk, 1992)) describe a hardy person as someone who views potentially stressful situations as meaningful and interesting (commitment); stressors are viewed as changeable (control); and change is seen as a normal aspect of life rather than a threat - also views change as an opportunity for growth (challenge).

Funk (1992) adds that hardiness alters perceptions of events to make them less stressful. It leads to better coping and also influences coping indirectly due to its influence on social support. It may also reduce illness due to minimising stress. The discussions of CM (see par 2.5), self-efficacy (see par 2.5.1) and life skills, especially as described by Egan (see par 2.5.2) includes the elements of hardiness. Egan's life skill problem management corresponds with control and opportunity identification with challenge.

Commitment appears to be one of the most important factors in CM (see par 2.5). The personality of individuals also play a part in $\mathrm{CM}$, but due to the focus of this study being on the organisational level and not the individual level, inclusion of personality questionnaires will not address the purpose of the study - the organisation will not be able to develop various individual characteristics for each individual or to change individuals' personalities. 
Psychological hardiness is, however, that part of a person's personality which seems to reflect the factors influencing CM. Bartone, Kelly and Matthews, (2013) describe psychological hardiness as those personality qualities found to characterise people who remain healthy and continue to perform well under a range of stressful conditions.

Hystad, Eid, Laberg and Bartone (2011) state that an extensive body of research has accumulated since 1979, showing that psychological hardiness protects against adverse effects of stress on health and performance, and that the "hardy-resilient style" person has a strong future orientation, or tendency to look to the future whilst also learning from the past. They add that the hardy-resilient style is also courageous in the face of new experiences as well as disappointments, is action-oriented, competent, and has a sense of humour. Furthermore, there is evidence pointing to the cross-cultural validity of the hardy-resilient style.

Dolan and Adler (2006) conducted a study on hardiness within the military context - to examine whether military hardiness buffered the impact of deployment demands on physical and psychological health. They found that soldiers with higher military hardiness scores reported lower depression levels. They further report that recent developments indicate that training can enhance psychological hardiness.

Leaders within the military context can be instrumental in enhancing military hardiness in the following ways (Dolan \& Adler, 2006):

- Model a hardy approach to military life/work that demonstrates commitment, control and challenge;

- Emphasising military identity in order to enhance commitment;

- Emphasising the significance of individual contributions to the mission in order to enhance control; and

- Framing work-related events as opportunities for members to work at their full potential.

Dolan and Adler (2006) further argue that while military training is primarily geared towards physical toughness or resilience, military hardiness training can enhance the development of psychological resilience. The Military Hardiness Scale by Dolan and Adler (2006) is used in this study to measure hardiness (see par 3.5.3). 
The above discussion on hardiness suggests that in relation to $\mathrm{CM}$, a hardy person may find his/her future career (and decisions in this regard) as meaningful and interesting. The hardy person would thus be committed toward making positive decisions about of his/her career (and/or setting goals). The hardy person would view him or herself as being in control of the direction of his/her future career (being able to take responsibility for his/her own career). Such a hardy person may also see changes in his/her career life as opportunities for growth rather than a threat or cause for extreme anxiety.

\subsubsection{External factors}

A person's context also plays an instrumental role in CM. Perron, et al. (1998) conducted a study in Canada of the relationship between ethnicity and CM and found that there was a positive relationship between ethnic identity and $\mathrm{CM}$ for both minority and majority groups. Stead (1996) indicates that the history and context of black South African adolescents has an influence on their career development. Reid-Van Niekerk and Van Niekerk (1990) conducted a study on the levels of CM among black, coloured and white RSA students before democratic reforms in the RSA. The CMI was used to measure CM in the study. White students had a mean score of $80 \%$, coloured students $69 \%$ and black students $56 \%$. The findings explain that the socio-economic status and differences in quality of education has an impact on CM.

According to Themba (2010), a large amount of research on the topic of CM focuses on the relationship between $\mathrm{CM}$ and demographic factors such as age, gender, race, people with disabilities and socio-economic factors. These relationships are not the focus of this study. It is, however, recorded for purposes of describing the sample and to provide additional information for consideration in the development of a career guidance programme for MSDS members.

Super's theory (1957) also includes the assumption that the nature of a person's career pattern is determined by the individual's parental socio-economic level, mental ability, educational skills and personality characteristics, as well as the opportunities to which the person is exposed. It can thus be deducted that external factors (a person's context, culture, socio-economic status, quality of education, etc) has an impact on the development of the self-concept and hence on $\mathrm{CM}$. A biographical information form was compiled to assess some of these external factors and to describe the characteristics of the sample. 


\subsubsection{A proposed diagnostic model of career maturity for MSDS members}

$\mathrm{CM}$ is a construct that have received much attention in research in the last two decades. For the purpose of this study, the factors influencing CM was summarised from the literature according to what can be realistically addressed within the MSDS context.

The aim is to identify factors for a diagnostic model to explain the existing level of CM of MSDS members in order to identify which factors could be addressed by the SANDF as an organisation towards the improvement of CM levels. The career counselling theories revealed factors such as personality, competency, interests, aspirations, self-concept, social background, life stage, context and meaning in life. These factors are, however not relevant only to $\mathrm{CM}$, but rather all areas concerning careers, such as choice of career, satisfaction or success in a career, career challenges and development, transitions, etc.

From the discussion on the definitions of $\mathrm{CM}$, the focus seems to be on adjustment (to the particular career life stage); being better prepared for one's career, being able to make better decisions and better coping with challenges of one's career life. A summary of all the factors mentioned in the discussion of $\mathrm{CM}$, indicates that two categories of factors play a role in $\mathrm{CM}$ : firstly, factors concerning the self and secondly, factors concerning the environment. The mentioned factors from the literature will be listed below under these two categories:

- Factors concerning the self

- Self-concept

- Self-efficacy

- Sense of self-worth

- Resilience

- Commitment to work (attitudes and emotions)

- Work salience (commitment, participation, value expectations)

- Knowledge (of world of work, work-role, detail about preferred occupations, use of resources, general career information)

- Traits (all associated with self-efficacy)

- Confidence

- Coping

- Commitment to change

- Risk tolerance

- Openness to new experiences 
- Internal locus of control

- Mental ability

○ Life skills

- Problem management

- Opportunity identification/development

- Sensible decision-making

- Skill of interpersonal relating

- Factors concerning the environment:

- Parental socio-economic level

- Social support

- Opportunities exposed to

- Prior experience with change

- Expectations of success

- Culture (e.g. what is deemed as acceptable careers for specific genders or socioeconomic class, etc)

- Specific circumstance (as proposed by Accident Theory, e.g. having to take over a family business without having much choice; being forced to take any available job).

To conclude with the focus on career guidance and youth development within the MSDS context, the following factors emerged as prominent to $\mathrm{CM}$ and will be investigated in this study:

- Self-efficacy (SE) - performance accomplishments, vicarious learning, managing anxiety, provision of encouragement and support, resilience, self-confidence, competency;

- Hardiness (HA): a psychological dimension characterised by a strong sense of commitment, control, and challenge (Funk, 1992).

- Life skills (LS) - problem management, opportunity identification and development, sensible decision making, interpersonal relationship skills, meaning in life, planning ahead (goal setting);

- External factors (EF) - socio-economic status, culture, socio-political context, social support, quality of education, etc.

These factors are interrelated. A conceptual diagnostic model is depicted in Figure 2.3. 


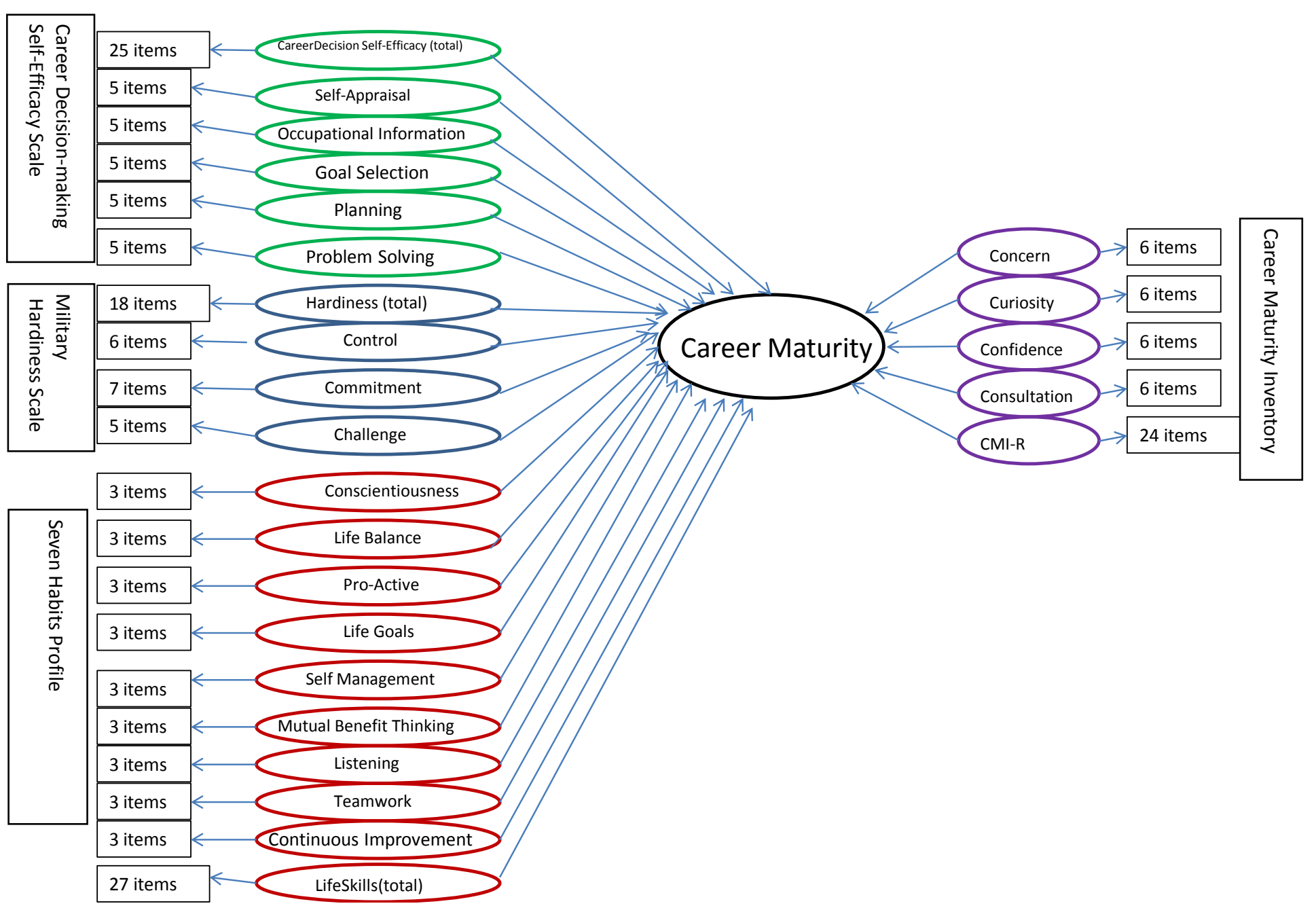

Figure 2.3 Diagnostic Model of the Factors Influencing CM 


\subsection{CHAPTER SUMMARY}

Chapter 2 provided a literature review for the study. An overview of youth development in the South African context was provided. Youth unemployment is a serious concern in the South African labour market. Taking ownership of one's own career and maintaining employability is therefore of great importance for RSA young people. Youth development emphasises providing services and opportunities to support young people in developing a sense of competence, usefulness, belonging and empowerment. The MSDS is the SANDF's contribution towards the National Skills Development Strategy of the RSA.

The choice of career affects most other aspects of a person's life. CM is defined in this study as a person's readiness to make realistic, well-informed, age-appropriate career decisions and formulate career goals based on self-knowledge, knowledge of employment opportunities, perceived employability and self-efficacy. Career services and CM are reviewed to theoretically substantiate the factors influencing $\mathrm{CM}$. Those factors that emerged as prominent within the context of the study and identified for purposes of measurement, were specifically discussed. Exploring the levels of these factors amongst MSDS young people will be used as guidance towards the requirements for a career guidance programme or other relevant measures within the SANDF for improved youth development. 


\section{CHAPTER 3 \\ RESEARCH DESIGN AND METHODOLOGY}

\subsection{INTRODUCTION}

Chapter 2 provided the theoretical foundation of the study leading to the identification of the most prominent factors influencing $\mathrm{CM}$ relevant to the specific context of MSDS young people. This present chapter describes the empirical phase of the study. The aim of this chapter is to outline the process followed in achieving the empirical objectives (see par 1.3.3). The empirical objectives of the study were to make use of a descriptive correlational research methodology (Babbie, 2010):

- To determine the level of CM of MSDS members of the SANDF.

- To determine the levels of factors identified as influencing CM within the specific population.

- To determine which of the factors, identified as influencing $\mathrm{CM}$, seem significant in influencing CM within the specific population.

To achieve these objectives, hypotheses will be formulated and the research design described. The population and sample will then be described, followed by a description of the measuring instruments chosen for the study. Ethical considerations are discussed, followed by a description of the statistical analysis and the chapter summary.

The research problem of this study is formulated as follows: Which factors influence career maturity and what is the level of career maturity of MSDS members in the SANDF and which of these factors could and/or should be addressed by the organisation towards achieving more effective youth development?

In this chapter, the focus is on the measurement of the factors influencing CM in order to identify which of these identified factors have the most significant relationship(s) with CM. Such significant factors will then be the focus for a career guidance programme within the SANDF towards effective youth development. 


\subsection{HYPOTHESES}

The necessity to provide answers to the research problem stated above and in order to satisfy the research objectives (see par 1.3), the following proposed hypotheses were formulated (see Figure 2.3):

$\mathrm{H} 1$ : There is a significant and positive relationship between total career decision self-efficacy (CDSE) and CM.

$\mathrm{H} 2$ : There is a significant and positive relationship between self-appraisal and CM.

H3: There is a significant and positive relationship between seeking occupational information and $\mathrm{CM}$.

$\mathrm{H} 4$ : There is a significant and positive relationship between goal selection and $\mathrm{CM}$.

H5: There is a significant and positive relationship between planning and CM.

H6: There is a significant and positive relationship between problem solving and CM.

$\mathrm{H7}$ : There is a significant and positive relationship between total hardiness and CM.

H8: There is a significant and positive relationship between control and CM.

H9: There is a significant and positive relationship between commitment and CM.

$\mathrm{H} 10$ : There is a significant and positive relationship between challenge and CM.

$\mathrm{H} 11$ : There is a significant and positive relationship between total life skills and CM.

$\mathrm{H12}$ : There is a significant and positive relationship between conscientiousness and CM.

H13: There is a significant and positive relationship between life balance and CM.

$\mathrm{H} 14$ : There is a significant and positive relationship between pro-active behaviour and CM. 
H15: There is a significant and positive relationship between life goals and CM.

$\mathrm{H} 16$ : There is a significant and positive relationship between self-management and CM.

$\mathrm{H} 17$ : There is a significant and positive relationship between mutual benefit thinking and CM.

$\mathrm{H} 18$ : There is a significant and positive relationship between listening and CM.

H19: There is a significant and positive relationship between teamwork and CM.

H20: There is a significant and positive relationship between continuous improvement and CM.

\subsection{RESEARCH DESIGN}

Kerlinger (1986) describes a research design as a plan, structure and strategy of investigation that is conceived in order to obtain answers to research questions or problems. Leedy (1997) describes it more simply, as the strategy for solving the central research problem.

This study makes use of a descriptive research design that is not truly experimental. Descriptive studies are studies in which information is collected without changing the environment - thus nothing is manipulated. Such studies are referred to as following a nonexperimental or nomothetic passive observation research design. Causal relations among variables are typically difficult to determine in these type of studies. Survey research is the most typical type of nomothetic passive observation research (Rogelberg, 2004).

According to Babbie (2010), surveys are appropriate for exploratory, descriptive or explanatory purposes. Descriptive studies aim to describe a social phenomenon and measure its incidence in a population, while relational surveys empirically examine the relationship between two or more constructs in an exploratory or confirmatory manner. Descriptive studies may also be conducted to demonstrate associations or relationships between social phenomena (Rogelberg, 2004). The aim of this study is to describe the levels of CM, the factors involved in CM and the relationships between these constructs. 
Descriptive studies are sometimes referred to as correlational or observational (simple descriptive) studies. Correlational descriptive studies describe the statistical association between two or more variables (Rogelberg, 2004). Simple descriptive research only aims to describe the observed phenomena being studied. Descriptive statistics are applied to the observed data gathered and then used to analyse such data. Simple descriptive research considers one variable at a time (i.e. univariate analysis), and is typically the entry-level type of research in a new area of inquiry. It typically describes what appears to be happening and what the important variables seem to be. Correlational research is used to determine the relationships among two or more variables. Data is gathered from multiple variables and correlational statistical techniques are then applied to the data. Correlational research may be seen as the next step after simple descriptive research; after the important variables have been identified, the relations among those variables are investigated. This type of research design is used to investigate a range of factors, including the nature of the relationship between two or more variables and the theoretical model that might be developed and tested to explain these resultant correlations. Correlation does not imply causation and can therefore only enable the researcher to make weak causal inferences at best (Lomax \& Li, 2013).

Quantitative research involves collecting quantifiable information (data) - obtaining information on things that can be counted or represented by numbers (quantities) (Hanna \& Demptster, 2012). According to Babbie (2010, p. 394), qualitative analysis involves "the nonnumerical examination and interpretation of observations, for the purpose of discovering underlying meanings and patterns or relationships". Henning, Van Rensburg and Smit (2004) propagate that a qualitative research design allows in-depth inquiry and absence of control or limited control over the "variables", as the focus is on freedom and natural development of action and representation.

This study uses a quantitative research design as constructs are quantified and measured. The nature of the research problem required that data be collected from a large sample of MSDS members in order to make generalisations about the population. The study is therefore quantitative in nature and aims to provide an understanding of the $\mathrm{CM}$ challenges or needs of a representative sample of SANDF MSDS members. 
A thorough literature review was done to investigate the factors that influence $\mathrm{CM}$ and the prominent factors identified for measurement purposes by means of recognised questionnaires. Analyses of questionnaire data may then shed light on the significance of relationships between these factors and CM within the MSDS sample and subsequently the priorities for factors to be addressed. The findings on these factors and how they may be prioritised in the context of the MSDS population will be used to recommend career services or other relevant measures within the SANDF, in order to improve CM levels for SANDF MSDS members.

Surveys are used in studies where individuals are the primary unit of analysis, as they must serve as respondents or informants. Surveys are, furthermore, useful in measuring attitudes and orientations in large populations (Babbie, 2010). The unit of analysis in this study will be the individual MSDS member, and the point of focus will be the orientation of the MSDS population in terms of positive or negative perceptions about their future careers and their overall level of $\mathrm{CM}$.

Survey research describes specific aspects of a given population. Such specific aspects are standardised in a questionnaire or structured list of questions so that data can be counted and analysed. This may include examining the relationships among variables. A selected portion of the population is used in survey research from which the findings can later be generalised back to the population (Glasow, 2005). A survey design was found to be the best practical method of collecting and analysing data to answer the research question.

Validity in research requires that the measure(s) used must accurately reflect the construct that it is intended to measure. Reliability requires that the data collection and analyses can be repeated for the same phenomenon over time (Babbie, 2010). The study will follow an ordered and systematic approach by using recognised measuring instruments.

According to Diamantopoulos and Sigauw (2000), an independent variable acts as a determinant of another variable, while a dependent variable is influenced or affected by another (independent) variable. In this study, CM is the dependent variable. 
The independent variables are the factors influencing $\mathrm{CM}$ and include career decision selfefficacy, self-appraisal, occupational information, goal selection, planning, problem solving, hardiness, control, challenge, commitment, conscientiousness, life balance, pro-active behaviour, life goals, self-management, mutual benefit thinking, listening, teamwork, continuous improvement and life skills (total) (see Figure 2.3).

\subsection{SAMPLING DESIGN}

A research population comprises all the possible cases (persons, objects, events) that constitute a known whole or the entire aggregation of cases that meet a designated set of criteria (http://explorable.com/research-population). The population for this study is the MSDS members of the SANDF of the 2013-2014 intake. The SANDF consist of military, uniformed members serving in one of four services, viz SA Army, SAAF, SAN and SA Medical Health Services (SAMHS). The MSDS population consists of young members who voluntarily join the SANDF on a two-year contract. After the two years, members may have their contracts renewed (and become medium-term service - MTS) or leave the SANDF. The SANDF currently takes in approximately 3000 MSDS members yearly.

A population as a whole is usually too large to participate in a research study and therefore a sample is taken from the population (http://explorable.com/research-population). The sample for this study consists of 310 MSDS members who were invited to complete five questionnaires. The ideal sampling method for surveys is probability sampling. This method takes a proportionate sample from the population and the elements of the population selected for the sample must have equal chances of selection. The fundamental principle behind probability sampling is that a sample of individuals from the population must contain essentially the same variations that exist in the population to provide a useful description of the total population (Babbie, 2010). Breakwell, Hammond and Fife-Shaw (1998, p. 107) adds that probability sampling is also referred to as simple random sampling that is aimed achieving a sample "where each person in the sampling frame has an equal chance of being selected for the survey." Names in a population list can be numbered and a random number generator used to select the participants for the sample. This method is, however, practically problematic for large populations. 
The cluster sampling procedure is an approach to overcome the practical difficulties of the probability sampling approach. This methods selects a smaller number of clustering units and then samples all the subjects in each unit (Breakwell et al., 1998). Non-probability sampling is described by Babbie (2010) as being dependent on the availability of subjects. Convenience sampling is one such non-probability sampling methods whereby subjects are included based on the most convenient way. It is also referred to as "haphazard" or "person-on-the-street" sampling for surveys that leaves little control over the representativeness of a sample (Babbie, 2010).

The probability sampling approach with the cluster sampling procedure was used to select a sample for this study in a practical manner, with due consideration of possible bias, in an attempt to select as many elements for the sample as is practically possible to ensure representativeness to the population (Babbie, 2010). This was done by identifying all the SANDF units where MSDS members are present - there are a limited number of units that accommodate MSDS members. Units were identified from the different Arms of Service of the SANDF (SA Army, SAAF, SAN and SAMHS) and were not conveniently available to the researcher in terms of nearby location or cost implication. An element of convenience was, however, present in that the units included (as clusters) in the sample were dependent on the availability of MSDS members within the units at the time of the study; some members (or the whole of the MSDS unit grouping) were on deployments, pre-mobilisation training, out-of-unit training exercises, or presidential inauguration duties. The implication was that no MSDS members of the SAMHS were available in units at the time of the study as they were between transfers to various training environments or functions.

The sample size was also an important factor in the sampling procedure. Based on the approximately 3000 MSDS members trained in the SANDF (or less during the 2012-2013 intake due to budget constraints and operational requirements), the sample size of 310 was sufficient for purposes of statistical analysis and even parameter estimates (Breakwell et al., 1998). 


\subsection{MEASURING INSTRUMENTS}

Four recognised instruments were used in this study: the Career Maturity Inventory Revised (CMI-R) short form, the Career Decision Self-efficacy Scale (CDSE) short form, the Military Hardiness Scale, the Seven Habits Profile Questionaire and one Biographical Information Form (BIF) compiled by the author of this study. It is recognised that due to the multidimentional nature of the $\mathrm{CM}$ construct, one instrument alone cannot measure all aspects of $\mathrm{CM}$. Questionnaires were chosen that will provide data on the factors influencing $\mathrm{CM}$ that are relevant to this study.

\subsubsection{Career maturity inventory revised (CMI-R)}

The CMI-R short form (Form C) (Crites \& Savickas, 1996) was used to measure CM of MSDS members. The CMI-R short form is a self-rated multi-factorial measure that contains 24 items in four subscales, and contains statements with "Agree" and "Disagree" options for the participant to choose from. The inventory provides five different scores. It provides a total score for career choice readiness - this total score for CM is based on the 18 items in the concern, curiosity and confidence scales (Dodd, 2013). The measurement further reflects levels of maturity in the following four subscales (Coertze \& Schepers, 2004):

- Concern;

- Curiosity;

- Confidence; and

- Consultation.

The CMI-R have acquired adequate psychometric validation to warrant their continued use (Lopienski \& Savickas, 2013). Tekke and Ghani (2013) reported an internal consistency Cronbach's Alpha of .81 using the CMI-R for their study on CM of foreign students in a public university. In a research study conducted by Savickas \& Portfeli (2011), the coefficient alpha for the CMI-R Form $\mathrm{C}$ total score was .86. The short form was chosen as it has less items and is therefore more practical to administer and score in large groups. Permission for use of the instrument was granted by SAGE Publications after payment. 


\subsubsection{Career decision self-efficacy scale (CDSE)}

The CDSE was used to measure self-efficacy for making career decisions. The concept of selfefficacy expectations provided the primary theoretical basis for scale development, while Crites's 1978 model of CM provided the CDSE scale authors, Taylor and Betz (1983), with a framework for deciding how to define and operationalise the skills required in career decisionmaking. A competency in decision-making emerged from the literature as one of the main elements of CM. Crites's model of CM hypothesized that sensible career decisions will be facilitated by competence with respect to five career choice processes and by mature versus immature attitudes regarding the career choice process.

The five competencies that make up the subscales of the CDSE, are (Betz \& Taylor, 2013):

- accurate self-appraisal;

- gathering occupational information;

- goal selection;

- making plans for the future; and

- problem solving.

The CDSE short form consists of 25 items with statements that ask participants to indicate how much confidence they have to accomplish each task as stated. There are five statements for each of the subscales. Responses are marked on a five-point Likert scale ranging from 1 (no confidence at all) to 5 (complete confidence). In order to use the CDSE, the researcher was required to purchase a license, as well as a user manual, from Mind Garden (www.mindgarden.com). In a study by Dodd (2013), the reliability coefficient for the CDSE short form was .95 for 127 usable respondents.

\subsubsection{Military hardiness scale (MHS)}

The MHS was used to measure hardiness in coping with the challenges of career decisions and transitions. The hardiness construct has three key facets: commitment - an active engagement and involvement with the world, and a sense of meaning in life (vs. isolation), control - a belief that one can influence events and outcomes by applying effort, and challenge - a receptivity to variety and change (Hystad et al., 2011). 
The MHS was developed by Dolan and Adler (2006) investigating military hardiness as a buffer of psychological health on return from deployment. It is a short, valid and reliable instrument that had a Cronbach's Alpha of .90 for the mentioned study. It consists of 18 items that reflect the three components of hardiness; seven items for military specific commitment, six items for military specific control and five items for challenge. Items of the MHS are presented to respondents in Likert-type format with a 4-point response scale that ranged from Not at All True (0) to Completely True (3). Permission was granted for the use of the instrument by $\mathrm{Dr} \mathrm{C}$. Dolan.

\subsubsection{Seven habits profile (SHP)}

The SHP questionnaire was used to measure life skills. The questionnaire consists of 27 items measuring 9 categories of life skills. These categories or "habits" were described in the literature review (see par 2.5.2). There are three items for each category. Respondents are asked to rate themselves on how well they perform in each category statement by making use of a 6-point Likert scale ranging from "very poor" to "outstanding". A score is calculated for each category by adding the adding the numbers marked on the three items of the category (Covey, n.d.).

The SHP questionnaire tests for a total score (for life skills) and for levels of categories of life skills which include (Covey, n.d.):

- Emotional bank account (conscientious)

- Life balance

- Be proactive (internal locus of control)

- Begin with the end in mind (goal setting)

- Put first things first (prioritising)

- Think win-win

- Seek first to understand

- Synergise

- Sharpen the saw (personal health and well-being)

In a study by Pahl (2011) on the level of autonomy of college students, the Cronbach's Alpha scores ranged between .70 and .79 for the subscales of this instrument. Permission to make use of the instrument was obtained from FranklinCovey situated in Centurion, South Africa. 


\subsubsection{Biographical information form (BIF)}

In order to assess the external factors that play a role in $\mathrm{CM}$, a biographical information form (BIF) was compiled by the author for this thesis ${ }_{2}$ to accompany the battery of questionnaires to be administered to the MSDS members of the sample group(s). It contains questions that cover biographical data and the external factors as relevant to this study. This includes the following:

- age;

- gender;

- ethnicity;

- previous work experience;

- consideration of other job options;

- supporting of dependents;

- ability to compile a good curriculum vitae;

- ability to search for jobs;

- ability to attend job interviews.

\subsection{ETHICAL CONSIDERATIONS}

All the ethical considerations for social research as required by the Health Professions Council of South Africa (HPCSA) were adhered to in this study. It was submitted for review and approval to the Departmental Ethics Screening Committee (Department of Industrial Psychology) and the Research Ethics Committee of Stellenbosch University. The SANDF Defence Intelligence Division (Release of Information section) provided organisational permission for conducting of the study within the SANDF and for approval of the release or publication of the findings of the research. Permission was granted in writing for the administering of questionnaires to MSDS members by the commanding officers of their units.

Voluntary participation in the study was emphasised when administering the questionnaires. The purpose of the study, the voluntary nature of participation and the right to withdraw from the study at any time were clearly communicated to participants before administering the questionnaires. 320 MSDS members were originally invited to participate. Six persons chose not to participate and four participants submitted incomplete questionnaires. Confidentiality of results and personal information, as well as the secure handling of the completed questionnaires, were also communicated to participants. Participants signed Informed Consent forms prior to participation. 


\subsection{STATISTICAL ANALYSIS}

The sample was described using summary tables to report frequencies (and percentages), means, minimums, maximums and standard deviations. Reliability analyses were conducted on the scales and subscales using Cronbach's Alpha. The relationships between the dependent and independent variables were described by calculating Pearson correlations for univariate comparison of variables. Regression analysis was conducted to investigate effects of independent variables (factors) on the dependent variable (CM). All analyses were done using STATISTICA 10. A five percent significance level $(p<.05)$ was used as guideline for significant relationships.

\subsection{CHAPTER SUMMARY}

This chapter provided an overview of the research design of the study. The empirical objectives of the study were listed, as well as 20 hypotheses formulated to achieve these objectives. The research problem of this study was stated as follows: Which factors influence career maturity and what is the level of career maturity of MSDS members in the SANDF and which of these factors could and/or should be addressed by the organisation towards achieving more effective youth development?

The study was described as following a descriptive correlational research design and makes use of a survey methodology. The population of the study is the MSDS of the SANDF. A sample of 310 MSDS members from three units were asked to complete five questionnaires. These questionnaires included: the CMI-R, CDSE, MHS, SHP and BIF. Ethical considerations were discussed and the type of statistical analyses used for the study was described. 


\section{CHAPTER 4}

\section{RESULTS}

\section{$4.1 \quad$ INTRODUCTION}

The theoretical foundation of this study (chapter 2) dealt with the identification of the factors that influence CM. In order to achieve the empirical objectives (see par 1.3.3) towards providing answers to the research problem, hypotheses were formulated (see par 3.2). This chapter provides the results of the statistical analyses. These results include a report on the descriptive statistics for the sample, analyses of the internal reliability of the different scales and inferential statistics describing the correlations for the hypothesised relationships. Multiple regression analysis results are also reported in order to arrive at a model that includes the significant relationships (see Figure 4.26). All analyses were done using STATISTICA 10.

\subsection{DESCRIPTIVE STATISTICS FOR THE SAMPLE}

Babbie (2010, p.G3) defines descriptive statistics as " statistical computations describing either the characteristics of a sample..." and that descriptive statistics "summarize a set of sample observations". Participants in this study included 310 MSDS members of the SANDF from the SA Army, SAN and SAAF services. The sample comprised of $201(65 \%)$ males and $109(35 \%)$ females. Figure 4.1 illustrates the age distribution of the sample.

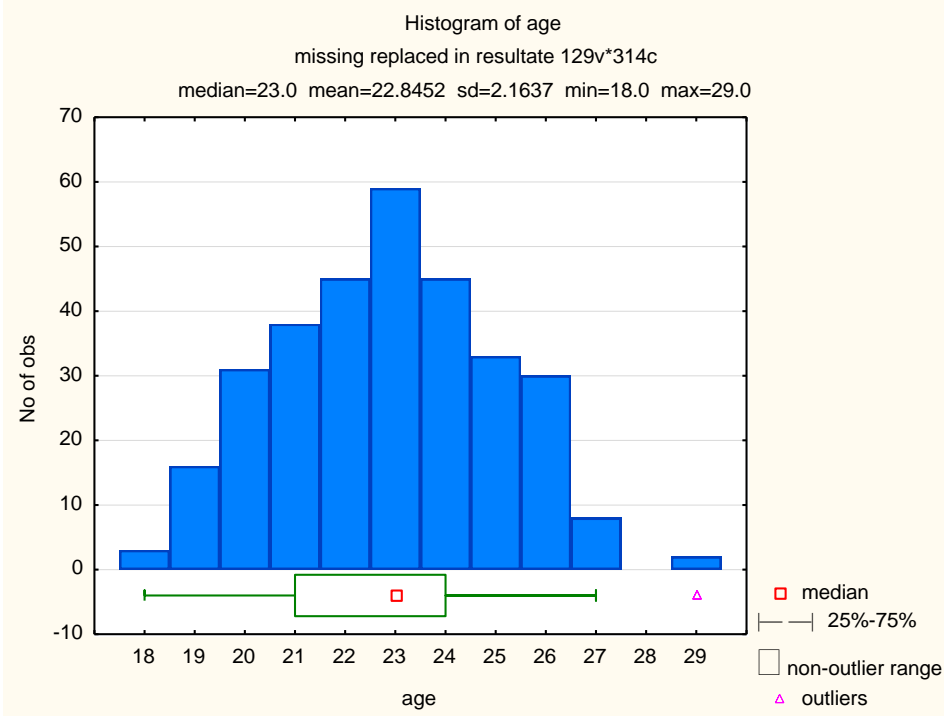

Figure 4.1 Age Distribution of Sample 
The ages ranged between 18 and 29 years with a mean of 22.8 and a median of 23 and a standard deviation of 2.16. This age distribution confirms that the sample can be considered late adolescents (and young adults) (see par 2.3.2).

The data on the ethnicity of the sample indicated that the majority of participants were African (90\%), with $6 \%$ being Coloured, $4 \%$ White, and one participant $0.3 \%$ Indian. Concerning the environmental factors influencing $\mathrm{CM}$, it is important to note that $76 \%$ of the participants have to be employed in the SANDF in order to support family members (dependents).

Figure 4.2 indicates the previous work experience (other than in the SANDF) that participants have been exposed to.

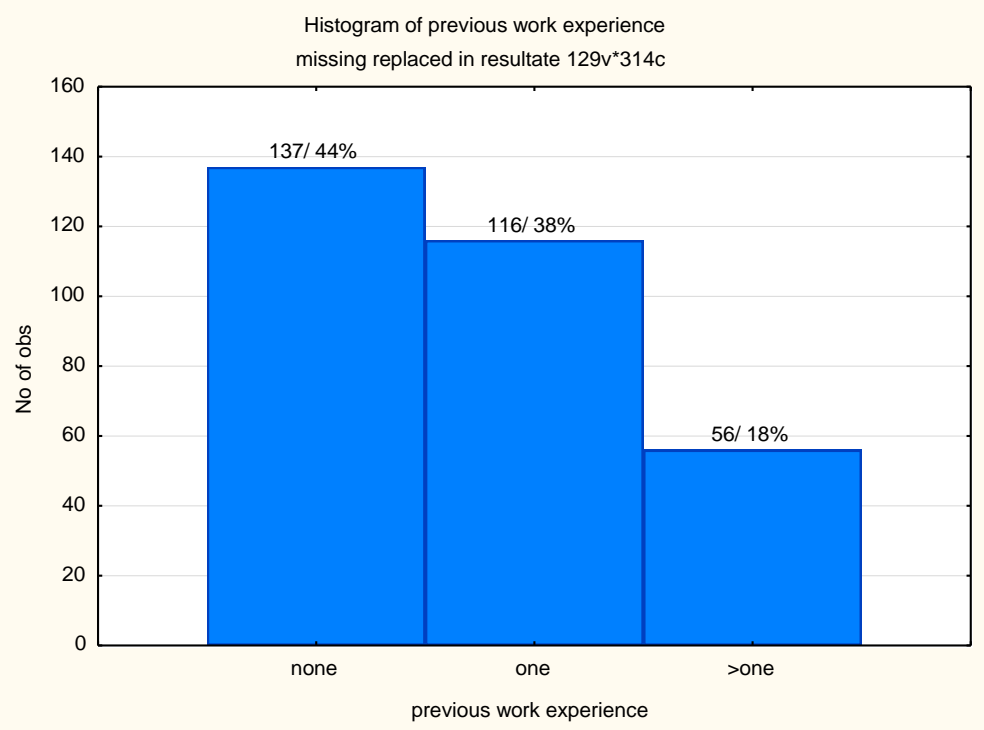

Figure 4.2 Previous Work Experience of Participants

The results show that $44 \%$ of the participants had no previous work experience, $38 \%$ indicated that they held one previous job and $18 \%$ had more than one previous job. The sample of this study therefore differs from many other studies of high school and college students with little or no previous work experience. It should, however, be noted that many of the jobs held were casual jobs such as life guard duties on the beach, being a waiter, shop assistant or examination invigilator. 
Figure 4.3 reflects the number of participants that are confident that they are able to compile a good cv.

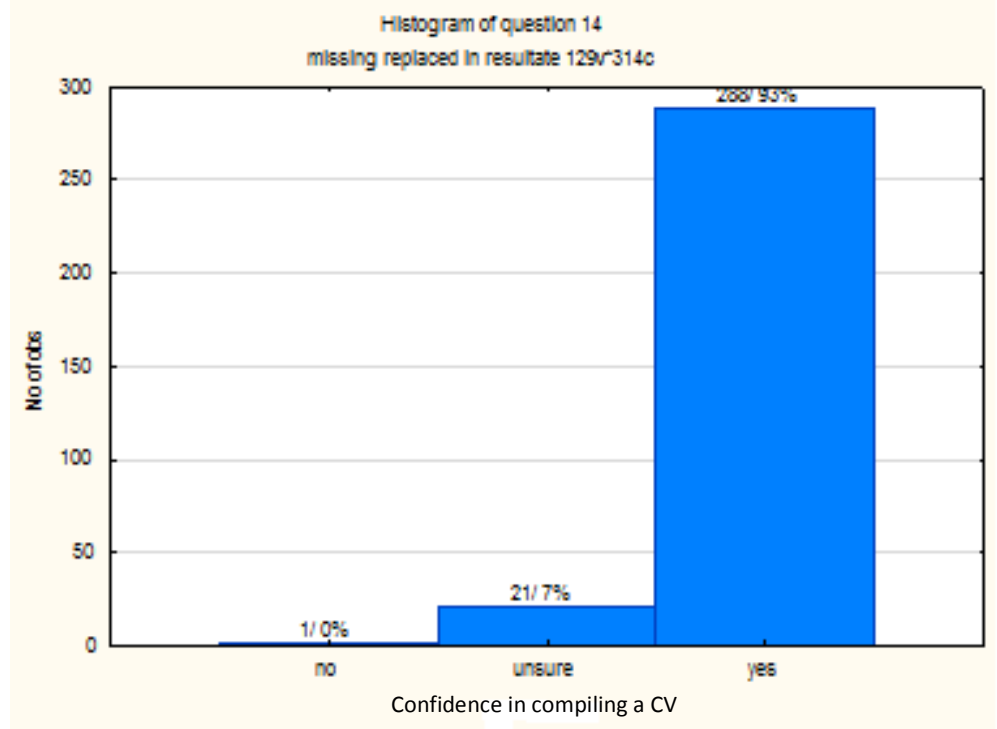

Figure 4.3 Perceived Ability to Compile a CV

Figure 4.3 shows that $93 \%$ of the sample indicated that they are able to compile a good CV. $7 \%$ were unsure if they have the ability to compile a good CV. Only one participant indicated that he/she is unable to compile a good CV. It would seem that MDSM members at present have no urgent requirement to learn how to compile a good CV.

Figure 4.4 reflects the confidence of participants in executing the process of searching for jobs.

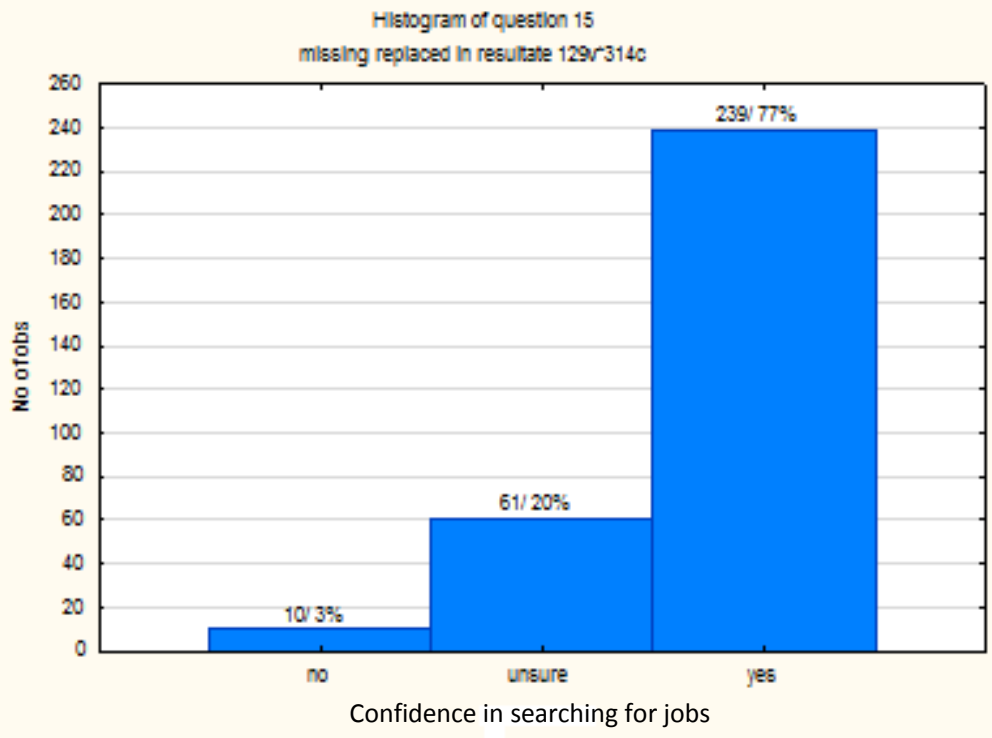

Figure 4.4 Perceived Ability to Search for Jobs 
Regarding the process to be followed in searching for jobs, $77 \%$ of the participants indicated that they have confidence to accomplish this task, while $20 \%$ are unsure and $3 \%$ do not know how to go about searching for jobs. These results suggest that there is only a moderate need for guidance in the process of searching for jobs

Figure 4.5 reflects the perceived ability of participants to prepare for and attend employment interviews.

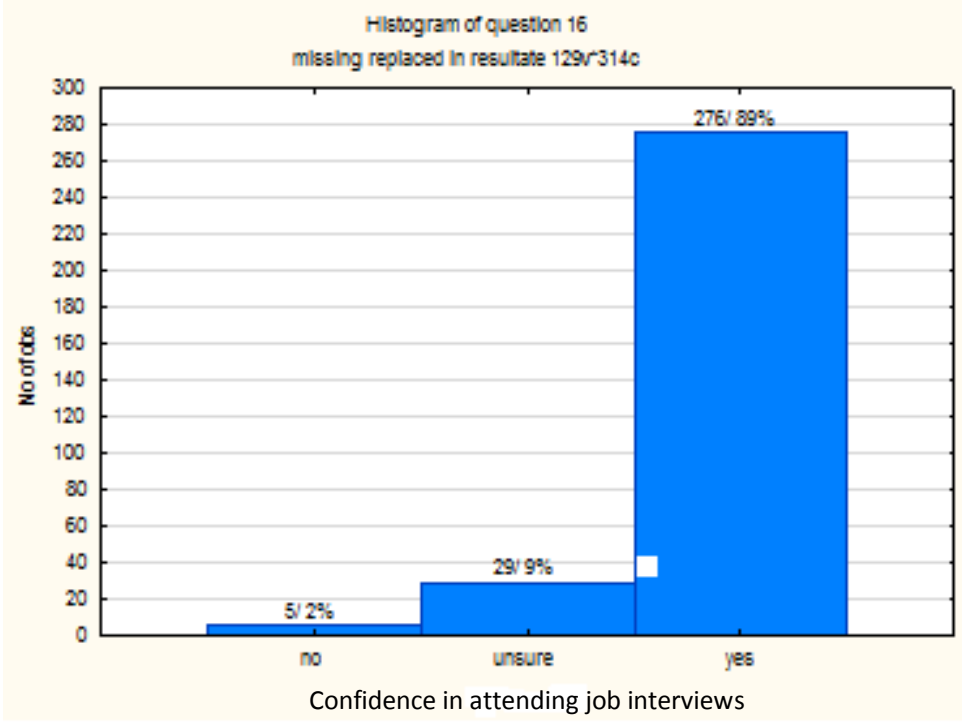

Figure 4.5 Perceived Ability to Successfully Attend Employment Interviews

Figure 4.5 shows that $89 \%$ of the sample indicated that they are able to handle themselves well during an employment interview, $9 \%$ of participants were unsure and $2 \%$ did not not think that they can successfully accomplish this task. This result is interesting to note when compared to the fact that only $18 \%$ of the sample have held more than one previous job (for which they may or may not have needed to attend a job interview).

\subsubsection{Mean scores on scales and subscales}

The mean scores of the sample $(\mathrm{N}=310)$ are presented in Table 4.1. These results present the levels of the factors among MSDS members. A discussion of these results follows thereafter. 
Table 4.1

Mean Scores on Scales and Subscales

\begin{tabular}{|c|c|c|c|}
\hline Scale & $\begin{array}{l}\text { Out of (highest } \\
\text { possible score) }\end{array}$ & Mean & $\begin{array}{c}\text { Standard } \\
\text { deviation (SD) }\end{array}$ \\
\hline Career Maturity (total) & 18 & 12.40 & 3.13 \\
\hline Concern & 6 & 4.02 & 1.16 \\
\hline Curiosity & 6 & 4.33 & 1.47 \\
\hline Confidence & 6 & 4.05 & 1.53 \\
\hline Consultation & 6 & 2.51 & 1.42 \\
\hline Career Decision Self-efficacy (total) & 5 & 4.09 & .45 \\
\hline Occupational information & 5 & 4.12 & .57 \\
\hline Goal selection & 5 & 4.10 & .54 \\
\hline Planning & 5 & 4.19 & .59 \\
\hline Problem solving & 5 & 3.87 & .61 \\
\hline Self appraisal & 5 & 4.19 & .55 \\
\hline Military hardiness (total) & 3 & 2.60 & .30 \\
\hline Commitment & 3 & 2.72 & .31 \\
\hline Challenge & 3 & 2.57 & .37 \\
\hline Control & 3 & 2.50 & .48 \\
\hline Seven habits profile (total) & 6 & 4.97 & .57 \\
\hline Conscientiousness & 6 & 4.83 & .86 \\
\hline Life balance & 6 & 4.90 & .78 \\
\hline Pro-active & 6 & 5.21 & .69 \\
\hline Life goals & 6 & 4.92 & .73 \\
\hline Self management & 6 & 4.89 & .83 \\
\hline Mutual benefit thinking & 6 & 5.16 & .81 \\
\hline Listening & 6 & 4.82 & .83 \\
\hline Teamwork & 6 & 4.82 & .82 \\
\hline Continuous improvement & 6 & 5.15 & .71 \\
\hline
\end{tabular}


CM was measured with the CMI-R SF. Participants scored a mean of 12.40 (out of 18) or 69 percent. This is a moderate score for CM (Savickas \& Portfeli, 2011).

A high score for concern indicates that participants are oriented towards and involved in the process of career decision-making, and a low score indicates little concern for career decisions. The mean score for concern is 4.02 (see Table 4.1), indicating moderate concern amongst participants (Savickas \& Portfeli, 2011).

A high score on curiosity indicates that participants are interested in exploring the world of work and obtaining information on occupations and their requirements. A low score indicates that persons are not interested in obtaining career information. The mean score for curiosity is 4.33 (see Table 4.1), indicating moderate curiosity among participants (Savickas \& Portfeli, 2011). .

A high score on confidence indicates that participants have faith intheir own ability to make wise career decisions. The mean score for confidence is 4.05 (see Table 4.1), indicating moderate confidence amongst participants to make wise career decisions (Savickas \& Portfeli, 2011).

A high score on consultation means that participants want help from other people in making decisions about their careers - there is a low desire to make choices independently. A low score indicates that participants prefer to make career decisions without advice from others. The mean score for consultation is 2.51 (see Table 4.1), indicating a relatively low need for consultation amongst participants (Savickas \& Portfeli, 2011).

The CDSE was used to measure the perceived self-efficacy of participants in making wise career decisions. The instrument makes use of a 5 point Likert scale where scores indicate the level of perceived confidence of participants ranging from 1 (no confidence at all) to 5 (complete confidence). The mean score of 4.09 (see Table 4.1) indicates that participants have much confidence (Likert scale term used) in making career decisions (Betz \& Taylor, 2013).

The mean score on occupational information of 4.12 (see Table 4.1) indicates that participants have much confidence in their ability to obtain occupational information (Betz \& Taylor, 2013).

The mean score on goal selection of 4.10 (see Table 4.1) indicates that participants have much confidence in their ability to define goals for their career future (Betz \& Taylor, 2013). 
The mean score on planning of 4.19 (see Table 4.1) indicates that participants have much confidence in their ability to identify and execute the steps to take towards achieving career goals (Betz \& Taylor, 2013).

The mean score on problem solving of 3.87 (see Table 4.1) indicates that participants have moderate to much confidence in their ability to find alternatives or solutions when encountering problems on their career path or execution of their career plans (Betz \& Taylor, 2013).

The mean score on self appraisal of 4.19 (see Table 4.1) indicates that participants have much confidence in their ability to accurately assess their own abilities (Betz \& Taylor, 2013).

The MHS was used to measure hardiness of participants. The MHS makes use of a 4 point Likert scale from 0 (not at all true) to 3 (completely true). The mean score for total hardiness (see Table 4.1) was 2.60, which indicates that the perceived levels of hardiness is high among MSDS members. The means of the subscales in comparison with one another, were highest for commitment (2.72), followed by challenge (2.57) and then control (2.50) (Dolan \& Adler, 2006).

The SHP was used to measure life skills. The SHP makes use of a 6 point Likert scale from 1 (very poor) to 6 (outstanding). The mean score for total life skills of 4.97 (see Table 4.1) indicates that the perceived life skills of MSDS members in the sample are very good (Covey, n.d.). Mean scores on the sub-scales ranged from 4.82 to 5.21 with listening and teamwork having the lowest average scores and pro-active behaviour, mutual benefit thinking and continuous improvement having the highest average scores.

\subsection{INTERNAL RELIABILITY ANALYSIS OF SCALES}

According to Babbie (2010, p. 150) reliability involves “...that quality of a measurement method that suggests that the same data would have been collected each time in repeated observations of the same phenomena." A reliable instrument will yield a given measurement dependably. The choice of instruments used in this study is based on acceptable internal consistency ratings documented in the literature (see par 3.5). This suggested a potential for high ratings in the validity of the study. Breakwell, Hammond and Fife-Shaw (1998, p. 204) describes internal consistency as a type of analysis "...based on the principle that each part of the test should be consistent with all other parts". 
The early approach to internal consistency analysis was Spearman's split-half reliability coefficient. Kuder and Richardson improved on this approach by calculating a formula to give an average of all the possible split-half combinations. Cronbach generalised the Kuder Richardson formula for use with items measured on continuous or rating scales and this came to be known as Cronbach's Alpha (Breakwell, et al., 1998). According to Babbie (2010), the value of Cronbach's Alpha can be classified on a reliability index classification where .90-1.00 is very high, .70-.89 is high, .30-.69 is moderate, and .00 to .30 is low. The number of items in a test affects the reliability and it can be expected that a small number of items will yield lower alpha's (Breakwell, et al., 1998). Cronbach's Alpha values were calculated for the internal reliability analyses of the measures used in this study.

Item analyses were performed on the different measures and its subscales.

- CMI: Item 2 ('I know very little about the requirements of jobs') in the curiosity subscale of the CMI was flagged as a poor item. Statistical analysis showed that the alpha increased from .73 to .78 if the item is deleted. The possible reason for the item being poor is that it seems to assess general knowledge regarding the requirements of all jobs. A person may not be interested in knowing the requirements of jobs in general, but rather having curiosity in the fields or jobs that are perceived as future options.

- CDSE: Item 16 (the confidence to 'make a career decision and then not worry whether it was right or wrong') in the goal selection subscale of the CDSE was flagged as a poor item. Statistical analysis showed that the alpha increased from .47 to .63 if the item is deleted. The possible reason for the item being poor is that it seems to assess internal reflection on a decision being right or wrong, rather than being able to select realistic goals.

Item 18 (the confidence to 'figure out what you are and are not ready to sacrifice to achieve your career goals') in the self appraisal subscale of the CDSE was also flagged as a poor item. Statistical analysis showed that the alpha increased from .57 to .63 if the item is deleted. The possible reason for the item being poor is that it seems to assess personal values (what would you sacrifice?) rather than accurate self-appraisal (being able to assess one's own abilities and what type of job would suit you). 
- MHS: Item 7 in the commitment subscale ('How I do in my job influences how I feel.') was flagged as a poor item. Statistical analysis showed that the alpha increased from .61 to .68 if the item is deleted. The possible reason for the poor item is that respondents could focus on things that would influence their feelings, rather than considering how important their job or contribution to the organisation is.

- SHP: Item 10 in the life goals subscale ('I know what I want to accomplish in life') was flagged as a poor item. Statistical analysis showed that the alpha increased from .52 to .57 if the item is deleted. The possible reason for the item appearing to be poor is that the other two items in this subscale ('I organize and prepare in a way that reduces having to work in a crisis mode' and 'I begin each week with aclear plan of what I desire to accomplish'), seem to focus more on working in a structured manner to achieve short term goals than on life goals. It was decided not to delete item 10.

The measures that were used for this study are recognised instruments. It was decided not to remove the poor items discussed above and to continue with the statistical analyses as the purpose of this study was not to psychometrically validate the instruments.

Table 4.2 shows the internal reliability of all the scales and subscales by reporting the Cronbach's alphas. A discussion on the reliability coefficients for the scales follows the presentation of the alphas in Table 4.2. 
Table 4.2

Internal Reliability of Scales and Subscales

\begin{tabular}{|c|c|}
\hline Scale & Cronbach's Alpha \\
\hline Career Maturity Inventory - Revised (short form) (total) & .71 \\
\hline Concern & .50 \\
\hline Curiosity & .73 \\
\hline Confidence & .80 \\
\hline Consultation & .67 \\
\hline Career Decision Self-efficacy (total) & .84 \\
\hline Occupational information & .56 \\
\hline Goal selection & .47 \\
\hline Planning & .67 \\
\hline Problem solving & .55 \\
\hline Self appraisal & .57 \\
\hline Military hardiness (total) & .67 \\
\hline Commitment & .61 \\
\hline Challenge & .49 \\
\hline Control & .71 \\
\hline Seven habits profile (total) & .89 \\
\hline Conscientiousness & .62 \\
\hline Life balance & .56 \\
\hline Pro-active & .56 \\
\hline Life goals & .52 \\
\hline Self management & .68 \\
\hline Mutual benefit thinking & .76 \\
\hline Listening & .71 \\
\hline Teamwork & .69 \\
\hline Continuous improvement & .47 \\
\hline
\end{tabular}


The subscales of the CMI-R yielded significant reliability coefficients from .50 to .80 and a total scale reliability coefficient of .71. Although concern and consultation yielded lower alphas, these scales were kept for further statistical analysis. The curiosity and confidence subscales yielded good alphas.

The subscales of the CDSE yielded significant reliability coefficients from .55 to .67 and a total scale reliability coefficient of .84. All five of the subscales had alphas lower than .70, but it was decided to keep these scales for further statistical analyis.

The subscales of the MHS yielded significant reliability coefficients from .49 to .71 and a total scale reliability coefficient of .67. The challenge subscale had the lowest alpha of .49, but it was decided to still proceed with further statistical analysis as all the item total correlation values were $>.01$ and positive.

The subscales of the SHP yielded significant reliability coefficients from .47 to .76 and a total scale reliability coefficient of $\mathbf{. 8 9}$. The continuous improvement subscale had the lowest alpha of .47. It was decided to keep this subscale for further statistical analysis as all the item total correlation values were $>.01$ and positive. The subscales with low alphas were kept considering the explanation by Breakwell, et al. (1998) that scales with few items may yield low alpha's.

\subsection{INFERENTIAL STATISTICS}

Inferential statistics are defined by Babbie (2010, p. 476) as "statistical computations relevant to making inferences from findings based on sample observations to some larger population". This section will discuss the results of correlations between the dependent variable and independent variables (predictors) followed by multiple regression analysis to provide information on the relationship between multiple predictor variables and the dependent variable.

\subsubsection{Correlations}

Regression analysis allows one to find out if one or more variables can predict an outcome variable (dependent variable). Regression can also determine the amount of variance in one variable which can be explained by other variables (Hanna \& Dempster, 2012). Hanna and Dempster, (2012, p. 190) define correlation coefficients as a "numerical way of expressing a linear relationship or a standardised way to report how the variables co-vary." 
The correlation coefficient indicates the strenght of the correlation as well as the direction of the relationship (positive or negative). The Pearson product-moment correlation coefficient was applied to investigate the relationships between the variables and to use these results to accept or reject the hypotheses of this study (see par 3.2).

Correlation coefficients are reported on a scale between 0 and 1. Hanna and Dempster (2012) provide guidelines for interpretation of the correlation coefficient: 1 indicates a weak relationship, .3 a moderate effect and .5 to 1 indicates a large effect. For the purpose of this study, hypotheses with moderate or large correlations were accepted and those below .2 were rejected. Table 4.3 provides a summary of the correlations between the independent and dependent variables.

Table 4.3

Correlation Coefficient Results for Hypothesised Relationships Between Variables

\begin{tabular}{llll}
\hline Independent Variable & Dependent Variable & Pearson r & Pearson p-value \\
\hline CDSE (total) & CM (total) & .39 & $<.01$ \\
Self-appraisal & CM (total) & .27 & $<.01$ \\
Occupational information & CM (total) & .29 & $<.01$ \\
Goal selection & CM (total) & .31 & $<.01$ \\
Planning & CM (total) & .33 & $<.01$ \\
Problem solving & CM (total) & .33 & $<.01$ \\
Hardiness (total) & CM (total) & .19 & $<.01$ \\
Commitment & CM (total) & .24 & $<.01$ \\
Control & CM (total) & .17 & $<.01$ \\
Challenge & CM (total) & .05 & .37 \\
Life skills (total) & CM (total) & .24 & $<.01$ \\
Conscientiousness & CM (total) & .20 & $<.01$ \\
Life balance & CM (total) & .16 & $<.01$ \\
Pro-active behaviour & CM (total) & .16 & $<.01$ \\
Life goals & CM (total) & .24 & $<.01$ \\
Self-management & CM (total) & .21 & $<.01$ \\
Mutual benefit thinking & CM (total) & .17 & $<.01$ \\
Listening & CM (total) & .15 & $<.01$ \\
Teamwork & CM (total) & .19 & $<.01$ \\
Continuous improvement & CM (total) & .04 & .46 \\
\hline
\end{tabular}

All the correlations were relatively low (none above .39), but all were positive and had low $p$ values (except two factors challenge and continuous improvement). It was decided to accept Pearson $r$ values of .2 and higher for the present study. 
$\mathrm{H} 1$ : There is a significant and positive relationship between total career decision self-efficacy (CDSE) and CM.

A total of 314 responses were returned, but four responses were removed from the dataset due to incomplete data. Subsequently, a dataset of 310 responses were analysed for the relationship between CDSE and CM. This sample size remains the same for all the hypotheses tested. The results of the analysis in Table 4.3 show a moderate significant positive correlation between CDSE and CM ( $r=.39 ; p<.01)$. $\mathrm{H} 1$ was accepted. Figure 4.6 presents the relationship between CDSE and CM in the form of a scatter-plot.

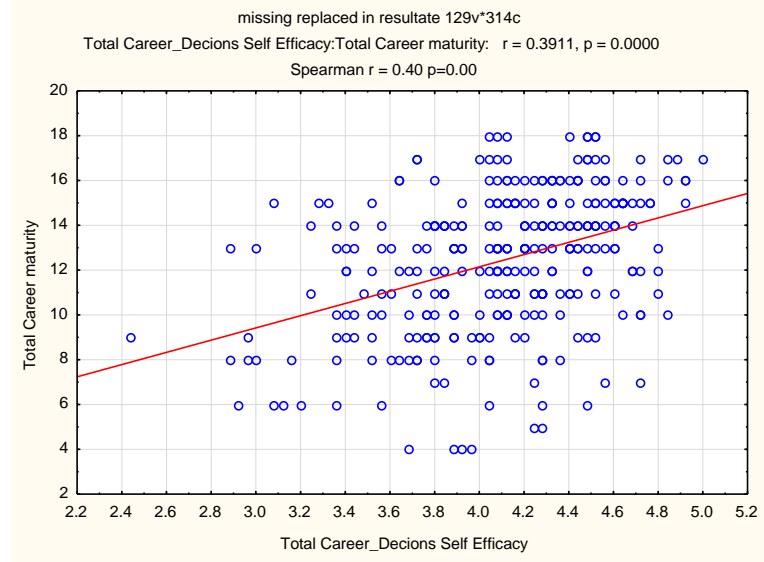

Figure 4.6 The Relationship Between Career Decision Self-efficacy and CM

$\mathrm{H} 2$ : There is a significant and positive relationship between self-appraisal and CM.

The results of the analysis in Table 4.3 show a moderate significant positive correlation between self-appraisal and $\mathrm{CM}(r=.27 ; p<.01)$. $\mathrm{H} 2$ was accepted. Figure 4.7 presents the relationship between self-appraisal and CM in the form of a scatter-plot.

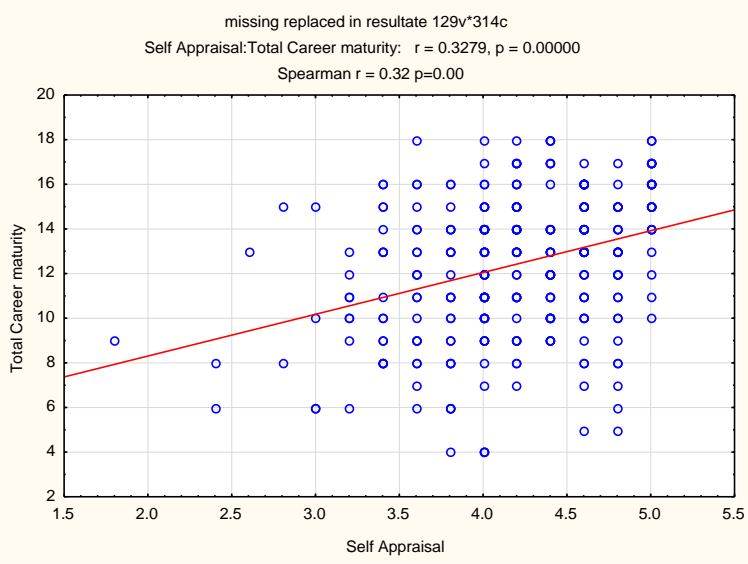

Figure 4.7 The Relationship Between Self-appraisal and CM 
H3: There is a significant and positive relationship between seeking occupational information and $\mathrm{CM}$.

The results of the analysis in Table 4.3 show a moderate significant positive correlation between occupational information and $\mathrm{CM}(\mathrm{r}=.29 ; \mathrm{p}<.01)$. $\mathrm{H} 3$ was accepted. Figure 4.8 presents the relationship between occupational information and $\mathrm{CM}$ in the form of a scatter-plot.

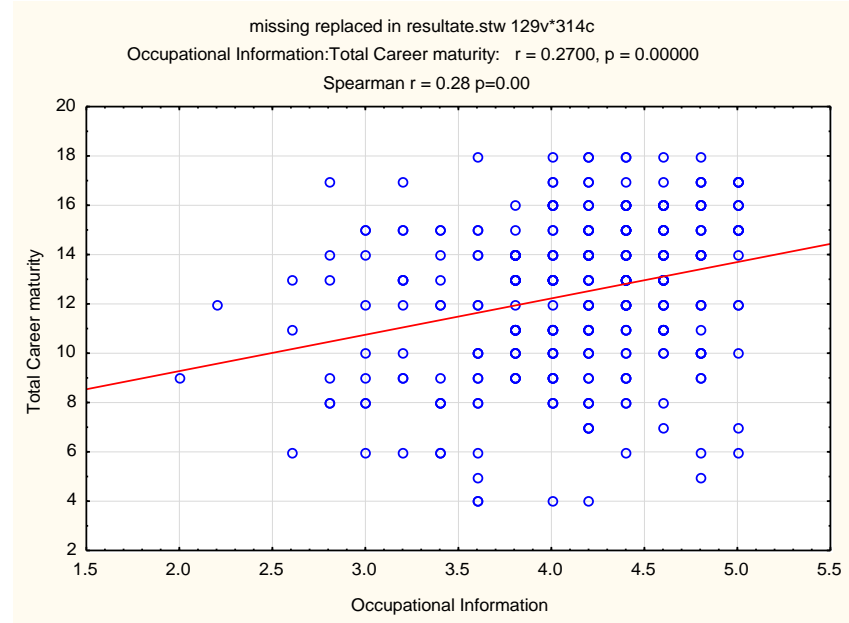

Figure 4.8 The Relationship Between Seeking Occupational Information and CM

$\mathrm{H} 4$ : There is a significant and positive relationship between goal selection and CM.

The results of the analysis in Table 4.3 shows a moderate significant positive correlation between goal selection and $\mathrm{CM}(\mathrm{r}=.31 ; \mathrm{p}<.01)$. $\mathrm{H} 4$ was accepted. Figure 4.9 presents the relationship between goal selection and $\mathrm{CM}$ in the form of a scatter-plot.

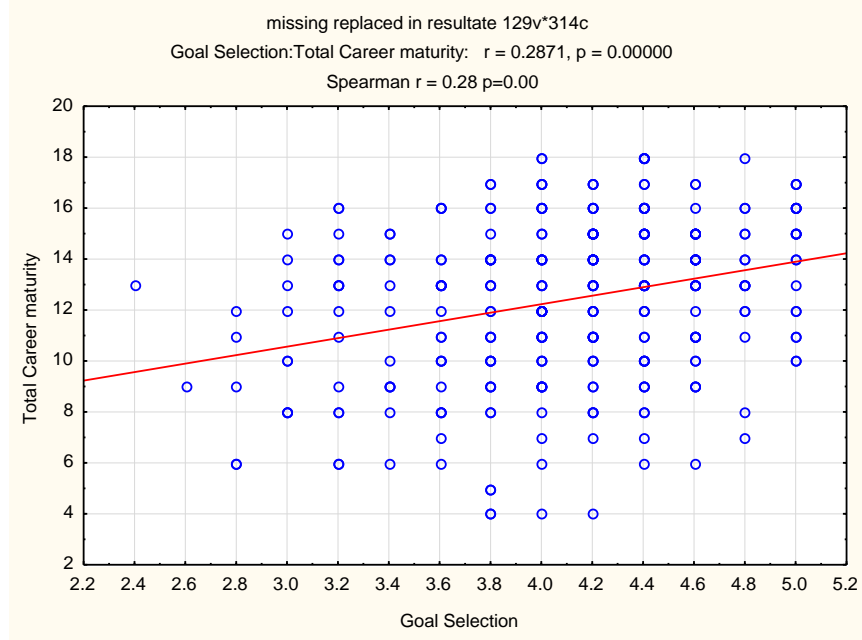

Figure 4.9 The Relationship Between Goal Selection and CM 
$\mathrm{H} 5$ : There is a significant and positive relationship between planning and $\mathrm{CM}$.

The results of the analysis in Table 4.3 show a moderate significant positive correlation between planning and $\mathrm{CM}(\mathrm{r}=.33 ; \mathrm{p}<.01)$. $\mathrm{H} 5$ was accepted. Figure 4.10 presents the relationship between planning and $\mathrm{CM}$ in the form of a scatter-plot.

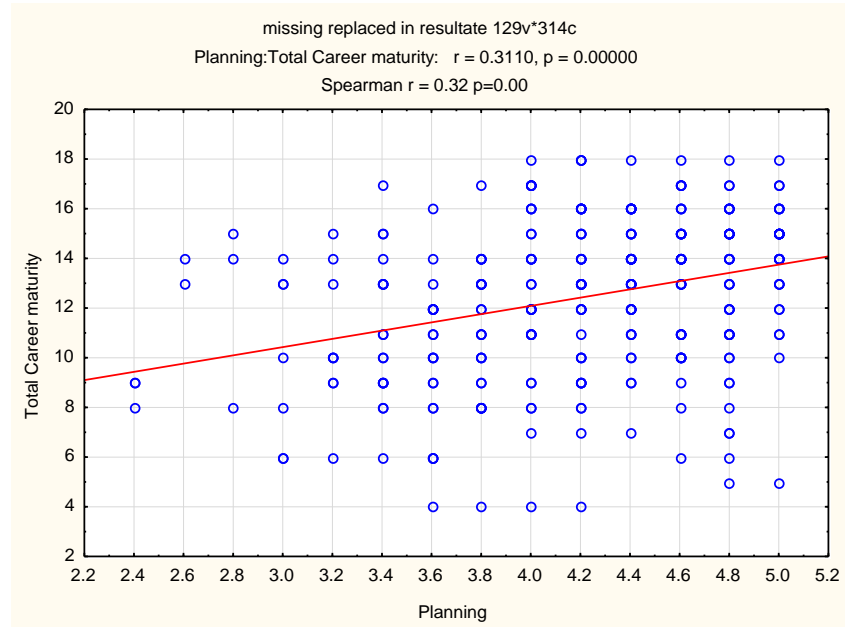

\section{Figure 4.10 The Relationship Between Planning and CM}

H6: There is a significant and positive relationship between problem solving and CM.

The results of the analysis in Table 4.3 show a moderate significant positive correlation between problem solving and $\mathrm{CM}(\mathrm{r}=.33 ; \mathrm{p}<.01)$. $\mathrm{H} 6$ was accepted. Figure 4.11 presents the relationship between problem solving and $\mathrm{CM}$ in the form of a scatter-plot.

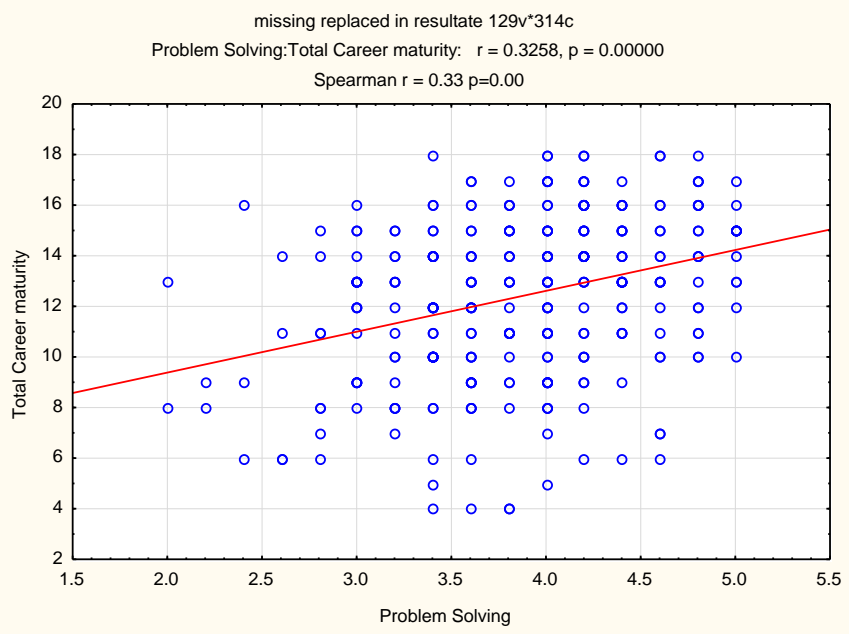

Figure 4.11 The Relationship Between Problem Solving and CM 
$\mathrm{H7}$ : There is a significant and positive relationship between total hardiness and CM.

The results of the analysis in Table 4.3 show a weak positive correlation between hardiness and $\mathrm{CM}(r=.19 ; p<.01)$. H7 was rejected. Figure 4.12 presents the relationship between hardiness and $\mathrm{CM}$ in the form of a scatter-plot.

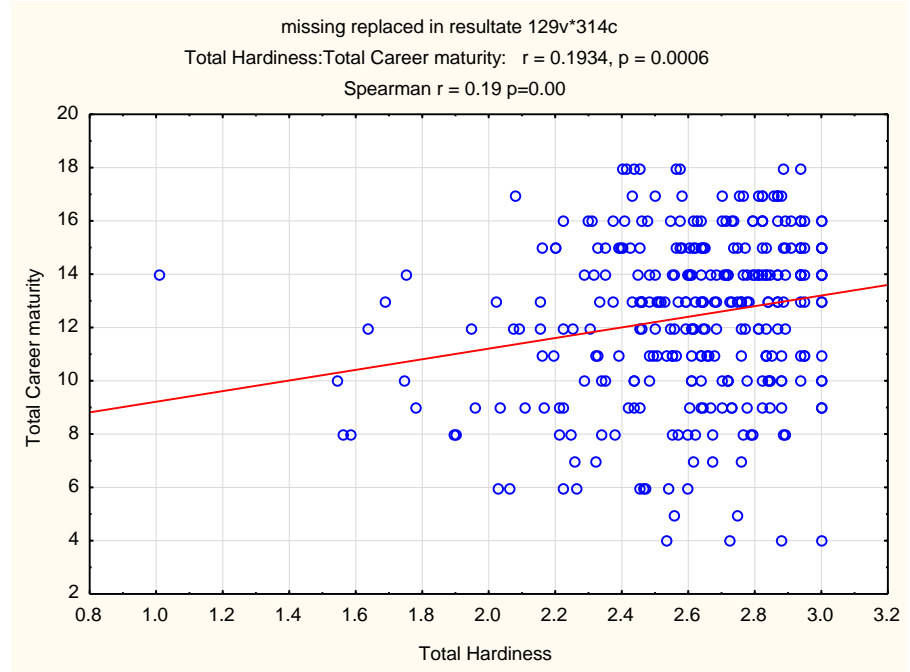

Figure 4.12 The Relationship Between Hardiness and CM

H8: There is a significant and positive relationship between control and CM.

The results of the analysis in Table 4.3 show a weak positive correlation between control and $\mathrm{CM}(r=.17 ; p<.01)$. H8 was rejected. Figure 4.13 presents the relationship between control and $\mathrm{CM}$ in the form of a scatter-plot.

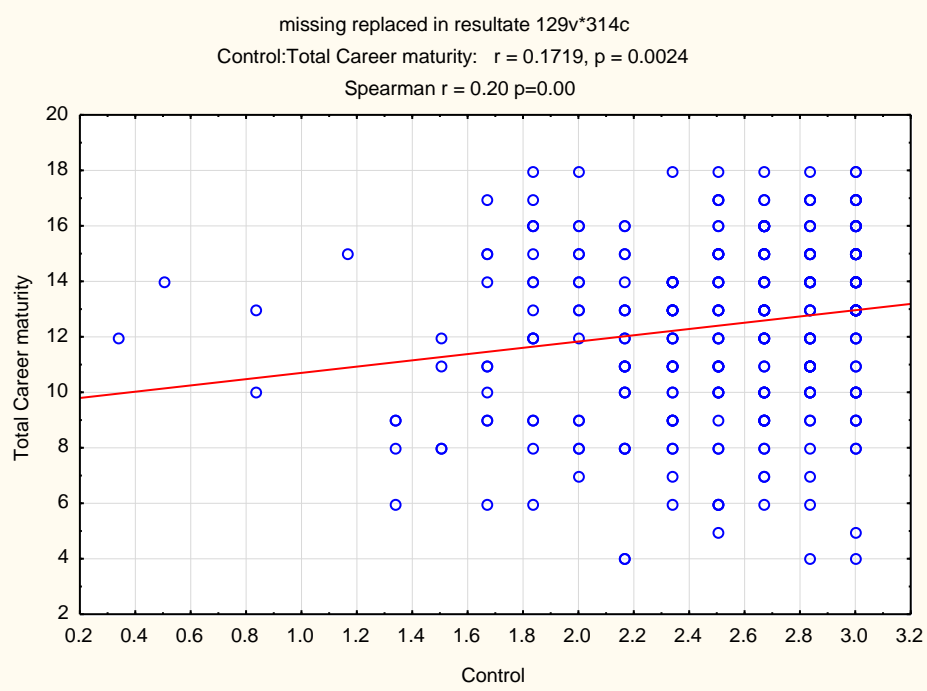

Figure 4.13 The Relationship Between Control and CM 
H9: There is a significant and positive relationship between commitment and CM.

The results of the analysis in Table 4.3 show a moderate significant positive correlation between commitment and $\mathrm{CM}(\mathrm{r}=.24 ; \mathrm{p}<.01)$. H9 was accepted. Figure 4.14 presents the relationship between commitment and $\mathrm{CM}$ in the form of a scatter-plot.

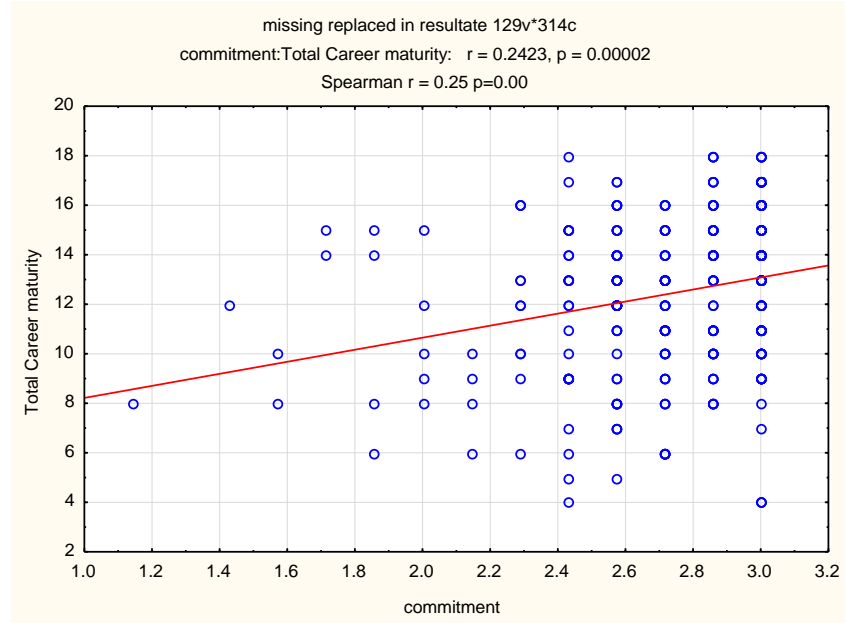

Figure 4.14 The Relationship Between Commitment and CM

$\mathrm{H} 10$ : There is a significant and positive relationship between challenge and $\mathrm{CM}$.

The results of the analysis in Table 4.3 show a very weak positive correlation between challenge and $\mathrm{CM}(\mathrm{r}=.05 ; \mathrm{p}=.37)$. $\mathrm{H} 10$ was rejected. Figure 4.15 presents the relationship between challenge and $\mathrm{CM}$ in the form of a scatter-plot.

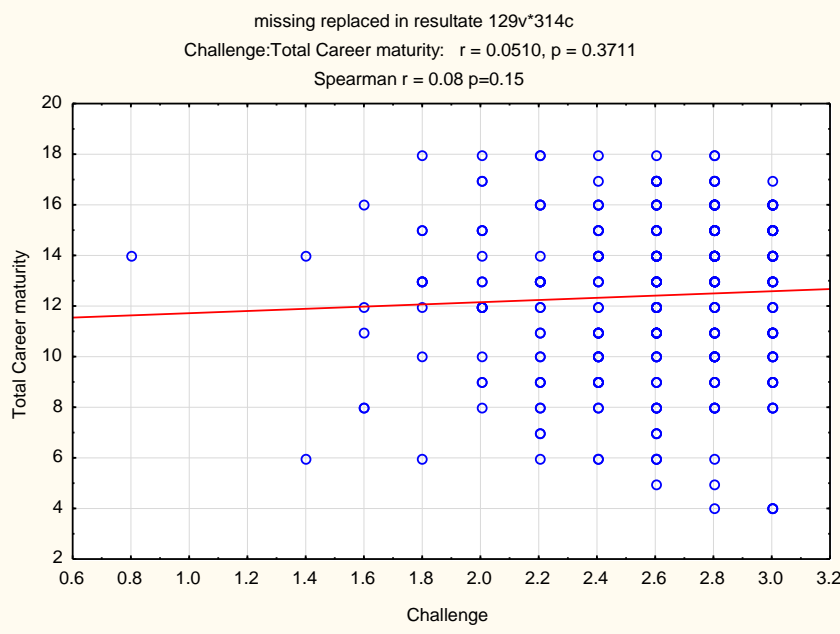

Figure 4.15 The Relationship Between Challenge and CM 
$\mathrm{H} 11$ : There is a significant and positive relationship between total life skills and CM.

The results of the analysis in Table 4.3 show a moderate significant positive correlation between life skills and $\mathrm{CM}(\mathrm{r}=.24 ; \mathrm{p}<.01)$. H11 was accepted. Figure 4.16 presents the relationship between life skills and $\mathrm{CM}$ in the form of a scatter-plot.

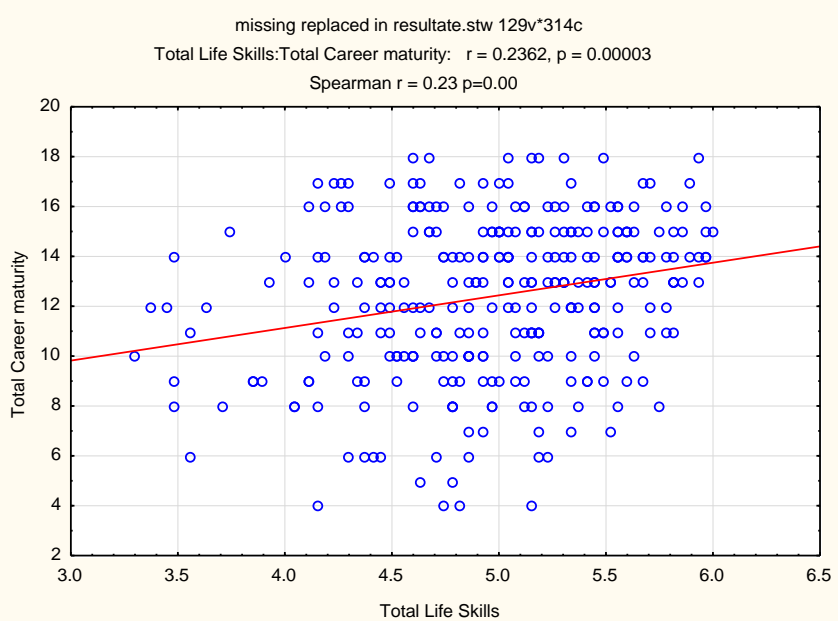

Figure 4.16 The Relationship Between Life Skills and CM

$\mathrm{H} 12$ : There is a significant and positive relationship between conscientiousness and CM.

The results of the analysis in Table 4.3 show a moderate significant positive correlation between conscientiousness and $\mathrm{CM}(\mathrm{r}=.20 ; \mathrm{p}<.01)$. $\mathrm{H} 12$ was accepted. Figure 4.17 presents the relationship between conscientiousness and $\mathrm{CM}$ in the form of a scatter-plot.

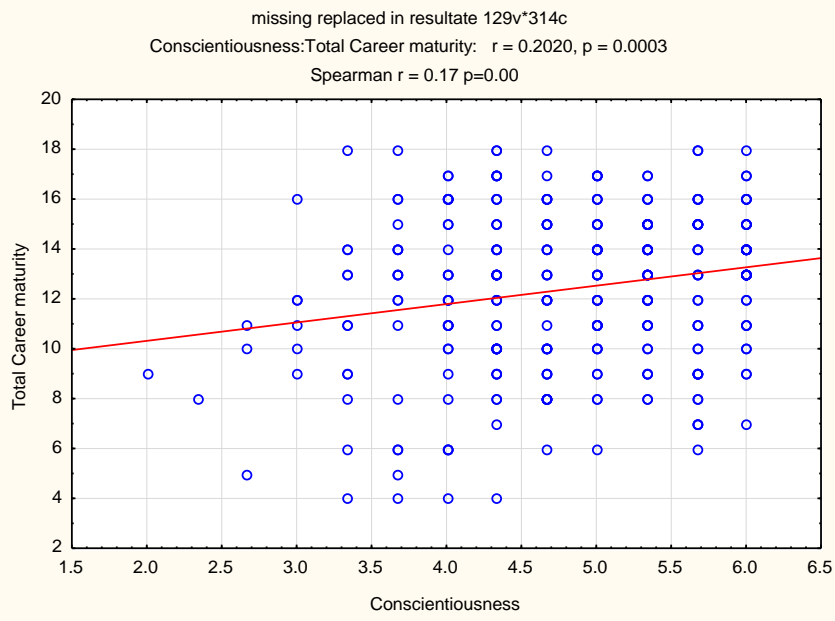

Figure 4.17 The Relationship Between Conscientiousness and CM 
H13: There is a significant and positive relationship between life balance and CM.

The results of the analysis in Table 4.3 show a weak positive correlation between life balance and $\mathrm{CM}(\mathrm{r}=.16 ; \mathrm{p}<.01)$. H13 was rejected. Figure 4.18 presents the relationship between life balance and $\mathrm{CM}$ in the form of a scatter-plot.

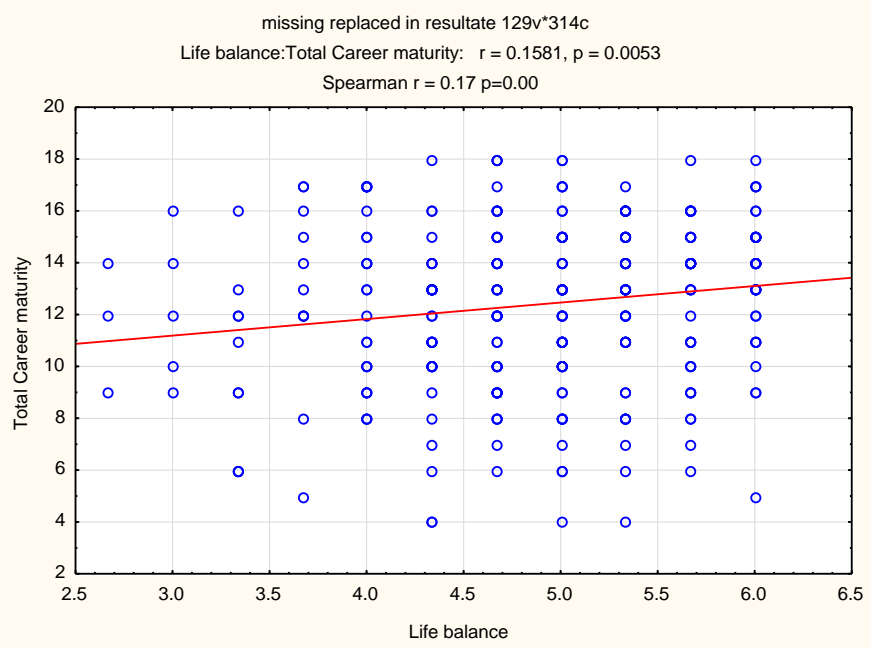

Figure 4.18 The Relationship Between Life Balance and CM

$\mathrm{H} 14$ : There is a significant and positive relationship between pro-active behaviour and CM.

The results of the analysis in Table 4.3 show a weak positive correlation between pro-active behaviour and $\mathrm{CM}(\mathrm{r}=.16 ; \mathrm{p}<.01)$. $\mathrm{H} 14$ was rejected. Figure 4.19 presents the relationship between pro-active behaviour and CM in the form of a scatter-plot.

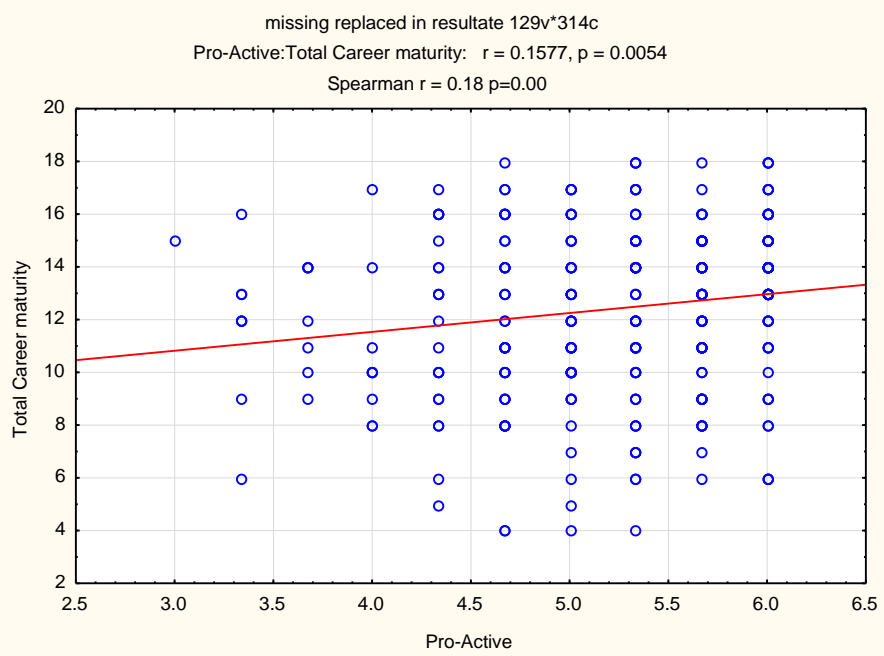

Figure 4.19 The Relationship Between Pro-active Behaviour and CM 
H15: There is a significant and positive relationship between life goals and CM.

The results of the analysis in Table 4.3 show a moderate significant positive correlation between life goals and $\mathrm{CM}(\mathrm{r}=.24 ; \mathrm{p}<.01)$. H15 was accepted. Figure 4.20 presents the relationship between life goals and $\mathrm{CM}$ in the form of a scatter-plot.

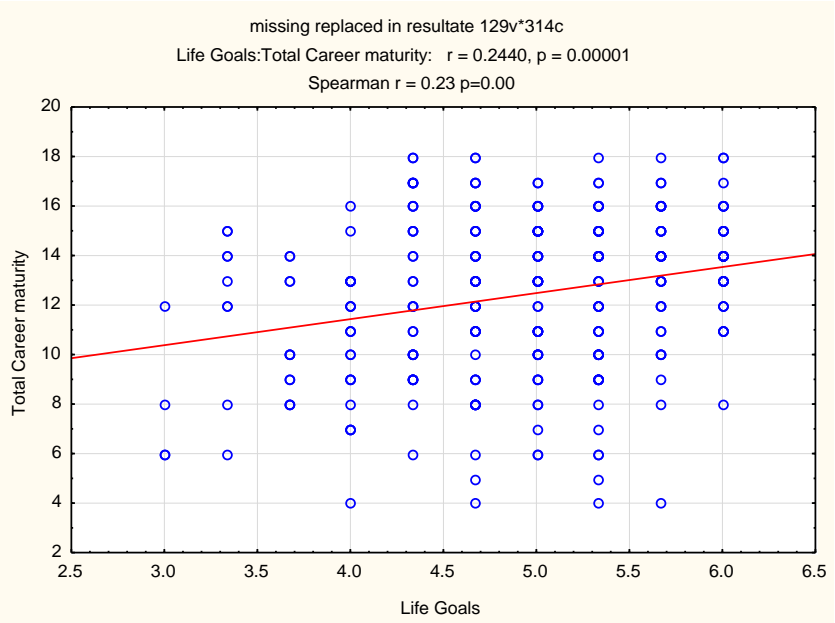

\section{Figure 4.20 The Relationship Between Life Goals and CM}

H16: There is a significant and positive relationship between self-management and CM.

The results of the analysis in Table 4.3 show a moderate significant positive correlation between self-management and $\mathrm{CM}(\mathrm{r}=.21 ; \mathrm{p}<.01)$. H16 was accepted. Figure 4.21 presents the relationship between self-management and $\mathrm{CM}$ in the form of a scatter-plot.

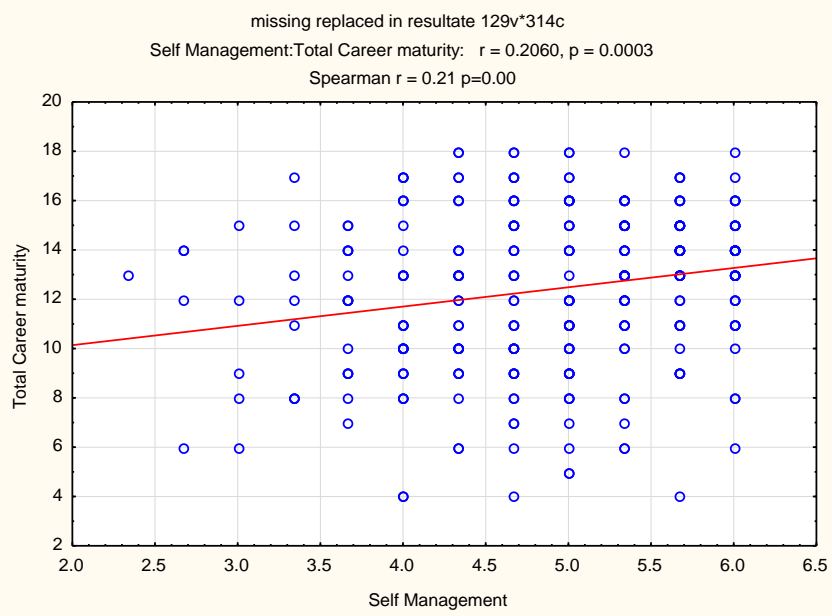

Figure 4.21 The Relationship Between Self management and CM 
$\mathrm{H} 17$ : There is a significant and positive relationship between mutual benefit thinking and CM.

The results of the analysis in Table 4.3 show a weak positive correlation between mutual benefit thinking and $\mathrm{CM}(\mathrm{r}=.17 ; \mathrm{p}<.01)$. $\mathrm{H} 17$ was rejected. Figure 4.22 presents the relationship between mutual benefit thinking and CM in the form of a scatter-plot.

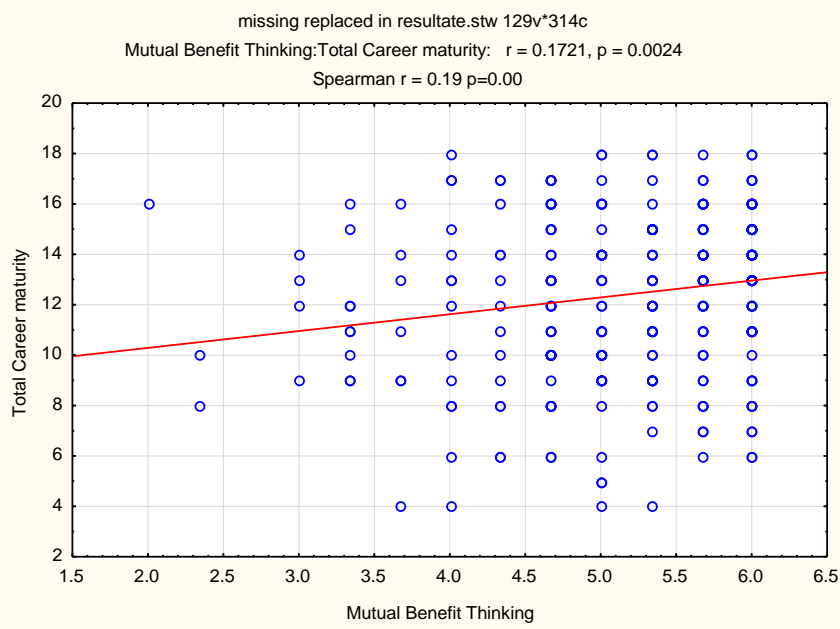

Figure 4.22 The Relationship Between Mutual Benefit Thinking and CM

$\mathrm{H} 18$ : There is a significant and positive relationship between listening and CM.

The results of the analysis in Table 4.3 show a weak positive correlation between listening and $\mathrm{CM}(r=.15 ; p<.01)$. H18 was rejected. Figure 4.23 presents the relationship between listening and $\mathrm{CM}$ in the form of a scatter-plot.

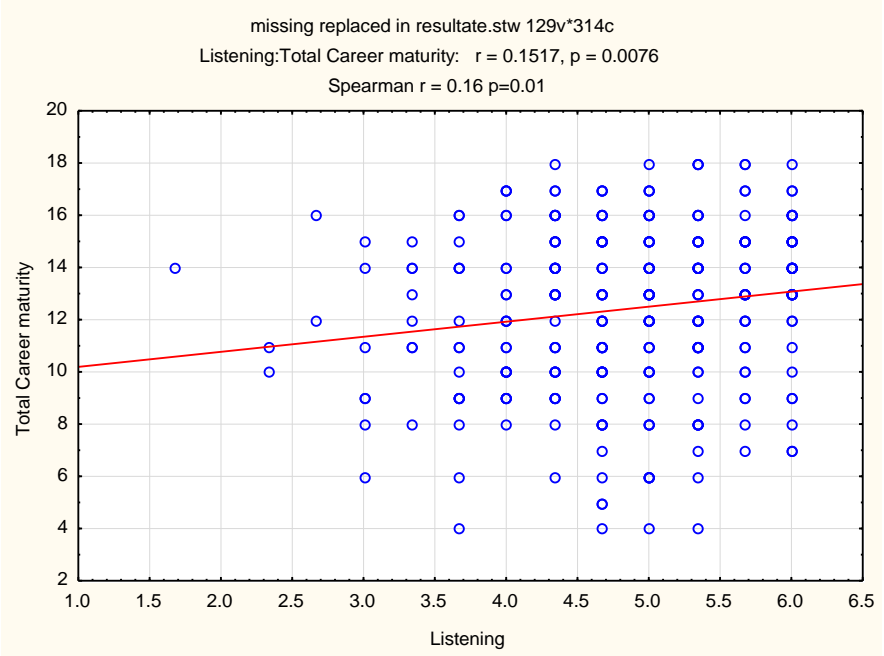

Figure 4.23 The Relationship Between Listening and CM 
$\mathrm{H} 19$ : There is a significant and positive relationship between teamwork and CM.

The results of the analysis in Table 4.3 show a weak positive correlation between teamwork and $\mathrm{CM}(\mathrm{r}=.19 ; \mathrm{p}<.01)$. H19 was rejected. Figure 4.24 presents the relationship between teamwork and $\mathrm{CM}$ in the form of a scatter-plot.

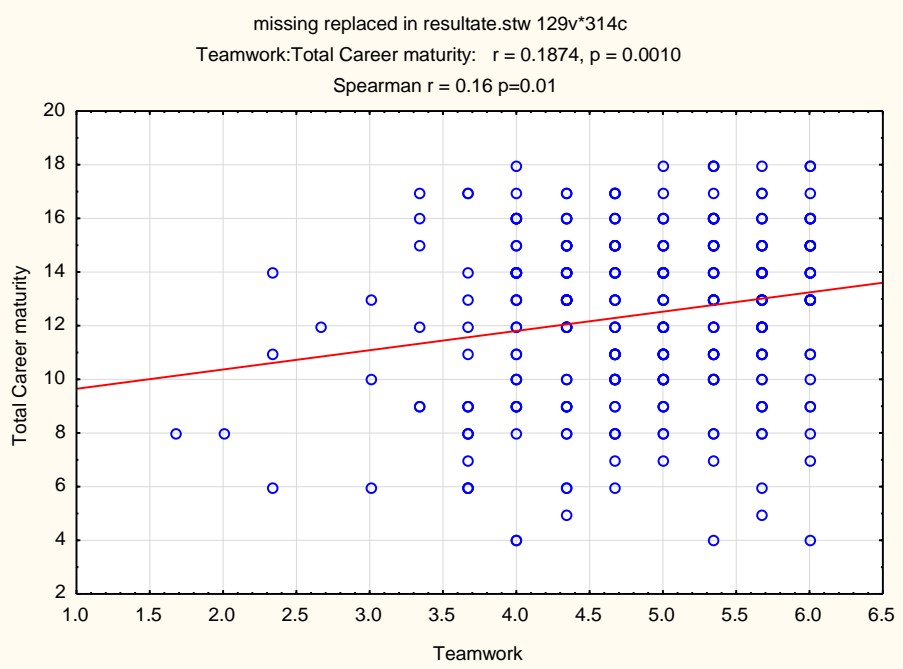

Figure 4.24 The Relationship Between Teamwork and CM

$\mathrm{H} 20$ : There is a significant and positive relationship between continuous improvement and CM.

The results of the analysis in Table 4.3 show a very weak positive correlation between continuous improvement and $\mathrm{CM}(\mathrm{r}=.04 ; \mathrm{p}=.46)$. H2O was rejected. Figure 4.25 presents the relationship between continuous improvement and $\mathrm{CM}$ in the form of a scatter-plot.

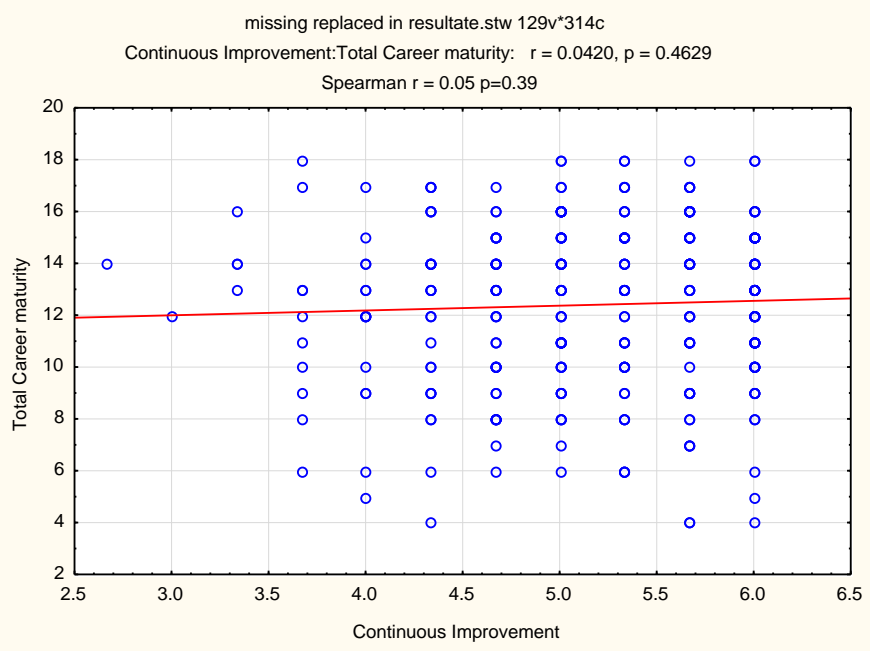

Figure 4.25 The Relationship Between Continuous Improvement and CM 
A summary of the accepted hypotheses include the following:

$\mathrm{H} 1$ : There is a significant and positive relationship between total career decision self-efficacy (CDSE) and CM.

$\mathrm{H} 2$ : There is a significant and positive relationship between self-appraisal and CM.

H3: There is a significant and positive relationship between seeking occupational information and $\mathrm{CM}$.

$\mathrm{H} 4$ : There is a significant and positive relationship between goal selection and $\mathrm{CM}$.

$\mathrm{H} 5$ : There is a significant and positive relationship between planning and CM.

H6: There is a significant and positive relationship between problem solving and CM.

H9: There is a significant and positive relationship between commitment and CM.

$\mathrm{H} 11$ : There is a significant and positive relationship between total life skills and CM.

$\mathrm{H} 12$ : There is a significant and positive relationship between conscientiousness and CM.

H15: There is a significant and positive relationship between life goals and CM.

$\mathrm{H} 16$ : There is a significant and positive relationship between self-management and CM.

\subsubsection{Multiple regression analysis}

Correlation does not imply causation and can therefore only enable the researcher to make weak causal inferences at best (http://www.education.com/refernce/article/correlationalresearch/). Breakwell et al. (1998) explain that covariance between the independent variables has an impact on the relationship of each seperate independent variable (predictor) on the dependent variable (criterion). Multiple regression analysis uses partitioning of variance to find the optimal prediction of one variable from among a number of predictors (Breakwell et al., 1998). 
Multiple regression is done to obtain "the relationship between each predictor and the criterion, after controlling the effect of all other predictors in the model" (Hanna \& Dempster, 2012, p. 223). Multiple regression analysis was performed, with inclusion of all the scales and subscales of the originally proposed model (see Figure 2.3), in order to identify the best set of predictor variables for the proposed diagnostic model of CM of the MSDS members.

The summary statistics for the whole regression model is presented in Table 4.4. for the scales (totals) and Table 4.5 for the subscales. These statistics are explained, followed by the regression summary for the dependent variable (and all the predictors) in Table 4.6.

Table 4.4

Summary Statistics for the Dependent Variable Scales

\begin{tabular}{ll}
\hline Statistics & Value \\
\hline Multiple $\mathrm{R}$ & .41 \\
Multiple $\mathrm{R}^{2}$ & .17 \\
Adjusted $\mathrm{R}^{2}$ & .16 \\
$\mathrm{~F}(3,304)$ & 20.53 \\
$\mathrm{P}$ & $<.01$ \\
Std error estimate & 2.88 \\
\hline
\end{tabular}

The multiple coefficient of determination $\left(\mathrm{R}^{2}\right)$ of the variation in the dependent variable (CM) shown in Table 4.4, accounted for by the predictor variables (career decision self-efficacy, hardiness and life skills), is .17. This means that approximately 17 percent of the variability of $\mathrm{CM}$ is explained by a combination of all the predictor variables (total scales) in the model. The adjusted multiple coefficient of determination (Adjusted $\mathrm{R}^{2}$ ) takes into account the number of predictors in the model; the value of .16 means that approximately 16 percent of the variability of $\mathrm{CM}$ is accounted for by the model. The $\mathrm{p}$-value explains the confidence of each predictor in relation to the criterion. The $p$-value for the whole regression was statistically significant $(<.01)$. 
Table 4.5

Summary Statistics for the Dependent Variable Subscales

\begin{tabular}{ll}
\hline Statistics & Value \\
\hline Multiple R & .46 \\
Multiple $\mathrm{R}^{2}$ & .21 \\
Adjusted $\mathrm{R}^{2}$ & .29 \\
$\mathrm{~F}(17,290)$ & 4.55 \\
$\mathrm{P}$ & $<.01$ \\
Std error estimate & 2.87 \\
\hline
\end{tabular}

The multiple coefficient of determination $\left(R^{2}\right)$ of the variation in the dependent variable $(C M)$ shown in Table 4.5, accounted for by the predictor variables (Occupational Information, Goal Selection, Planning, Problem-Solving, Self-Appraisal, Commitment, Challenge, Control, Conscientiousness, Life balance, Pro-Active, Life Goals, Self Management, Mutual Benefit Thinking, Listening, Teamwork, Continuous Improvement) is .21. This means that approximately 21 percent of the variability of $\mathrm{CM}$ is explained by a combination of all the predictor variables (subscales) in the model. The adjusted multiple coefficient of determination (Adjusted $\mathrm{R}^{2}$ ) takes into account the number of predictors in the model; the value of 29 means that approximately 29 percent of the variability of $\mathrm{CM}$ is accounted for by the model. The $\mathrm{p}$ value explains the confidence of each predictor in relation to the criterion. The $p$-value for the whole regression was statistically significant $(<.01)$

The differences in the summary statistics for the scales in Table 4.4 (total CDSE, hardiness and life skills) and the subscales in Table 4.5, gives an indication that the various subscales (as factors of $\mathrm{CM}$ ) provide a better explanation for the variability of $\mathrm{CM}$ than the totals only.

The results of the evaluation of the impact of each predictor on the criterion after controlling the effect of all other predictors in the model are presented in Table 4.6 (for the total scales) and Table 4.7 (for the subscales) by reporting the standardised coefficients. 
Table 4.6

Standardised Coefficients for Total Scales $(N=310)$

\begin{tabular}{lllll}
\hline Independent variable & Beta $(\boldsymbol{\beta})$ & Std Err ofBeta $(\boldsymbol{\beta})$ & t-value & p-value (sig) \\
\hline CDSE (total) & .37 & .60 & 6.11 & .00 \\
Hardiness (total) & .07 & .06 & 1.20 & .22 \\
Life skills (total) & .03 & .06 & .39 & .69 \\
\hline
\end{tabular}

When looking at the beta values of the total scales in Table 4.6 compared to the beta values of the subscales in Table 4.7, one reaches the conclusion that identifying the significant subscale predictors provides a realistic set of significant predictors, while the beta values in Table 4.6 suggest that only self-efficacy is a significant predictor of CM in this study.

Table 4.7

Standardised Coefficients for Subscales ( $N=310)$

\begin{tabular}{lllll}
\hline Independent variable & Beta $(\boldsymbol{\beta})$ & Std Err ofBeta $(\boldsymbol{\beta})$ & t-value & p-value (sig) \\
\hline Self-appraisal & .15 & .07 & 1.95 & .05 \\
Occupational information & .13 & .07 & 1.99 & .05 \\
Goal selection & .05 & .07 & .79 & .44 \\
Planning & .05 & .08 & .70 & .49 \\
Problem solving & .10 & .07 & 1.47 & .14 \\
Commitment & .12 & .07 & 1.82 & .07 \\
Challenge & .13 & .06 & 2.13 & .03 \\
Control & .06 & .07 & .97 & .33 \\
Conscientiousness & .12 & .07 & 1.85 & .07 \\
Life balance & .09 & .07 & 1.24 & .21 \\
Pro-active behaviour & .03 & .07 & .41 & .69 \\
Life goals & .03 & .08 & .32 & .75 \\
Self-management & .01 & .07 & .15 & .88 \\
Mutual benefit thinking & .05 & .08 & .66 & .51 \\
Listening & .00 & .08 & .04 & .97 \\
Teamwork & .02 & .08 & .22 & .83 \\
Continuous improvement & .11 & .63 & 1.72 & .09 \\
\hline
\end{tabular}


Standardised regression coefficients express the same relationship in standard deviation units, in order to predict how strongly each predictor variable influences the criterion. The higher the beta value, the greater the impact of the predictor variable on the criterion variable. A large tvalue and a small p-value (sig) is an indication of a good predictor (Menard, 2014).

A p-value below .05 means that the predictor is making a significant contribution at a 5 percent level of significance and a $p$-value below .10 means that the predictor is making a significant contribution at the 10 percent level of significance (Breakwell et al., 1998). For the purposes of this study, $p$-values below .10 was accepted as significant.

Evaluation of the predictor variables on the basis of the beta values, t-values and $p$-values, indicated that the following factors have a significant impact on the dependent variable (CM):

- Self-Efficacy

- Occupational Information

- Self-Appraisal

- Commitment

- Challenge

- Conscientiousness (conscientiousness)

- Continuous improvement.

The statistical analyses on the factors in the proposed diagnostic model (see Figure 2.3), have resulted in the model for the most significant factors influencing CM presented in Figure 4.26.

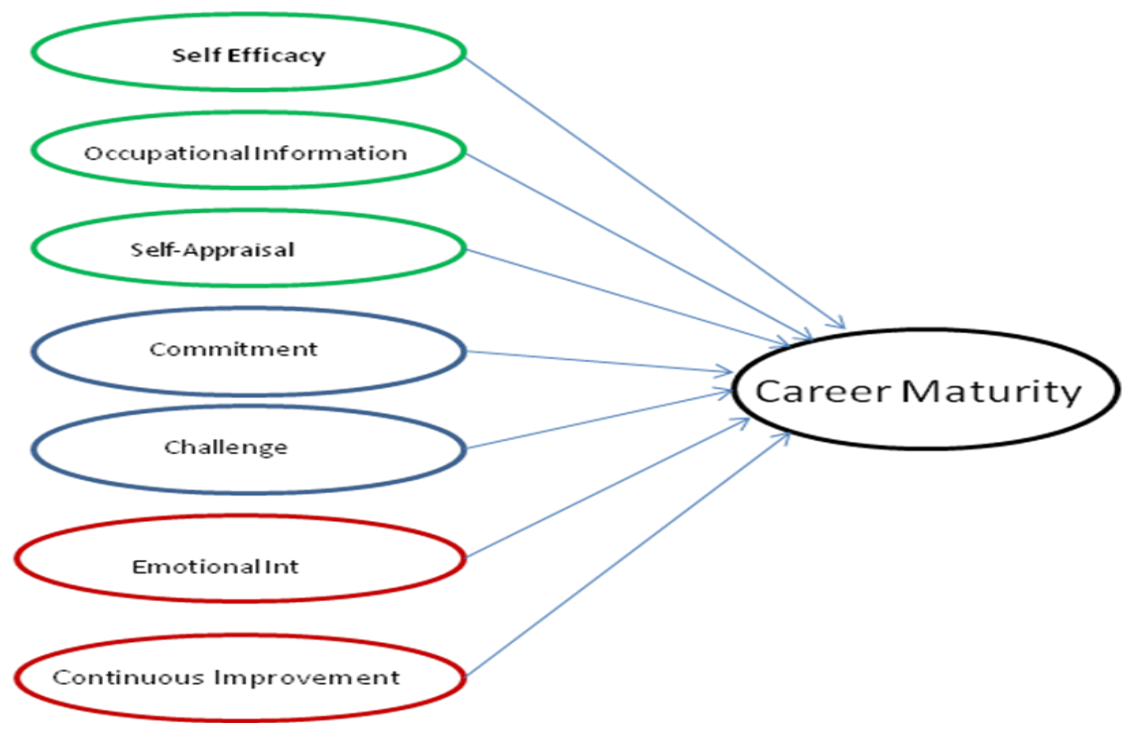

Figure 4.26 Significant Influencing Factors of CM 


\subsubsection{Redundancy of independent variables}

According to Breakwell et al (1998), a problem with multiple regression is that if the predictor variables are highly correlated with each other, the analyses loses its accuracy as it would mean that two (or more) variables are explaining the same part of the variation in the criterion. This is called multicollinearity (Breakwell et al., 1998). Analyses were preformed to determine the redundancy of the independent variables (subscales). The results are presented in Table 4.8.

Table 4.8

Redundancy of Independent Variables

\begin{tabular}{|c|c|c|c|c|}
\hline Independent variable & Tolerance & R-square & $\begin{array}{l}\text { Partial } \\
\text { correlation }\end{array}$ & $\begin{array}{l}\text { Semi-partial } \\
\text { correlation }\end{array}$ \\
\hline Self-appraisal & .49 & .51 & .11 & .10 \\
\hline Occupational information & .64 & .36 & .12 & .10 \\
\hline Goal selection & .56 & .43 & .05 & .04 \\
\hline Planning & .44 & .56 & .04 & .04 \\
\hline Problem solving & .56 & .44 & .09 & .08 \\
\hline Commitment & .59 & .41 & .11 & .10 \\
\hline Challenge & .76 & .24 & -.12 & -.11 \\
\hline Control & .65 & .35 & .06 & .05 \\
\hline Conscientiousness & .60 & .39 & .11 & .10 \\
\hline Life balance & .50 & .50 & -.07 & -.06 \\
\hline Pro-active behaviour & .60 & .40 & .02 & .02 \\
\hline Life goals & .41 & .59 & .02 & .02 \\
\hline Self-management & .50 & .50 & .01 & .01 \\
\hline Mutual benefit thinking & .45 & .55 & .04 & .03 \\
\hline Listening & .48 & .52 & -.01 & -.01 \\
\hline Teamwork & .41 & .59 & -.01 & -.01 \\
\hline Continuous improvement & .68 & .32 & -.10 & -.09 \\
\hline
\end{tabular}




\subsubsection{Normality}

The large sample size $(\mathrm{N}=310)$ allows the assumption that the data is normaly distributed because if there are outliers, it will not have a significant effect on the results of the statistical analyses. Normality of the data was also confirmed with the normal probability plot of residuals (P-P). Figure 4.27 shows the results of this plot.

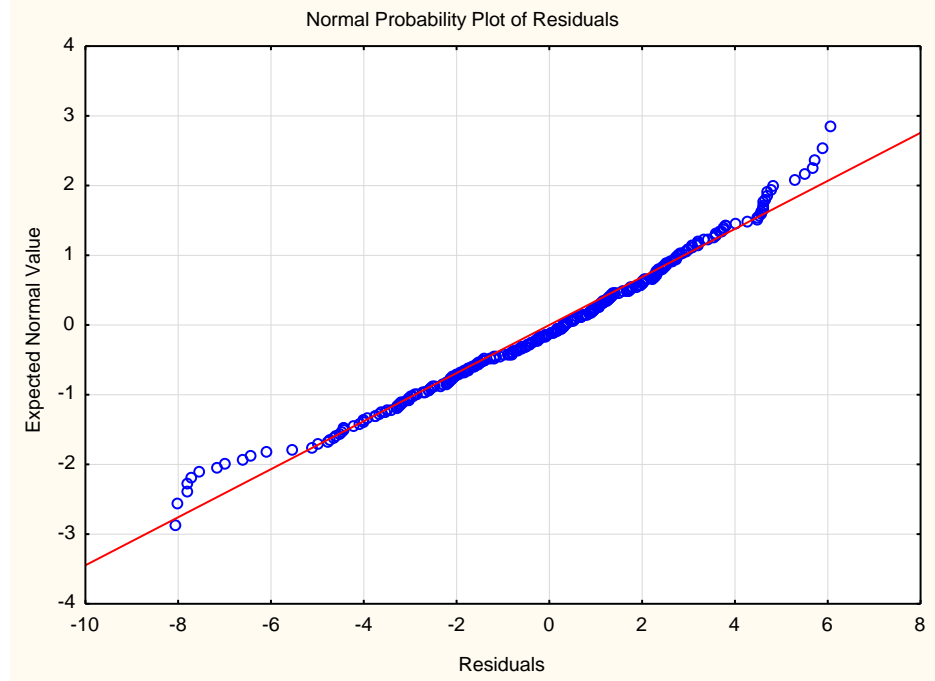

Figure 4.27 Normal Probability Plot of Residuals

The reasonably straight diagonal line of the plot suggests that there are no major deviations from normality.

\subsection{CHAPTER SUMMARY}

In this chapter, the results of the statistical analyses were reported for the data obtained from the responses of a sample of 310 MSDS members on five questionnaires. The descriptive statistics were reported from the biographical data obtained from the BIF. This included the demographics of the sample, histograms of relevant sample characteristics and a table reflecting the mean scores achieved on all the scales and subscales. Internal reliability analyses were reported to determine the internal validity of the scales.

Inferential statistical analyses were reported to indicate the correlations between each of the independent variables and the dependent variable (CM) by making use of the Pearson productmoment correlation coefficient. For the purpose of this study, correlations below .2 were rejected as insignificant. 
Significant moderate positive correlations were found between the dependent variable $(\mathrm{CM})$ and the following independent variables:

- CDSE (total) $(r=.39 ; p<.01)$

- Self-appraisal $(r=.27 ; p<.01)$

- Occupational information $(r=.29 ; p<.01)$

- Goal selection $(r=.31 ; p<.01)$

- Planning $(r=.33 ; p<.01)$

- Problem solving $(r=.33 ; p<.01)$

- Commitment $(r=.24 ; p<.01)$

- Life skills $(r=.24 ; p<.01)$

- Conscientiousness $(r=.20 ; p<.01)$

- Life goals $(r=.24 ; p<.01)$

- Self-management $(r=.21 ; p<.01)$

Multiple regression investigates the combined effects of predictor variables on the dependent variables. The summary statistics showed that 21 percent of the variance in CM can be accounted for by a combination of all the independent variables. Multiple regression analysis was also performed to identify the best set of predictor variables after controlling the effect of all other predictors on each other in the model. The standardised coefficients were reported on for this latter purpose. Evaluation of the independent variables on the basis of the beta values, $t$ values and $p$-values, indicated that the factors which have a significant impact on the dependent variable $(\mathrm{CM})$ include:

- occupational Information;

- self-appraisal;

- commitment;

- challenge;

- conscientiousness

- continuous improvement.

The tolerance levels of all the predictor variables were $>.3$, indicating no multicolinearity. 


\section{CHAPTER 5 DISCUSSION OF RESULTS}

\section{$5.1 \quad$ INTRODUCTION}

Chapter 4 presented the results of the statistical analyses performed on the sample of 310 MSDS members of the SANDF to investigate the most significant set of predictors for the CM criterion. This chapter aims to discuss the results by commenting on the levels of CM and the identified prominent factors influencing it. Correlation results between the predictors and CM (see par 4.4.1) and the multiple regression analysis (see par 4.4.2) between the combined predictors and the criterion, CM, is then discussed.

\subsection{DISCUSSION OF LEVELS OF CM AND FACTORS}

The research question of this study was formulated as follows: Which factors influence career maturity and what is the level of career maturity of MSDS members in the SANDF and which of these factors could and/or should be addressed by the organisation towards achieving more effective youth development? This section discusses the levels of CM of MSDS members in the SANDF and the perceived levels of factors influencing CM as reflected in the results of the measurements of the study.

The MSDS is the SANDF's contribution towards the NSDS of the RSA (see par 2.3.1) - to develop skills to ensure economic growth and global competitiveness for the South African labour market. The third theme of the DOD Overarching HR Strategy (2009) also propagates the social responsibility of the SANDF towards the RSA. One of these primary social responsibilities is youth development. It is expected that the outcome of the MSDS programme adresses the objectives of the NSDS of the RSA - cultivating lifelong learning and employability (gaining knowledge, skills and experience) and awareness of trends in the labour market (knowledge of the world of work). Teipel (2002) states that youth development is aimed at enhancing competence, connectedness, confidence, character and a person's contribution to society. The RSA youth that form part of the MSDS of the SANDF fall between the ages of 18 and 27 years and can be considered late adolescents or young adults. Havigurst (1972) lists the developmental tasks of this life stage (see par 2.3.2). 
The developmental tasks in the list that are relevant to $\mathrm{CM}$ include the following:

- Emotional independence

- Preparing for an economic career

- Developing values and an ethical system of behaviour (executing socially responsible behaviour)

- Assuming civic responsibility

- Starting a family, managing a home, rearing children (and other life skills) - this requires being able to obtain a sustainable income (having a career).

CM is defined in this study (see par 2.5) as a person's readiness to make realistic, well informed, age appropriate career decisions and formulate career goals based on self knowledge, knowledge of employment opportunities, perceived employability and self-efficacy. From the discussions above, and the definition provided, it can be accepted that $\mathrm{CM}$ forms an integral part of youth development. Any career development initiatives in general would contribute towards ensuring that the MSDS of the SANDF addresses youth development. A context specific and focused career counselling programme for improving CM of MSDS members would, however be of greater value. It is for this purpose that the results of the study are applied.

The descriptive statistics of provided results for the levels of $\mathrm{CM}$ and the factors in the form of the mean scores of the scales and subscales (see Table 4.1). These results will be discussed in the section to follow.

\subsubsection{CM levels of the sample}

Schreuder and Theron (2004) explain that CM refers to the adjustment to the developmental tasks of a given stage in the context of one's career. Coetzee and Roythorne-Jacobs (2007) describe $\mathrm{CM}$ as involving both individual characteristics (decisiveness, self-reliance, independence) and being able to compromise between one's personal needs and the requirements of one's career situation (see par 2.5). MSDS members are in the exploration stage of Super's career life rainbow (and some entering the establishment) (see par 2.4.2.5.1 and Figure 2.2). 
The exploration stage involves becoming aware of the need to make a career choice, to gather information about careers and start narrowing down options. A person may enter a particular field (e.g. the SANDF) as a result of parental expectations or circumstances - such as having to support dependents. Such early career choices may result in problematic career transitions due to the notion of viewing a career as encompassing an occupation (e.g. a soldier), rather than as different roles or directions (Louw, 1994). It would seem that MSDS members therefore experience both push factors and pull factors towards making career decisions - on the one hand, their personal needs and characteristics would pull them towards own preferences, and on the other hand, the current unemployment rate and having to support dependents may push them towards finding any available source of income. Either way, coming to the end of their contract period necessitates taking career decisions.

CM was measured with the CMI-R short form. Participants scored a mean of 12.40 (out of 18) (see Table 4.1). This is a moderate score for CM. The levels of the three subscales (concern, curiosity, confidence) for total CM that added up to the total mean (of 12.40) were similar - all three subscales had mean scores close to 4 and all three had medians of 4 . Concern and confidence were very similar with mean scores of 4.02 and 4.05 respectively. Curiosity had a slightly higher mean on 4.33 .

Higher levels of curiosity may be explained by the fact that the sample comprises of MSDS members whose contracts would be expiring in a few months. It can be expected that they would be interested in exploring other options for employment, especially because they have been receiving a salary for two years and subsequently established a lifestyle which they wish to uphold. The relatively high level of concern is possibly due to the fact that $76 \%$ of the sample need the income they receive from the SANDF to support dependents (see par 4.2).

The results of the sample (see Table 4.1) suggest that MSDS members are moderately confident in their ability to make wise career decisions and realistic career choices. When compared to a study done by Reid-Van Niekerk and Van Niekerk (1990) to investigate the levels of CM of black, coloured and white South African students in 1990, the results of this study show an improvement. In the Reid-Van Niekerk and Van Niekerk study, black students (of the same age group as the sample in this study) achieved a mean score of $56 \%$ on the CMI-R. The mean score for this study was $69 \%$ for a sample consisting of $90 \%$ black South African young people. 
The improvement in CM levels among black South African young people is assumed to be due to the new political dispensation since 1994. Although the levels of CM seem to be adequate, improvement of CM among future MSDS members will benefit the individual, the organisation and the South African society at large.

\subsubsection{Self-efficacy levels of the sample}

Self-efficacy involves a person's tendency to feel comfortable to deal with situations that require his/her perceived capabilities - applying already aquired skills (see par 2.5.1). A person will have confidence that he/she can perform a task, if he/she has already previously learned the required skill and/or demonstrated the ability to accomplish the specific task (Bandura, 1977). Military training places a lot of emphasis on practicing the skills taught to soldiers repeatedly in order to ensure that soldiers have no doubts about their abilities, or that they are able to do more than they thought themselves capable of, when having to act in combat. It may be expected that military training improves the general self-efficacy of a person.

Levels of self-efficacy of MSDS members in the context of career decision-making was measured by making use of the CDSE (see par 3.5.2). The results (see Table 4.1) of the mean score for total CDSE for the sample was 4.09 , indicating that MSDS members have much confidence in their own abilities in career decision-making. The results are commented on in terms of the subscales that make up the CDSE total.

Self-appraisal (as a subscale of CDSE) refers to the self-evaluation process involved in determining the level of self-efficacy (Betz \& Taylor, 2013; McWhirter, 1997; Schreuder \& Theron, 2004). This involves the perceptions that a person has regarding his/her own strong or weak points and abilities. The mean score on this subscale indicates that MSDS members have much confidence that they can accurately assess their own abilities. A high level of selfappraisal among MSDS members may be due to their exposure to SANDF training. Such training frequently involves having to execute challenging tasks in a team, where the possibilities of quiting or failing to engage the task are not part of the options. These situations provides opportunities for individuals to learn a great deal about their own preferences, skills and strong or weak points. This is in line with Bandura's argument that through experiences of mastery in relatively safe contexts, self-efficacy can be enhanced and defensive behaviours reduced (Bandura, 1977). 
Seeking occupational information (as a subscale of CDSE) involves a concern for and engaging in the activites of obtaining knowledge of the world of work (Betz \& Taylor, 2013). The results on the CDSE (see Table 4.1) suggest that MSDS members have a high level of confidence in their own ability to obtain occupational information. A high level of confidence in this subscale is beneficial for individuals in that it may decrease levels of anxiety caused by uncertainty (e.g. of the MSDS contract not being renewed). If one knows what career options are available and what is required for the various options, one can proceed to set goals and plan a career. A concern for obtaining occupational information and starting to narrow down one's options is associated with the exploration stage of Super's career life rainbow - the stage that the participants in this study find themselves in. The results are therefore aligned with Super's theory of career life stages (see par 2.4.2.5.1).

Goal selection (as a subscale of CDSE) involves the ability to define goals for one's career future (Betz \& Taylor, 2013). The results (see Table 4.1) on the CDSE show that the MSDS members have much confidence in their own ability to set career goals. The high level of confidence may be explained by the fact that military training places a lot of emphasis on achieving one's mission - to achieve the objective. During training, many exercises are executed where a group (e.g. platoon or section) is given a briefing on a scenario or SANDF mission that the grouping is to support. Members are required to assess the abilities, resources and limitations of their grouping and present how they could support the mission. This involves selecting and setting goals - defining the mission for the specific grouping (within the larger mission). Even when MSDS members have not all undergone junior leadership training, where they are required to take responsibility for this type of planning, members are continuously exposed to receiving orders from instructors or leaders and become accustomed to all activites having an aim. According to Ingrid et al. (2009), having goals and striving towards achieving them, positively contributes to the overall wellbeing of a person. A high level of confidence in setting career goals is therefore beneficial to both the wellbeing and the future careers of MSDS members.

Planning (as a subscale of CDSE) involves the ability to define a series of activities and obtain resources for the attainment of career goals. According to Betz and Taylor (2013) this subscale includes knowledge of how to implement an educational or career choice, including enrolling in educational programs, job search, resume writing and job interviewing. 
The results on the CDSE show that MSDS members have much confidence in their own ability to plan for their career future based on the activities as listed by Betz and Taylor (2013), developers of the CDSE scale. The high level of confidence in this subscale of the CDSE may be explained by frequent exposure to planning during military training. One level down from defining one's specific mission, is receiving specific taskings that have to be successfully executed; a specific and challenging objective is given to a grouping that has to come up with a detailed plan. This plan must then be executed. The successful and negative aspects of the plan is evaluated afterwards, providing a learning experience. Planning is an essential element in the military environment, as the commodity being managed is expensive - human lives. Having confidence in planning is beneficial for the MSDS individual in that they may be able to formulate an own career plan by identifying the activites to execute towards achieving their career goals.

Problem solving (as a subscale of CDSE) involves the ability to figure out alternative plans or coping strategies when plans do not go as intended (Betz \& Taylor, 2013). The results on the CDSE (see Table 4.1) show that MSDS members have much confidence in their own ability to conceive alternative plans or come up with solutions to challenges in their career. The exposure to the military planning and training environment as discussed for the planning subscale, may also provide an explanation to why MSDS members are confident in this factor. The results showing high levels of confidence in problem solving, setting of goals and planning towards the achievement thereof is aligned with Egan's approach (see par 2.4.3.4) and its similarities with the military planning models as discussed in chapter 2 . It entails investigating the current capability and the required capability and compiling a plan based on the gap analysis between what is currently available and future requirements. Military training could therefore be assumed to be contributing towards CM levels of MSDS members.

High levels of self-efficacy will be beneficial to MSDS members faced with the challenge of having to seek other vocations. Egan states that to overcome challenges, a person must be guided in developing a better sense of him or herself (self-appraisal). The client must be helped to undergo constructive change that will lead to life-enhancing results, outcomes and achievements - this is aligned with the social cognitive theory of Bandura (1986). Positive outcomes and achievements will lead to satisfaction, symptom reduction, a better perception of self and overall improved functioning (Egan, 2014). 
When going through some change or challenge, Egan also advocates assistance in regaining self-confidence and self-respect. Having a sense of worth will ensure more assertiveness for the client facing a challenge in his or her life or career (Egan, 2014). This can be seen as being related to self-efficacy in one's career context. The MSDS as a military training programme should address the improvement of self-efficacy as an important learning outcome towards youth development.

The findings on self-efficacy is beneficial towards the SANDF in that it seems that the MSDS members are overall confident that they can perform the tasks associated with CM. Even if MSDS members have not been exposed to a large amount of career decision-making situations, the findings suggest that they are confident enough to approach, explore and engage in career activities. One may hope to assume that the self-efficacy of MSDS members can be generalised to include areas other than $\mathrm{CM}$ and subsequently be beneficial for military combat readiness as well as the execution of a variety of tasks.

\subsubsection{Hardiness levels of the sample}

Dolan and Adler (2006, p.110) defines hardiness as "personality style or tendency, fairly stable over time, that is composed of the following interrelated components: (1) commitment (vs. alienation), referring to the ability to feel deeply involved in activities of life; (2) control (vs powerlessness), the belief one can control or influence events of one's experience; and (3) challenge (vs. threat), the sense of anticipation of change and an exciting challenge to further development" (see par 2.5.3).

Levels of hardiness was measured by making use of the MHS (see par 3.5.3) compiled by Dolan and Adler (2006). The mean score for the sample for total hardiness was 2.6 indicating a high level of hardiness. The level of hardiness will be described in terms of the subscales of hardiness measured by means of the MHS.

Commitment produced the highest mean score (2.72), followed by challenge (2.57) and control (2.50) (see Table 4.1). These results suggest that MSDS members seem to feel involved in the activities of the SANDF (items on the subscale refer to the applicant's current job). In studies conducted by Super and Nevill (Nevill \& Super, 1988; Super \& Nevill, 1984) as well as by Matzeder and Krieshok (1995), findings report that commitment to work seems to be the primary determinant of $\mathrm{CM}$. 
Nevill and Super (1988) concluded that external factors such as socio-economic status and gender are only important as functions of commitment to work. Super and Nevill (1984) found that the importance of a work role (work salience) is described by the dimensions of commitment, participation and value expectations - these are similar to the dimensions of hardiness as described by Dolan and Adler (2006). Matzeder and Krieshok (1995) found that work salience is determined by commitment to the role. This commitment includes attitudes and emotions, participation in the role and knowledge about the role.

High levels of commitment among the MSDS members is therefore beneficial, not only to military functioning, but also to future work salience. In the military, emphasis is placed on teamwork and being part of the group, and very few activities are based on the personal needs of the individual. Being a soldier, requires commitment. This approach could explain the high levels of commitment of the sample. MSDS training may therefore be beneficial for CM in that it influences the character of a person towards being committed towards achieving required outcomes. The high levels of commitment may also be explained, as previously mentioned, by $76 \%$ of participants having to financially support dependents. The unemployment rate in the RSA resulting in less available opportunities and more competition, may create greater concern for commitment towards one's current job and future career.

The definition of challenge provided by Dolan and Adler (2006) as part of the hardiness construct cited above seems to refer to a general sense of anticipation of change and an exciting challenge to further development. The items of the subscale seem to, however, refer to how challenging respondents perceive their job to be and how much personal resources it requires. It appears that MSDS members do not always regard their current jobs as as highly challenging. It could be beneficial to expose MSDS members to the challenging environments of other occupations (or different kind of challenge as that of military functioning) during their last contract year. Yukl (2013) argues that a person's self-confidence and prior experience with change (self-efficacy) as well as openness to new experiences and internal locus of control will be instrumental in the confidence to cope with change. Creating awareness among MSDS members about the world of work outside of the military, may enhance their sense of anticipation and excitement towards change (future careers) and improve confidence to cope with change. 
The lower mean score on the control subscale may be due to the military training environment where MSDS members have to carry out orders continuously and have little power to influence their own activities on a daily basis. MSDS members who do not undergo junior leadership training, should be exposed to opportunities where they are expected to take responsibility for some tasks or outcomes - to exercise control and be held accountable. This may be beneficial for the development of internal locus of control and realisation of one's ability to influence outcomes. This ability is essential in the current age of protean careers that require of individuals to take responsibility for and to manage their own careers as well as maintain employability (Schreuder \& Theron, 2004).

High levels of hardiness may may be beneficial to the individual MSDS members (South African young people), the SANDF and society at large. Economic empowerment requires more hardy entrepeneurs than despondent welfare-seekers. High levels of hardiness may also positively influence levels of $\mathrm{CM}$ as the challenge dimension (general sense of anticipation and viewing future developments as challenge rather than threat) would enhance the desire to obtain knowledge of employment opportunities and requirements and formulating goals; commitment may contribute towards the realisation of the requirement for setting career goals and making wise decisions; and control may enhance the taking of responsibility for one's career choices and future.

\subsubsection{Life skills levels of the sample}

De Villiers (2001) describes life skills as a variety of skills that are empowering and extend the abilities of individuals towards greater chances for success in the endeavours undertaken in their lives (see par 2.5.2). In the current era of rapid technical advancement and protean careers, people must be prepared to not only change jobs, but also their skills a few times in their lives - individuals should not only be prepared for jobs, but also for areas of competence to succeed in their career lives (De Villiers, 2001). Egan (2014) adds that improved life skills will assist individuals toward the outcome of better problem situation management and opportunity development. He mentions skills such as (among others) problem management, opportunity identification, sensible decision-making and skill of interpersonal relating. Life skills are seen as preventative measures that can be learned by clients and be applied when required so that individuals become effective self-helpers (Egan, 2014). 
The life skills (subscales) measured in the SHP (see par 3.5.4) correspond to those mentioned by Egan (problem management, opportunity identification, sensible decision-making, skill of interpersonal relating) and with the subscales of the CDSE (self-appraisal, seeking occupational information, goal selection, planning and problem solving). The results of the SHP (see Table 4.1) show that MSDS members in the sample group perceive themselves as having very good life skills. The mean total score was 4.97 (out of a maximum of 6).

Mean scores on the subscales indicated that MSDS members in the sample perceive themselves as being very good at pro-active behaviour (assuming responsibility and focusing on the things that one can control and influence), mutual benefit thinking (collaborating effectively with others by means of relationships built on trust and mutual benefit), and continuous improvement (making time for one's physical health, improving relationships with others and finding meaning in life).

The lowest mean scores - although it still falls within the category of "very good" - were achieved on the subscales of teamwork (cooperating with others and being oriented towards finding solutions that benefit all), listening (developing an understanding for the needs and perspectives of others) and conscientiousness (showing kindness and considerations towards others and honouring commitments) (Covey, 1992). The first three of these factors (pro-active behaviour, mutual benefit thinking and continuous improvement) is beneficial to levels of $\mathrm{CM}$ as it incorporates elements of the $\mathrm{CM}$ construct definition. Making wise and informed decisions requires pro-active behaviour and mutual benefit thinking - considering how your choices will affect others. Basing good career decisions on self-knowledge, employability and self-efficacy would be enhanced by a realisation of the necessity of continuous improvement - sharpening the saw will ensure that one can cut down even hardwoods.

Teamwork, listening and conscientiousness are also important life skills, especially in the workplace. It may, however, be less relevant to CM due to the focus on setting career goals, making decisions and maintaining employability and self-efficacy on an individual level.

The perceptions of the MSDS members of their own life skills are very positive. This is beneficial on the one hand, as it probably contributes towards feelings of self-efficacy and therefore positively impact on $\mathrm{CM}$. On the other hand, perceptions may be too positive and leave little perceived need for improvement in life skills. 


\subsection{DISCUSSION OF CORRELATION RESULTS}

The aim of the study (in order to answer the research question) was to identify the factors reported to influence $\mathrm{CM}$ according to the literature, and to then determine which of these factors significantly correlate with the CM of MSDS members in the SANDF. Identifying a set of contextually significant factors that play a role in $\mathrm{CM}$, will provide guidelines towards the appropriate focus for a proposed career guidance programme for MSDS members.

Hypotheses were formulated in an attempt to show relationships between the independent variables and the dependent variable (CM) (see par 3.2). The statistical analyses on correlations presented in chapter 4 , resulted in the rejection of some of the hypotheses on the basis of the weakness of the relationships (see par 4.4.1). The statistical analyses and subsequent results, are however, based on the specific measuring instruments (short forms thereof) used in this study.

The purpose of the study is to follow a diagnostic approach in exploring the factors that influence CM in the context of the MSDS. Hypotheses regarding the relationships between influencing factors and CM serve to confirm these factors identified from the literature review as playing a role in $\mathrm{CM}$. Correlations, however, only indicate that the variables co-vary - how the variance in one variable may be explained by the variance of another (Hanna \& Dempster, 2012). All the hypothesised relationships had, however been positive (as hypothesised). This provides an indication that, although not all the identified factors impact equally (or significantly) on $\mathrm{CM}$, that they may all play a role in $\mathrm{CM}$.

The factors influencing $\mathrm{CM}$ were extensively researched in the literature review of this study (see par 2.5 to 2.5.5 and Figure 2.3). A comprehensive career counselling programme for MSDS members could therefore include as much of these elements as possible. Extensive programmes are, however, not practical in terms of resources (e.g. time, capacity, budget). The results of the study allows a focus on fewer factors for the development of a career counselling and guidance programme for MSDS members. This would benefit the individual, in being able to make better career decisions (and transitions), both within the SANDF if his/her contract is renewed, or when embarking on a career outside of the SANDF. The results of the correlations between the independent variables (factors) and CM will be discussed in this section to provide insight into and possible explanations for the relationships. 


\subsubsection{Self-efficacy and CM}

$\mathrm{H} 1$, stating that there is a significant and positive relationship between total career decision selfefficacy (CDSE) and CM, was accepted. According to the standards propagated by Hanna and Dempster (2012), the Pearson's product-moment correlation co-efficient results (see Table 4.3) showed a moderate significant positive correlation $(r=.39 ; p<.01)$.

These findings are in line with a study by Walker (2010), who also tested the hypothesis of a relationship between self-efficacy and $\mathrm{CM}$, using the same instruments as was used for this present study. She found that the the CMI-R was positively correlated with the CDSE short form total score $(r=.44 ; n=347 ; p=<.001)$.

All the subcales of the CDSE provided correlation results significant enough for accepting of the hypotheses formulated. These include $\mathrm{H} 2, \mathrm{H} 3, \mathrm{H} 4, \mathrm{H} 5, \mathrm{H} 6$ for the relationships between $\mathrm{CM}$ and self-appraisal, seeking occupational information, goal selection, planning, and problem solving which all showed significant moderate positive relationships with $\mathrm{CM}$. The significant correlations between self-efficacy and its subscales with $\mathrm{CM}$, may be explained by the descriptions of the subscales of the CMI-R short form (see par 2.5) as described by Savickas and Portfeli (2011). The concern subscale includes becoming aware of choices (CDSE goal selection); the curiosity subscale involves exploring the world of work and self-assessment (CDSE self appraisal and seeking occupational information); and the confidence subscale includes making wise and realistic career choices and solving problems (CDSE planning and problem solving).

The relationship between seeking occupational information and CM $(r=.29, p<.01)$ could be explained in that a person can only be able to make decisions regarding his/her career once he/she has identified options to choose from. Such options are identified by exposure to career options and/or obtaining of career information. The seeking occupational information subscale seem to be aligned with the curiosity (the extent to which a person is exploring the world of work and seeking to obtain occupational information) subscale of the CMI-R. Holland's theory of person and environment fit (see par 2.4.2.2) is incorporated in Super's theory of CM (see par 2.4.2.5.1). Super (1957) recognises Holland's trait theories in that people differ in their personalities, abilities, needs, values, interests, traits and self-concepts. By virtue of these characteristics, people qualify for specific occupations. 
Gottfredson (2002) adds that people have a zone of acceptable alternatives consisting of a range of occupations acceptable for the individual's place in society. A young person, such as MSDS members, entering the career world, would need to explore the world of work to find out which occupations may fit their specific characteristics before being able to make wise career decsions.

The relationship between goals selection and $\mathrm{CM}(r=.31, p<.01)$ is visible in the definition of $\mathrm{CM}$ which includes to "...formulate career goals based on self-knowledge, knowledge of employment opportunities, perceived employability and self-efficacy" (see par 2.5). The concern subscale of the CMI-R includes becoming aware of choices. Setting career goals is a necessity for $\mathrm{CM}$ - to be able to decide on a route or even know which map to consult, one needs to know the destination - establishing the desired outcome precedes decisions on the ways and means of achieving the outcome.

This is aligned with Egan's approach (see par 2.4.3.4) - investigating the current scenario, identifying the required outcome or ideal scenario and and then devising (and committing) to a plan to achieve the required outcome. The link between Egan's approach and the subscales of self-efficacy were adressed in par 5.2.1.

The relationship between planning and $\mathrm{CM}(\mathrm{r}=.33, \mathrm{p}<.01)$ may explained by the fact that planning involves deciding on the most appropriate course of action (activites) and to execute it. The military environment is beneficial for the MSDS members to develop self-efficacy in planning due to continuous exposure to the need for planning and precise execution of the plans in order to ensure reaching the objective. Having a planning mindset will benefit the MSDS members in their career context as well.

The relationship between problem solving and $\mathrm{CM}(\mathrm{r}=.33, \mathrm{p}<.01)$ may be explained in that the achievement of one's career goals is rarely as simple as deciding on the goals, compiling a plan and executing it. On the route towards one's destination, obstacles or detours are bound to appear. The destination may even change. Having a high level of $\mathrm{CM}$ sould therefore also require the confidence to deal with challenges and obstacles on the path to achieving one's career goals. 
Planning and problem solving both presented (equally) the highest correlation with $\mathrm{CM}(\mathrm{r}=.33$, $p<.01)$. The results of these correlations confirm that there is a positive relationship between self-efficacy in career decision-making and CM. Having high levels of confidence about one's ability to make wise career decisions will therefore ususally mean that the same person will present high levels of $\mathrm{CM}$. The significant relationship may be explained in that a person has to be able to evaluate him or herself in order to have confidence in deciding what career may suit him/her and/or what career goals are feasible in relation to his/her own abilities.

\subsubsection{Hardiness and CM}

$\mathrm{H} 7$ states that there is a significant and positive relationship between total hardiness and $\mathrm{CM}$. This hypothesis was rejected due to a weak positive correlation (not significant) result ( $r=19$, $p<.01)$. The hypotheses for two of the subscales of hardiness, $\mathrm{H} 8$ control $(r=.17, p<.01)$ and $\mathrm{H} 10$ challenge $(r=.05, p<.01)$ were also rejected on the basis of weak positive correlation. The commitment subscale $\mathrm{H} 9$ showed a significant positive moderate correlation with $\mathrm{CM}$ and $\mathrm{H} 9$ was accepted. The acceptance of the hypothesis of the relationship between commitment and $\mathrm{CM}$ is aligned with the literature, as was discussed in par 5.2.3. Acceptance of H9 is also aligned with results from studies by other researchers.

Nevill and Super (1988) conducted a study on 372 undergraduate students to investigate the relationships between $\mathrm{CM}$ and commitment to work, gender, socio-economic status and college level. They describe commitment as being the immediate determinant of CM. The results of their study indicated that younger participants (high school and first year students) were less committed to making decisions and committing to a specific career than older students. The explanation was that younger people still view the world of work as remote and can make generalised decisions on what to study or investigate, without choosing a specific occupation. The study could not confirm the researchers' assumption however (due to not having enough older participants in the sample), that older students tend to be more knowledgeable of a specific occupational group. The current study included older participants (18-29 years) of MSDS members and a moderate significant positive relationship between commitment and CM - this may serve as confirmation of the explanation provided by Nevill and Super (1988) in their study. 
Patton and Creed (2002), in a more recent study on 377 Australian students enrolled in grades 9 through 12. Analyses were conducted with the four subscales of the Australian version of the Career Development Inventory (CDI-A) as the dependent variable, and two levels of work commitment (high/low). as one of the independent variables. Work commitment was moderately correlated with all the subscales of the CDI-A. Although work commitment accounted for a significant proportion of the variance in $\mathrm{CM}$ attitude, this variable was not the most powerful predictor of $\mathrm{CM}$. These reported outcomes are similar to the results of the current study.

A possible explanation for the rejection of the hypotheses for relationship of $\mathrm{CM}$ with the hardiness subscales of control $(r=.17, p<.01)$ and challenge $(r=.05, p<.01)$, may be explained by the content of the items of the MHS for these subscales. The items refer to how challenging one's current job is and how much control one perceives to have in one's current job. The activities of the MSDS members in training units are mostly repetitive and provide little opportunity for personal control. Other working environments within the SANDF or other organisations may elicit better responses for the control and challenge constructs.

The correlation results, indicating that commitment has the significant relationship with $\mathrm{CM}$, is also aligned with the results of the mean scores achieved on the MHS subscales indicating the highest levels (out of a maximum of 3 on a Likert scale) for commitment (2.71), followed by challenge (2.57) and control (2.50). Having high levels of commitment is very beneficial for both the individual's career and the SANDF (or any future employer). This is, however, also true for challenge and control as it may ensure that individuals engage in, explore and take responsibility for their own careers.

\subsubsection{Life skills and $\mathrm{CM}$}

$\mathrm{H} 11$, which states that there is a significant and positive relationship between total life skills and CM, was accepted. Regression analysis results showed a significant positive moderate correlation $(r=.24, p<.01)$ between total life skills and $C M$. 
Three of the subscales of the SHP used to measure life skills also showed significant positive moderate correlations and the following hypotheses were accepted:

- H12: there is a significant and positive relationship between conscientiousness and $\mathrm{CM}(\mathrm{r}=.20, \mathrm{p}<.01)$;

- H15: there is a significant and positive relationship between life goals and CM $(r=.24$, $p<.01)$ and;

- H16: there is a significant and positive relationship between self-management and CM $(r=.21, p<.01)$

The hypotheses for the relationships between CM and the rest of the subscales of the SHP, being life balance, pro-active behaviour, mutual benefit thinking, listening, teamwork and continuous improvement, were rejected based on low correlation scores. The rejection of these hypotheses may be explained in that each subscale has only three items. Testing of these hypotheses using more comprehensive measuring instruments may yield better results. Total life skills and life goals yielded the most significant correlations with $\mathrm{CM}$. This is aligned with the description of De Villiers (2001) that life skills are a variety of skills (a combination of many) that are empowering and extend the abilities of individuals towards greater chances for success. Egan (2014) adds that life skills include a set of preventative measures that can be learned and applied for individuals to become effective self-helpers. It would seem from these descriptions that the value of life skills lie in the combination of various skills and not in the ability to apply only one or two.

The SHP subscale measuring conscientiousness $(\mathrm{H} 12)$ is based on the habit described by Covey (1992) as 'emotional bank account' and refers to the maintenance and improving of relationships with others. It is based primarily on developing mutual trust. Being able to build relationships is essential throughout one's life and also one's career life.

Life goals (as subscale of the SHP) refers to defining clear measures of success and creating the plans to achieve them (Covey, 1992). The relationship of life goals and CM (H15) may be explained in that CM involves activities similar to the description of life goals - deciding on a career and defining career goals and subsequently executing actions to achieve such goals. This is again, aligned with Egan's approach and with the planning models of the SANDF as decribed in par 5.2.2. This life skill, however, refers to setting goals for one's life and not only for one's career. 
This is aligned with the logotherapy approach (see par 2.4.3.2) based on Frankl's existential theory involving recognition of the human spirit and finding meaning in life (Frankl, 1986), as well as the transpersonal approaches to career counselling (see par 2.4.3.3) - viewing one's career as part of a life journey and considering one's contribution towards making the world a better place (Coetzee \& Roythorne-Jacobs, 2007). The conscious formulation of life goals could be assumed to provide the motivation towards achieving career goals and to empower a person in overcoming obstacles on the journey towards achieving career goals. This life skill is developed in Covey workshops by the participants being led to compile a "Personal Mission Statement", which involves a process of identifying one's own values, preferences, abilities and ideals and compiling a statement of consciously defined life and/or career goals. MSDS members may benefit greatly by being led through such a process.

Self management (as a subscale of SHP) involves being able to prioritse and to achieve important goals rather than constantly operating in a reactive manner. The correlation with $\mathrm{CM}$ (H16) may be explained by the similarities in the concern subscale of the CMI-R, which refers to becoming engaged in the need to make career deicisons - becoming aware of choices and being involved in making them (Savickas \& Portfeli, 2011) rather than merely "going where the road leads you".

The discussion of the results of the significant and positive correlations of 11 of the 20 factors identified in the original model (see Figure 2.3) and the possible explanations for the low correlations and subsequent rejected hypotheses for the other nine factors, indicate that there is value in the original model, but that some factors play. a more significant role in influencing the CM of MSDS members. The discussions of the relationships between the seperate factors and $\mathrm{CM}$, also recognised similarities and interrelatedness of some of the factors (independent variables). Multiple regression analysis was performed in order to shed more light on the most significant influencing factors of $\mathrm{CM}$ by testing the relationship between each factor and CM, after controlling the effect of the covariance between the independent variables (Breakwell et al., 1998) 


\subsection{DISCUSSION OF MULTIPLE REGRESSION RESULTS}

The results of the evaluation of the impact of each factor on $\mathrm{CM}$, after controlling the effect of all other factors in the model, produced standardised regression coefficients. Evaluation of the factors (predictor variables) on the basis of the beta values, $t$-values and $p$-values, indicated that the following factors have a significant impact on the dependent variable (CM).

- Self Efficacy $(\beta=.37, t=6.11, p($ sig $)=.00)$

- Occupational Information $(\beta=.13, t=1.99, p(s i g)=.05)$

- Self-Appraisal $(\beta=.15, t=1.95, p(\operatorname{sig})=.05)$

- Commitment $(\beta=.12, t=1.82, p(\mathrm{sig})=.07)$

- Challenge $(\beta=.13, t=2.13, p(s i g)=.03)$

- Conscientiousness (conscientiousness) $(\beta=.12, \mathrm{t}=1.85, \mathrm{p}(\mathrm{sig})=.07$ )

- Continuous improvement $(\beta=.11, t=1.72, p(s i g)=.09)$

This set of predictors includes subscales of all three of the measured prominent factors; selfefficacy (in career decision-making), hardiness and life skills. The greatest contributor to CM, based on the beta values, was self-efficacy $(\beta=.37)$, followed by self-appraisal $(\beta=.15)$, occupational information $(\beta=.13)$ and challenge $(\beta=.13)$. The factors (scales and subscales) presented in Table 4.6 and Table 4.7 which yielded beta values below .10 were found insignificant predictors.

The multiple regression analysis results have some overlap with the results of the regression analyses per (independent) variable. The factors that emerged as significant predictors which also showed significant Pearson product moment correlations include self-efficacy, seeking occupational information, self-appraisal, commitment and conscientiousness. The other two significant predictors, challenge and continuous improvement showed very low Pearson $r$ correlation values. It is noted, however, that significant correlation does not necessarily imply causation (http://www.education.com/refernce/article/correlational-research/).

The career challenges in the current South African context include the global changes in employment patterns. Employees must now maintain own employability and take ownership of their careers. This requires knowledge of market trends and the development of relevant knowledge and skills (Cima, 2002; Coetzee \& Roythorne-Jacobs, 2007; Lee \& Johnston, 2001). 
High complexity in the technological age and high unemployment rates in the RSA pose psychological challenges, and the requirement for lifelong learning is an added stressor. People's careers are central to their identity and affects all other areas of their lives. Career dilemmas can also manifest in emotional and interpersonal problems (Coetzee \& RoythorneJacobs, 2007; Mutchinsky et al., 2002). This description of the world of careers, that require the application of CM (making realistic decisions, formulating career goals), touches on the factors identified in this study as significant influencers:

- Maintaining employability and taking ownership - self-efficacy;

- Knowledge of market trends, development of relevant knowledge - seeking occupational information;

- Developing relevant knowledge and skills, lifelong learning - continuous improvement;

- Challenges and stressors of the current work environment - challenge, commitment (hardiness)

- Career success or dilemmas may affect interpersonal relationships - conscientiousness.

The discussions of the levels of the factors measured in the MSDS sample (see par 5.2) and the discussion of the correlation results between the factors and CM (see par 5.3) provided possible explanations for the significance or insignificance of factors as impacting on CM. Linkages of the findings with previous studies and the literature review were also addressed. For the purposes of this study, the factors identified as significant predictors will be used as guidelines for the recommendations towards a career guidance programme for MSDS members in the SANDF. These recommendations are included in chapter 6 .

\subsection{CHAPTER SUMMARY}

The significant and mentionable results of the study was discussed in this chapter. The levels of $\mathrm{CM}$ and levels of the prominent factors (scales), self-efficacy, hardiness and life skills, with its subscales, were reported. MSDS members in the sample group present with moderate levels of CM (69\%). They have much confidence in their abilities to execute tasks associated with CM (self-efficacy levels are high). The perceived levels of life skills are also very good.

Significant correlations were found for the relationship between CM (dependent variable) and total CDSE (self-efficacy), self-appraisal, seeking occupational information, goal selection, planning, problem solving, commitment, total life skills, conscientiousness, life goals and selfmanagement. 
These correlations do not, however imply causation. Multiple regression analysis results yielded a set of significant influencing factors based on the beta values, $t$ values and $p$ values of significance. The set of significant influencing factors includes self-efficacy, seeking occupational information, self-appraisal, commitment, challenge, conscientiousness and continuous improvement. This significant set of factors will be used as guidelines for the recommendations towards a career guidance programme for MSDS members in the SANDF. 


\section{CHAPTER 6 \\ CONCLUSIONS, LIMITATIONS AND RECOMMENDATIONS}

\subsection{CONCLUSIONS}

Youth unemployment is a serious concern in the South African labour market (Coetzee \& Esterhuizen, 2010). The current character of careers is described in the concept of protean careers to include a focus on psychological success, being managed by the individual, including a series of identity changes, continuous learning, age not being important, employability, high levels of self awareness, personal responsibility and mobility (Mutchinsky et al., 2002). National youth development within the RSA is aimed at increasing the number of economically contributing people in the labour market towards economic sustainability and global competitiveness.

Results of the study indicate that $76 \%$ of the youth in the MSDS system of the SANDF need to support dependents. This is an added stressor in the employment environment that South African young people are exposed to. Youth development is aimed at empowering the youth towards achievement of the developmental tasks of their life stage (see par 2.3.2) and, according to Teipel (2002), to enhance competence, connectedness, confidence, character and a person's contribution towards society. The South African government addresses this need in the provision of the National Skills Development Strategy. The SANDF is the military contribution in support of this national strategy. The current DOD Overarching HR Strategy (2009) also provides the governance for youth development within the SANDF by referring to it in theme three of the document which addresses the SANDF's social responsibility towards the RSA.

The researcher saw a need to determine if the SANDF is indeed succeeding its social responsibility towards youth development. In order to answer this question, the CM levels of MSDS members were investigated as the CM construct includes the elements required for successful youth development. The aim of the study was consequently to investigate the factors influencing $\mathrm{CM}$, in order to identity which factors may be focussed on in a proposed career guidance programme for MSDS. The main objective of the study was to determine if there is a need for career education and guidance programme(s) for MSDS members in the SANDF and if such a need exists, what would be feasible. 
Scientific research methodology was used to identify the most significant set of influencing factors for improvement of CM among MSDS members. A detailed literature review on youth development, career services and sareer maturity $\mathrm{CM}$ led to the identification of a list of factors said to play a role in CM. The list was summarised into the most prominent factors for measurement. The mean scores (raw scores) of the measurement results for the sample were discussed to comment on the levels of CM and the identified factors of MSDS members. The conclusion is that MSDS members show moderate levels of CM $(69 \%)$, have high levels of selfefficacy and high levels of perceived life skills. The discussion of the results in chapter 5 suggest that the MSDS experience does contribute towards youth development. Seen in the light of the current employment environment of the RSA and the national drive for youth development, as well as previous South African studies resulting in much higher CM levels for parts of the sample, it may be concluded that a need does exist for career education and guidance programmes in the SANDF. Such programmes may be to the benefit of the individual, the SANDF as an organisation and the RSA as a country.

Further statistical analyses were performed in order to determine what the focus should be for career education and guidance programmes in the MSDS. Regression analyses between the dependent variable $(\mathrm{CM})$ and the independent variables (CDSE total, occupational information, goal selection, planning, problem solving, self-appraisal, total hardiness, commitment, challenge, control, total life skills, conscientiousness, life balance, pro-active, life goals, self management, mutual benefit thinking, listening, teamwork and continuous improvement), revealed that significant and positive relationships exist between $\mathrm{CM}$ and the following factors:

- CDSE total (self-efficacy);

- occupational information;

- self-appraisal;

- goal selection;

- planning;

- problem solving;

- commitment;

- total life skills;

- conscientiousness;

- life goals;

- self-management. 
The output of multiple regression analysis was a set of most significant predictor variables (factors influencing CM). These factors may serve as guidelines towards a focussed and context specific career guidance programme for MSDS members. The study contributed towards a new body of knowledge by identifying the significant predictors for $\mathrm{CM}$ in this specific context.

The multiple regression analysis results indicated that self efficacy $(\beta=.37)$, was the strongest predictor of CM. Self-appraisal $(\beta=.15)$, seeking occupational information $(\beta=.13)$ and challenge were the next strongest predictors $(\beta=.13)$, followed by commitment $(\beta=.12)$ and conscientiousness $(\beta=.12)$ and then continuous improvement $(\beta=.11)$. Independent variables with beta values below .10 were seen as insignificant predictors.

It may be concluded from all the statistical analyses that self-efficacy in career decision-making is the most significant factor influencing CM. All the subscales of the CDSE showed significant and positive correlations and CDSE (total) had the highest standardised coefficient score $(\beta=.37, t=6.11, p(s i g)=.00)$ in the multiple regression analysis. The subscales of the CDSE also contain elements of life skills (setting goals, problem solving, planning). A career guidance programme that focuses on self-efficacy, self-appraisal, occupational information, goal selection, planning and problem solving (CDSE total and subscales) would therefore also improve levels of CM among MSDS towards improved youth development.

\section{$6.2 \quad$ LIMITATIONS}

The limitations of the study are recognised as they qualify and temper the findings. The limitations of the study may also serve to identify possible areas for future research. The following limitations should be considered when viewing the results of the study:

- Data for the study was collected by means of self-report measurement instruments. Self-report data can artificially inflate the results as a spill-over effect of response biases from respondents in an attempt to create more favourable impressions of themselves.

- The study was based on the perceptions of MSDS members only. It may be advisable to add qualitative data from leaders and instructors of MSDS members regarding the CM of MSDS members to create a holistic picture of CM levels of MSDS members. 
- A probability sampling method was used to select a number of participants which will include as many elements for the sample as is practically possible to ensure representativeness to the population. Although a large sample of 310 MSDS members participated, they included members of only three of the four services of the SANDF. The similarities in responses obtained from the participants of the three services (SA Army, SAN and SAAF) however suggest that responses from SAMHS MSDS members can be expected to conform to the current results. Extension of this study, with equal numbers of participants from all four services, may provide a better understanding of the success in youth development contribution efforts of the SANDF.

- A descriptive correlational research design was applied in the study. As correlation does not imply causation, only weak causal inferences can be made at best. The objective of the study was, however, not to test a model, but to describe the levels of CM and identify (describe) the factors that seem significant in influencing $\mathrm{CM}$ in order to arrive at feasible input towards the development of a career guidance programme for MSDS members.

- Due to practicality and time constraints, the short forms of the CMI-R and the CDSE were used in the study. Making use of the more comprehensive forms of the instruments and even choosing alternative instruments for measuring the same constructs as were investigated in this study, may provide better results or may confirm the findings of this study.

- Language may have affected the results of the study. All five questionnaires were presented in English. The majority of participants' ( $>90 \%)$ first language is not English, which leaves the possibility of items in the questionnaires being misinterpreted.

- Culture may have had an effect on the study. Some of the constructs used in the study (e.g. self-efficacy, self-appraisal) may not be conceptualised in the African cultures and could have an influence on the study.

- The sample consisted of participants in more than one of Super's career life stages. The majority of participants fall within the age group of the exploration stage (18-24 years), while approximately a quarter of the sample are between 25 and 29 years and fall within the establishment stage (see par 2.4.2.5.1). Responses of participants $<25$ years could be separated from those being 25 years and older. 
Although there are limitations in the study, it is still regarded as providing valuable insight into the CM levels of MSDS members as well as the factors that influence CM levels which may be addressed by the organisation towards improvements in youth development efforts. It is also hoped that the exposure of participants to the concepts measured and reasons for the study (during the informative presentation of the researcher before administering of questionnaires), as well as the activities mentioned in the items of the questionnaires, could have enhanced awareness of the MSDS participants towards CM.

\subsection{RECOMMENDATIONS}

Recommendations discussed in this section will include suggestions regarding the content and approach to career guidance programmes or interventions in the MSDS of the SANDF, as well as recommendations regarding future research in this area.

\subsubsection{Recommendations regarding future research}

The following are suggestions for future research to enhance the understanding of the $\mathrm{CM}$ phenomenon within the context of the SANDF MSDS (youth):

- The model of the predictors of CM may be tested. This would include obtaining more data by administering questionnaires to another sample of MSDS members or by reviewing the battery of questionnaires used after model specification based on the results of the current study.

- Equal numbers of MSDS participants from all four services of the SANDF (SA Army, SAAF, SAN and SAMHS) may be included in a study investigating levels of CM. Differences in the levels of $\mathrm{CM}$ in the various services may be compared with reports on the differences in training activities, approaches and circumstances of the services' training environments.

- An experimental research design may be used to test the abilities of MSDS members to achieve tasks associated with CM in a simulated environment, in order to follow up on the results of this study.

- If the results of this study are applied by the providing of career services or a career guidance programme to MSDS members, a pre-test and post-test methodology may provide evidence of the success of such efforts. 
- The results of the study suggest that career decision-making self-efficacy is the most significant factor influencing $\mathrm{CM}$. A culture and context specific questionnaire or adaptation of the CDSE could be designed and psychometrically validated for use in the SANDF (career guidance programmes) and/or RSA career guidance context.

\subsubsection{Recommendations for career guidance programme for MSDS members}

Currently, the SANDF follows a strategy of jointness. This term involves an integrated effort by all the Services and Divisions to provide joint capabilities with high levels of coordination and interoperability. Such coordinated efforts or capabilities require capability management. The SAMHS Psychological Services of the SANDF may be responsible for the coordination and management of career guidance activities for MSDS members in the SANDF. This does not imply that SAMHS psychologists will execute all activities for career guidance in the MSDS, but that activities by various role players within the SANDF Services and Divisions will be coordinated by the SAMHS Psychological Services. The Faculty of Military Science at the SAMA (University of Stellenbosch) may furthermore provide useful academic input and services.

According to Noe et al. (2008), development involves the acquisition of knowledge, skills and behaviours which will enable an employee to meet the demands of the current labour market. Development involves a process of continuous improvement - it is not a one-time event. Youth development during the MSDS two year period of service would need a continuous effort towards improvement in the $\mathrm{CM}$ of young members. This may require a series of events and/or general approach in training activities aimed at addressing the factors identified in this study. An integrated programme may be coordinated by the SAMHS Psychological Services. Such activities and events will have to be integrated with the rest of the military training and deployments of the members. The following section provides suggestions for activities that could be included in a career guidance and educational programme aimed at improving CM levels of MSDS members. 


\subsubsection{Career counselling workshops}

Workshops may be held for MSDS members to address an awareness regarding career development and planning. A strong focus on accurate self-appraisal and taking responsibility for one's own future (commitment and challenge) can be viewed as the main objective of such workshops. This aim could be achieved by including content that integrates the approaches to career counselling (see par 2.4.3). The other significant predictors (commitment, challenge, conscientiousness and the need for continuous improvement) may also be addressed in the content of such workshops. Career counselling workshops may be presented by the SAMHS Psychological Services (e.g. Military Psychological Institute). Such workshops can be classified as career counselling according to the diagnostic framework for career services (see Table 2.1).

Suggestions for such integrated content for career counselling workshops include:

- Narrative approach (Freedman \& Combs, 1996)

- Writing down your story - create awareness that your story is not factual.

- Constructing new stories.

- Changing from a pessimistic outlook on life to being optimistic - be solutiondriven rather than problem driven.

- Logotherapy (Frankl, 1986)

- Finding meaning in life (create awareness) or expectations in life.

- Challenge participants into seeking meaning in their work and life roles - make your life count.

- Transpersonal approach (Coetzee \& Roythorne-Jacobs, 2007)

- See careers as contributions towards making the world a better place.

- Emphasise striving towards one's highest potential.

- Building up of self-esteem and self-worth towards improved self-efficacy.

- Awareness of the decision-making process and the consequences of one's choices.

- Egan's approach (Egan, 2014)

- Assist participants in investigating and writing down their current situation regarding their career life stage.

- Decide where you want to be in five years and in ten years - set goals.

- Consider what you would need to do to reach these goals - compile a career development plan. 


\subsubsection{Career days}

To provide MSDS members with exposure to careers and occupational information, it is suggested that MSDS training units arrange career seminars. During such events, volunteers from society (e.g. from various employment sectors) may be invited to deliver informative talks on their jobs or careers (typical tasks, working environment, requirements, etc) and opportunities for questions can be provided. This may be enjoyable events and also contribute towards building positive relationships between the military and other public or private sectors of the RSA. The Corporate Communications environment of the DOD could take responsibility for the arrangement of such events. Career days could be classified as career coaching according to the diagnostic framework for career services (see Table 2.1).

\subsubsection{Intranet career services}

The DOD intranet may be utilised to provide information, self-assessments and short courses for MSDS members (or any other SANDF members interested). During the two years of the MSDS contract, especially after completion of courses (basic military training, junior leaders, functional training), there may be periods of low activity. Such available time periods could be utilised by MSDS members to explore career related topics on the DOD intranet. Computer centres may be provided at training units with supervised periods scheduled for career services via the intranet. Participants may even be guided by training personnel to follow a structured approach in the use of the services provided.

Web pages may be included that provide occupational information in an interesting manner. Online self-assessments may provide opportunities towards enhancing self-awareness (selfappraisal). Short courses may be compiled by subject specialists and placed on the intranet. This could include approximately five pages of information followed by an online test (of randomised questions) that may even provide printable results for inclusion in a career workbook. Having successfully completed such short courses may improve self-efficacy in the specific subject. Examples of such short courses include: the RSA and global employment environment, the current character of careers (introduction to careers), occupational information from different employment sectors, life skills, attitudinal courses and courses based on the factors influencing CM (e.g. commitment, challenge, decision-making, problem solving, goal setting, planning, family planning, compiling of CV's, searching for jobs, job interviews, etc). 
Information on what services career counsellors can provide could also be included on a webpage. Listings of recommended career counsellors and contact details per region may also be provided. Information on services provided by the SAMHS psychological services and the SAMHS multi-professional teams, as well as procedures to follow when requiring such services, may also be included on the intranet. The CMIS Division of the SANDF would play a large role in the development of such an intranet service for the SANDF and specifically MSDS members. Such intranet services may be classified as career guidance according to the diagnostic framework for career services (see Table 2.1).

\subsubsection{Covey life skills workshops}

During the course of this study, it was discovered that the SAAF's Management and Renewal Services Directorate have been presenting workshops on Covey's seven habits for some years with great success (Personal communication, Lt Col A. Schoeman on 22 August 2014). These workshops can be presented by FranklinCovey (distributors of the Stephen Covey personal development solution) or by accredited facilitators - SANDF personnel trained to facilitate Covey workshops.

The Covey life skills workshops follow an "inside-out approach" for personal development. The approach is aimed at empowering individuals towards achieving personal success (including career life) as well as organisational success and providing a contribution to society. Figure 6.1 illustrates this approach.

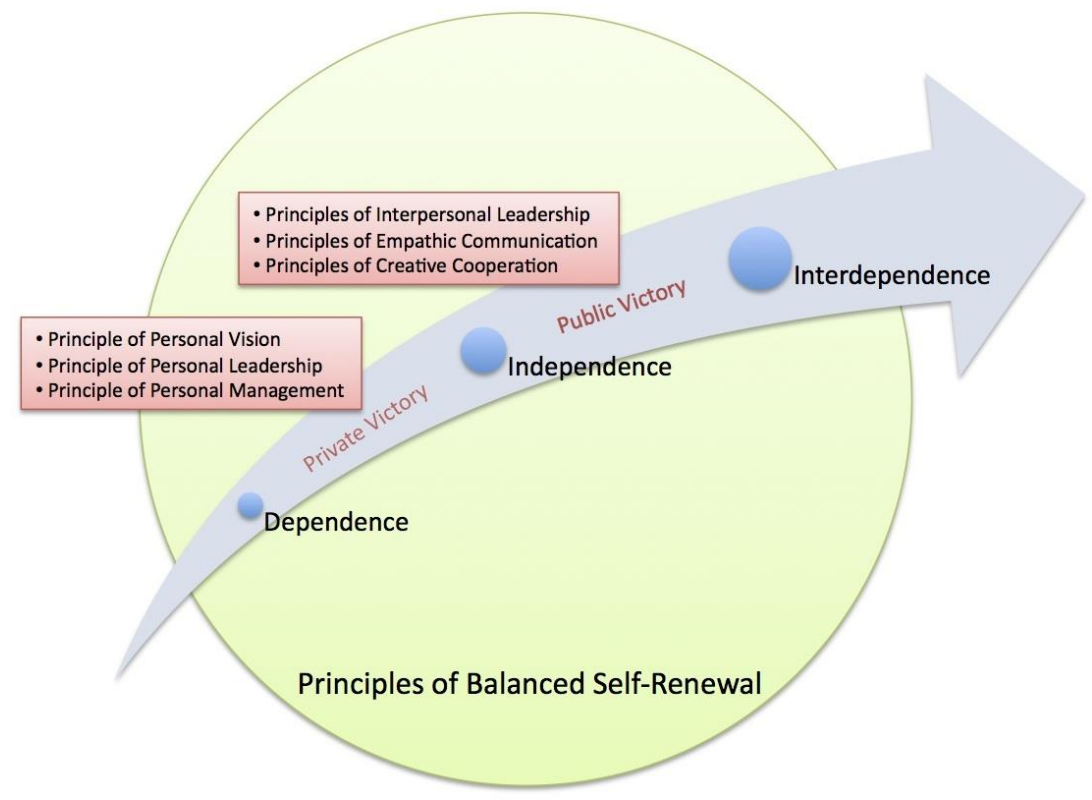

Figure 6.1 Covey's Inside-out Approach 
A person must, firstly, learn to move from dependence to independence/ self-mastery(see par 2.5.2 for detail of Covey principles). The aim is to build one's own character and self-efficacy during this stage. People must be cautious not to become overly independent, as this may lead to a primary focus on own needs - becoming selfish. The second stage involves growth from independence to interdependence - towards awareness interacting with others (conscientiousness). The third stage focuses on continuous improvement - making yourself relevant as society changes. This implies that one's skills have to be relevant to the requirements and complexities of the working environment.

The SAAF have presented Covey workshops from 2005-2008 during senior officers' staff courses, and have since presented workshops at various courses at the SAAF College and at units that indicate such requirements. Feedback from students at the SAAF College (which include young SAAF members) in the form of reported experiences and ratings, indicate that participants were highly positive towards the experience. Feedback from a most negative general participating in a leadership refinement workshop (Covey workshop) even included a statement saying: "I should have done this at the beginning of my career". The SAAF Management and Renewal Services directorate cannot keep up with the requirements for workshops at SAAF units. A waiting list was created pending the availability of accredited personnel and/or funds available to present workshops.

It is suggested that Covey workshops be presented to all MSDS members. Such workshops have cost implications. It is the opinion of the researcher, however, that the results and individual, organisational and societal benefits of such workshops may outweigh the cost by far. Three-day workshops currently cost approximately R4000 per person. The package includes high-quality course material (including CD's and tools) as well as seven weeks' follow-up services provided by FranklinCovey. A cheaper one-day Foundation Programme also exists for younger participants (such as MSDS) and new programmes have been developed specifically for the military environment including "Seven habits of highly effective people for soldiers" and "Seven habits of highly effective people for soldiers' families" (Personal communication, Jonathan Ramsamy, FranklinCoveysa on 7 August 2014). Such workshops may be classified as career counselling and career education according to the diagnostic framework for career services (see Table 2.1). 
An alternative to presenting of Covey workshops, is to include the inside-out development approach of Covey in MSDS training programmes. Begin with activities focusing on overcoming challenges and becoming aware of one's own abilities and strengths (self-appraisal and selfefficacy). Proceed to team building (interdependence) elements in training followed by a stage focusing on the third stage of Covey's approach (continuous improvement and conscientiousness) in the last 6 months of MSDS training.

\subsubsection{Career workbooks}

Career workbooks are part of the organisational approach to career counselling currently being applied in some organisations. Due to the focus of effort of the military psychological services being on the whole of the SANDF and other priority functions, such as continuous health assessments for combat readiness, individual career counselling services for MSDS members may not be feasible. Career workbooks could be compiled and produced for all MSDS members to use for the duration of their initial two year contract. Such workbooks will be compiled to specifically include the set of most significant factors influencing CM. Figure 6.2 is a proposed table of contents compiled by the researcher, based on the information gathered during this study. Career workbooks will contain the elements of career guidance according to the diagnostic framework for career services (see Table 2.1).

\section{CAREER WORKBOOK}

1. Introduction

- Your career: What is it and what does it mean?

- You have a national responsibility too! (economically contributing)

- Protean careers

- Know yourself

- Develop yourself (KSA's) - I will not be the same in five years

- Career counsellors: what can they do for me?

2. What is my Personal Style?

3. Compiling my Personal Mission Statement

4. Continuous assessment is essential (taking stock)

- What does it matter?

- I will make choices throughout my life

- 3 monthly assessments (360 degrees)

- $\quad$ Giving and receiving ( I have a responsibility to absorb)

5. My Developmental plan (I have to keep my KSA's relevant)

6. CV writing tips

7. Looking for jobs

8. Going for a job interview

Figure 6.2 Proposed career workbook content 


\subsubsection{Career challenge exercises}

MSDS training personnel can incorporate fun exercises into the MSDS training curriculum aimed at the challenge, self-efficacy, occupational information and conscientiousness factors. During such exercises, groups of participants may engage in board games that contain elements of different workplace settings and occupational information. Participants may also be tasked to perform role play exercises in dealing with dilemmas in the workplace setting other than the military. The handling of the role-play scenario by the chosen actors will then then discussed. This would serve as exposure to different workplace settings and improvement of self-efficacy with regards to behaviour and requirements of the workplace other than the military. It will also serve as team building and morale building exercises. Career challenge exercises may be classified as career education and career coaching according to the diagnostic framework for career services (see Table 2.1).

\subsubsection{Career research exercises}

During their training programme(s), MSDS members may be tasked to each write a staff paper on a specific career (other than the well-known options of policeman, nurse, teacher, preacher, etc). This would include detail on the industry, the typical tasks, requirements (job profile), typical working environment and organisations. MSDS members must then present their papers to the group. Source documents (information packets), prepared by training personnel or information specialists (DOD library personnel), could be provided to each member on loan for this task, if a library is not available at the unit. Such research exercises may be beneficial in improving occupational information and self-efficacy (in research and presentation). It will expose the whole group to a variety of occupations and may stimulate curiosity towards further investigations. Career research exercises can be classified as career education according to the diagnostic framework for career services (see Table 2.1).

\subsubsection{Career guidance and educational DVD}

The SAMHS Psychological Services and the Stellenbosch University Faculty of Military Science's Department of Industrial Psychology could compile a script for a context specific educational DVD for MSDS members aimed at addressing CM. The script will be based on the factors influencing $\mathrm{CM}$, as identified from this study. 
Such a DVD can be made by making use of the SANDF resources or subcontractors. This may provide a standardised training resource that can be included in the training of all MSDS members within all the SANDF Services and Divisions.

\subsubsection{General recommendation for improvement of CM}

The suggestions listed in this section may remain mere suggestions if a decision is not taken by top management in the SANDF (level 1 and 2) for implementing career services towards improved youth development in the MSDS. It is therefore recommended that SANDF top management be made aware of such requirements and recommendations.

\subsection{OVERALL ASSESSMENT OF THE STUDY}

The main objective of the study was to determine if a need exists for career guidance and education programmes for MSDS members of the SANDF. A diagnostic model was compiled from a detailed literature review to determine the levels of $\mathrm{CM}$ and the factors that influence $\mathrm{CM}$ in order to answer this question. The factors identified in the model were measured in a sample of 310 MSDS members and from the results it was concluded that a need does exist for career services within the MSDS in the SANDF. It is, however, evident from the results that guidance and education will be beneficial in some areas (factors) while other factors show high levels of perceived confidence and may not need to be addressed by the organisation. The possible explanations for the results, especially high levels of self-efficacy, suggest that the MSDS experience does contribute towards youth development and CM.

The theoretical objectives of the study were achieved in the literature review. Youth development and career services were conceptualised. Career maturity was also addressed in depth and factors were identified that were reported to play a role in CM. The empirical objectives were also achieved:

- The level of CM of MSDS members of the SANDF was measured and discussed.

- The levels of the factors influencing CM were measured and discussed.

- It was determined which identified factors seem to be the most significant influencers of CM by performing inferential statistical analyses on the data. 
The results of this study adds value to the field of industrial psychology as it included an indepth review of the literature on career services and CM in the context of youth development. The findings commented on or confirmed results of studies by other authors. The recommendations based on the findings may furthermore be implemented towards further research and towards improvement in the CM levels of future MSDS members of the SANDF. This would increase the success of the SANDF's societal responsibility towards youth development.

\subsection{CHAPTER SUMMARY}

The chapter provided conclusions of the study and listed the limitations of the study to be considered with the results. Recommendations were provided regarding possible future research in the area of CM within the SANDF MSDS context. Recommendations were also made regarding possible career guidance activities for MSDS members. Suggestions included career counselling workshops, career days, intranet career services, Covey life skills workshops, career workbooks, career challenge exercises and career research exercises. 


\section{REFERENCES}

Babbie, E. (2010). The practice of social research. (12th edn.). Belmont, CA, USA: Wadsworth Cengage Learning.

Bandura, A. (1977). Self-efficacy: toward a unifying theory of behavioural change. Psychological Review, 84 (2), 191-215.

Bandura, A. (1986). Social Foundations of thought and action: a social cognitive theory. Englewood Cliffs, NJ, USA: Prentice Hall.

Bandura, A. (1988). Organisational applications of social cognitive theory. Australian Journal of Management, 13(2), 275-302.

Bandura, A. (1997). Self-efficacy: the exercise of control. New York, USA: W.H. Freeman \& Co. Worth Publishers.

Bartone, P.T., Kelly, D.R., \& Matthews, M.D. (2013). Psychological hardiness predicts adaptability in military leaders: a prospective study. International Journal of Selection and Assessment, 21(2), 200-210.

Betz, N.E., \& Taylor, K.M. (2013). Career decision making self-efficacy scale manual. Retrieved October 24, 2013 from http://www.mindgarden.com/products/cdse.htm

Breakwell, G.M., Hammond, S., \& Fife-Shaw, C. (1998). Research methods in psychology. London, UK: Sage Publications.

Bretz, R.D., \& Judge, T.A. (1994). Person-organisation fit and the theory of work adjustment: implications for satisfaction, tenure and career success. Journal of Vocational Behavior, 44(11), 32-54.

Brewer, L. (2013). Enhancing youth employability: What? Why? and How? Guide to core work skills. Geneva, Switzerland: International Labour Organization.

Campbell, R.E., \& Cellini, J.V. (1981). A diagnostic taxonomy of adult career problems. Journal of Vocational Behavior, 19, 175-190.

Carr, A. (2007). Positive psychology the science of happiness and human strengths. New York, NY, USA: Routledge.

Cascio, W.F., \& Aguinis, H. (2005). Applied psychology in human resource management. (6th edn.). London, UK: Pearson Prentice Hall.

Center for Youth Development and Policy. What is Youth Development? Academy for Educational Development. Retrieved on October 24, 2013 from http://cyd.aed.org/whatishtml.

Cima. (2002). Technical briefing - developing and promoting strategy: mentoring and coaching An overview. Retrieved on August 3, 2012 from http://www.leadersfirst.com/pdf/Coaching\%20_\%20Mentoring\%20Research.pdf. 
Coertze, S., \& Schepers, J.M. (2004). Some personality and cognitive correlates of career maturity. SA Journal of Industrial Psychology, 30(2), 56-73.

Coetzee, M., \& Esterhuizen, K. (2010). Psychological career resources and coping resources of the young unemployed African graduate: An exploratory study. SA Journal of Industrial Psychology, 36(1), 23-31.

Coetzee, M., \& Roythorne-Jacobs, H. (2007). Career counselling and guidance in the workplace - a manual for career practitioners. Cape Town, South Africa: Juta.

Covey, S.R. (1992). The seven habits of highly effective people- powerful lessons in personal change. London, UK: Simon \& Schuster Ltd.

Covey, S.R. (n.d.). Seven Habits Profile. Retrieved November 21, 2012 from http://www.franklincovey.ca/FCCAWeb/mmedia/pdf/library/7_Habits_Profile.pdf

Crites, J.O. (1978). Career maturity inventory. Monterey, CA, USA: CTB/McGraw-Hill.

Crites, J.O., \& Savickas, M. L. (1996). Revision of the career maturity inventory, Journal of Career Assessment, 4, 131-138.

Cummings, T.G., \& Worley, C.G. (2008). Organization development and change. (9th edn.). Mason, OH, USA: South-Western Cengage Learning.

Department of Defence. (2009). Department of Defence overarching human resource strategy part 1: strategic direction. Pretoria, South Africa: DOD.

Department of Higher Education and Training Republic of South Africa. (2014). National skills development strategy III. Retrieved on June 3, 2014 from http://www.dhet.gov.za/Booklets/NSDSIII.pdf

De Villiers, S.L. (2001). Aspects of professional career success and the implications for life skills education. Unpublished doctoral dissertation. University of South Africa, Pretoria, South Africa.

Diamantopoulos, A., \& Siguaw, J.A. (2000). Introducing LISREL - a guide for the uninitiated. London, UK: Sage Publications.

Dodd, C.F. (2013). The development of career maturity and career decision self-efficacy among high school aged youth enrolled in the Texas 4-H healthy lifestyles program. Doctoral dissertation. A\&M University, Texas, USA.

Dolan, C.A., \& Adler, A.B. (2006). Military hardiness as a buffer of psychological health on return from deployment. Military Medicine, Feb 1, 110-115.

Egan, G. (2014). The skilled helper a problem-management and opportunity-development approach to helping. (10th edn.). Mason, OH, USA: Brooks/Cole Cengage Learning.

Evans, W.D., Silber-Ashley, O., \& Gard, J. (2007) Social marketing as a strategy to reduce unintended adolescent pregnancy. The Open Communication Journal 1, 1-81.

Foxcroft, C., \& Roodt, G. (2009). Introduction to psychological assessment in the South African context. Cape Town, South Africa: Oxford University Press, Southern Africa. 
Frankl, V.E. (1986). The doctor and the soul from psychotherapy to logotherapy. (3rd edn.). New York, USA: Vintage Books Random House.

Freedman, J., \& Combs, G. (1996). Narrative therapy - the social construction of preferred realities. New York, NY, USA: W.W. Norton \& Company.

French, W.L., \& Bell, C.H. (1999). Organization development behavioural science interventions for organization improvement (6th edn.). Upper Saddle River, New Jersey, USA: Prentice Hall International, Inc.

Funk, S.C. (1992). Hardiness: a review of theory and research. Health Psychology, 11(5), 355-345.

Gikopoulou, N. (2008). Career guide for schools: report on effective career guidance. London, European Union: EPINOIA S.A.

Gladding, S.T. (2000). Counseling: a comprehensive profession. (4th edn.). Upper Saddle River, New Jersey, USA: Prentice Hall International, Inc.

Glasgow, P.A. (2005). Fundamentals of survey research methodology. Washington, USA: Mitre.

Gottfredson, L.S. (2002). Gottfredson's theory of circumscription, compromise, and self creation. In D. Brown (Ed.), Career Choice and Development. (4th edn.). San Francisco: JosseyBass, pp. 85-148.

Hanna, D., \& Dempster, M. (2012). Psychology statistics for dummies. Chichester, West Sussex, England: John Wiley \& Sons Ltd.

Hansen, J.C. (1974). Review of J.O.Crites, career maturity inventory. Journal of Counseling Psychology, 21, 168-172.

Havighurst, R (1972) Developmental Tasks and Education. (3rd edn.). New York. NY, USA: David McKay Company, Inc.

Hawkins, J.D., \& Weiss, J.G. (1985). The social development model: an integrative approach to delinquency prevention. Journal of Primary Prevention, 6(2), 73-97.

Henning, E., Van Rensburg, W., \& Smit, B. (2004) Finding your way in qualitative research. Pretoria, South Africa: Van Schaik Publishers.

Hopson, B. (2009). From vocational guidance to portfolio careers: a critical reflection. Derby, UK: University of Derby International Centre for Guidance Studies

Hystad, S.W., Eid, J., Laberg, J.C., \& Bartone, P.T. (2011). Psychological hardiness predicts admission into Norwegian military officer schools. Military Psychology, 23, 381-389.

Ingrid, B., Majda, R., \& Dubravka, M. (2009). Life goals and well-being: are extrinsic aspirations always detrimental to well-being? Psychological Topics, 18, 317-334.

Kelloway, E.K., \& Barling, J. (1991). Job characteristics, role stress and mental health. Journal of Occupational Psychology, 64, 291-304. 
Kerlinger, F.N. (1986). Foundations of behavioural research. (3rd edn.). Fort Worth, USA: Harcourt Brace Jovanovich College Publishers.

Key competencies. In Victorian Curriculum and Assessment Authority Online. Retrieved on July 1, 2014 from " http://www.vcaa.vic.edu.au/faqs/acronymsglossary.html.

King, S. (1989). Sex differences in a causal model of career maturity. Journal of Counseling \& Development, 68, 208-215.

Lee, F.K. \& Johnston, J.A. (2001). Innovations in career counseling. Journal of Career Development, 27(3), 177-185.

Leedy, P.D. (1997). Practical research planning and design. (6th edn.). Upper Saddle River: Prentice Hall.

Lent, R.W., Brown, S.D., \& Hackett, G. (1994). Toward a unifying social cognitive theory of career and academic interest, choice, and performance. Journal of Vocational Behaviour, 45(1), 79-122.

Levinson, E. M., Ohler, D. L., Caswell, S., \& Kiewra, K. (1998). Six approaches to the assessment of career maturity. Journal of Counseling and Development, 76, 475-482.

Lomax, R., \& Li, J. (2013). Definitions of quantitative methods of research. Retrieved on October 24, 2013 from http://www.education.com/reference/article/correlational-research/

Lopienski, S.A. \& Savickas, M.L. (2013). Career maturity inventory. Retrieved on October 24, 2013 from http://srmo.sagepub.com/view/encyclopedia-of-measurement-andstatistics/n69.xml

Louw, D.A. (1994). Menslike ontwikkeling. Pretoria, South Africa: HAUM-Tersier.

Matsumoto, D. (2009). The Cambridge dictionary of psychology. New York, NY, USA: Cambridge University Press.

Matzeder, M.E. \& Krieshok, T.S. (1995). Career self-efficacy and the prediction of work and home role salience. Journal of Career Assessment, 3(3), 331-340.

Mayer Development Bank of Southern Africa. (2011). Towards a youth employment strategy for South Africa. Development Planning Division Working Paper, 28.

McWhirter, E.H. (1997). Career counseling: counseling for life. In D. Capuzzi \& D.R. Gross (Eds.), Introduction to the counseling profession (2nd edn., pp. 191-214). Boston, USA: Allyn and Bacon.

Menard, S. Standardized regression coefficients. Retrieved on August 22, 2014 from http://srmo.sagepub.com/view/the-sage-encyclopedia-of-social-science-researchmethods/n959.xml

Miars, R.D., Burden, C.A., \& Pedersen, M.M. (1997). The helping relationship. In D. Capuzzi \& D.R. Gross (Eds.), Introduction to the counseling profession (2nd ed., pp. 64-84). Boston, USA: Allyn and Bacon. 
Muchinsky, P.M., Kriek, H.J., \& Schreuder, A.M.G. (2002). Personnel psychology (2nd edn.). Cape Town, South Africa: Oxford University Press, Southern Africa.

National Clearinghouse on Families \& Youth (NCFY). (2001). Positive youth development. Silver Spring, Maryland, USA. Retrieved on October 24, 2013 from www.ncfy.com

Nevill, D.D., \& Super, D.E. (1988). Career maturity and commitment to work in university students. Journal of Vocational Behaviour 32, 139-151.

Noe, R.A., Hollenbeck, J.R., Gerhart, B., \& Wright, P.M. (2008). Human resource management - gaining a competitive advantage. (6th edn.). New York, NY, USA: McGraw Hill Irwin.

Pahl, C. M. (2011). Moving through autonomy toward interdependence: the relationship between Chickering and Reisser's third vector and Stephen Covey's seven habits of highly effective people. Unpublished master's theses. Eastern Illinois University, Charlestown, IL, USA.

Perron, J., Vondracek, F.W., Skorikov, V.B., Tremblay, C., \& Corbiere, M. (1998). A longitudinal study of vocational maturity and ethnic identity development. Journal of Vocational Behavior 52, 409-424

Powell, D. F., \& Luzzo, D. A. (1998). Evaluating factors associated with the career maturity of high school students. The Career Development Quarterly, 47, 145-158.

Reardon, R.C., \& Lenz, J.G. (2006) Self-Directed Search. In J.H. Greenhaus \& G.H. Callanan (eds), Encyclopedia of career development, pp 881-887. Thousand Oaks, USA: Sage Publications, Inc.

Reid-Van Nlekerk, H.H., \& Van Niekerk, E.C. (1990). Career maturity of black, coloured and white universitystudents. Journal of Industrial Psychology, 16(1), 1-4.

Research Polulation. In Explorable Research Online. Retrieved on July 1, 2014 from http://explorable.com/ research-polulation.

Robbins, S.P. (1993). Organizational behaviour (6th edn.). Englewood Cliffs, New Jersey, USA: Prentice Hall, Inc.

Rogelberg, S.G. (Ed). (2004). Handbook of research methods in industrial and organizational psychology. West Sussex, UK: Wiley-Blackwell.

Salomone, P.R. (1988). Career counseling: steps and stages beyond Parsons. The Career Development Quarterly 36(3), 218-221.

SAPA-AFP (2012, 04 September). Bleak outlook for young South Africans. Fin24. Retrieved October 15, 2012 from http://www.fin24.com/Economy/Bleak-outlook-for-young-SouthAfricans-20120904\#

Savickas, M.L. (1984). Career maturity: The construct and its measurement. Vocational Guidance Quarterly, 32, 222-231.

Savickas, M.L., \& Portfeli, E. (2011). Revision of the CMI: the adaptability form. Journal of Career Assessment 19(4), 355-374. 
Search Institute. Forty Developmental Assets. Retrieved June 29, 2014 from https://www.wvdhhr.org/ahi/assets.pdf

Schreuder, A.M.G., \& Theron, A.L. (2004). Careers an organisational perspective. (2nd edn.). Landsdowne, South Africa: Juta.

Stats SA (Statistics South Africa), (2011). Quarterly Labour Force Survey: Quarter 3 (QLFS3). Retrieved on October 24, 2013 from www.gov.za/documents/download.php?f=200123

Stead, G.B. (1996). Career development of black South African adolescents: a developmentalcontextual perspective. Journal of Counseling \& Development 74, 270-275.

Super, D.E. (1957) The psychology of careers, New York, NY, USA: Harper and Row.

Super, D.E. (1990). A life-span, life-space approach to career development. In D. Brown \& L. Brooks (eds), Career choice and development, pp 197-261. San Francisco, CA, USA: Jossey-Bass.

Super, D.E., \& Nevill, D.D. (1984). Work role salience as a determinant of career maturity in high school students. Journal of Vocational Behaviour 25, 30-44.

Super's career life rainbow. Retrieved June 07, 2014 from (http://www.careers.govt.nz/educators-practitioners/career-practice/career-theorymodels/supers-theory).

Taylor, K.M., \& Betz, N. (1983). Applications of self-efficacy theory to the understanding and treatment of career indecision. Journal of Vocational Behavior, 22(1), 63-81.

Tekke, M., \& Ghani, M.F.A. (2013). Examining the level of career maturity among Asian foreign students in a public university: gender and academic achievement. Hope Journal of Research - House of Pakistani Educationists 1(1), 101-121.

Teipel, K., (2002). Minnesota adolescent health action plan, forthcoming; findings from key informant interviews conducted by Stephen Conley for the Partnership; Community Programs to promote youth development. Washington, DC, USA: National Academy Press.

Themba, M.A. (2010). Career maturity across career stages in the South African military. Unpublished master's thesis. University of South Africa, Pretoria, South-Africa.

Vondracek, F.W., \& Reitzle, M. (1998). The viability of career maturity theory: a developmentalcontextual perspective. Career Development Quarterly 47(1), 6-15.

Walker, Q.D. (2010). An investigation of the relationship between career maturity, career decision self-efficacy and self-advocacy of college students with and without disability. Unpublished doctoral dissertation. University of lowa, lowa City, USA.

Walker, J., \& Dunham, T. Understanding youth development work. Retrieved June 29, 2014 from http://www.extension.umn.edu/youth/training-events/understanding-youthdevelopment-work/

Young, J., \& Chapman, E. (2010) Generic competency frameworks: a brief historical overview. Education Research and Perspectives 37(1), 1-24. 
Yukl, G. (2013). Leadership in organizations (8th edn.). London, UK: Pearson. 